\title{
What Do You Have in Mind? Measures to Assess Mental State Reasoning in Neuropsychiatric Populations
}

\author{
Clare M. Eddy ${ }^{1,2 *}$ \\ ${ }^{1}$ Research and Innovation, BSMHFT National Centre for Mental Health, Birmingham, United Kingdom, ${ }^{2}$ Institute of Clinical \\ Sciences, College of Medical and Dental Sciences, University of Birmingham, Birmingham, United Kingdom
}

OPEN ACCESS

Edited by:

Sandra Baez,

University of Los Andes,

Colombia

Reviewed by:

Antonella Marchetti,

Catholic University of

the Sacred Heart, Italy

Elena Cavallini,

University of Pavia, Italy

*Correspondence:

Clare Eddy

clare.eddy1@nhs.net c.eddy@bham.ac.uk

Specialty section:

This article was submitted to

Social Cognition,

a section of the journal

Frontiers in Psychiatry

Received: 12 March 2019

Accepted: 29 May 2019

Published: 04 July 2019

Citation:

Eddy CM (2019) What Do You Have in Mind? Measures to Assess

Mental State Reasoning in Neuropsychiatric Populations. Front. Psychiatry 10:425. doi: 10.3389/fpsyt.2019.00425
Social interaction is closely associated with both functional capacity and well-being. Previous research has not only revealed evidence of social dysfunction in individuals with a wide range of psychiatric and neurological disorders but also generated an abundance of potential measures for assessing social cognition. This review explores the most popular measures used within neuropsychiatric populations to investigate the ability to recognize or reason about the mental states of others. Measures are also critically analyzed in terms of strengths and limitations to aid task selection in future clinical studies. The most frequently applied assessment tools use verbal, visual or audiovisual forms of presentation and assess recognition of mental states from facial features, self-rated empathy, the understanding of other's cognitive mental states such as beliefs and intentions, or the ability to combine knowledge of other's thoughts and emotions in order to understand subtle communications or socially inappropriate behavior. Key weaknesses of previous research include limited investigation of relationships with clinical symptoms, and underutilization of measures of everyday social functioning that offer a useful counterpart to traditional "lab" tasks. Future studies should aim to carefully select measures not only based on the range of skills to be assessed but also taking into account potential difficulties with interpretation and the need to gain insight into the application of social cognitive skills as well as ability per se. Some of the best measures include those with well-matched control trials (e.g., Yoni Task) or those that restrict the influence of verbal deficits (e.g., intentions comic strip task), elicit spontaneous mentalizing (e.g., Animations Task), and possess greater ecological validity (e.g., Movie for the Assessment of Social Cognition). Social cognitive research within psychiatric populations will be further enhanced through the development of more closely matched control tasks, and the exploration of relationships between task performance, medication, strategy use, and broader emotional and motor functions.

Keywords: assessment, empathy, measures, psychiatry, social cognition, theory of mind 


\section{INTRODUCTION}

Over the last few decades, a rich body of research has developed into the social cognitive abilities of patients with neuropsychiatric disorders. A scoping search in PubMed (October 2018) using the terms social cognition or theory of mind or empathy plus measure or task or assessment plus psychiatr*; including only reviews/clinical trials/full articles, in humans, in English, date range 1990-2018, generated 123,755 results. There is recognition that social interaction is a central part of life, related to functional capacity and individual well-being, and social skills will therefore have a fundamental role to play in the assessment of ill health, resilience, and recovery. We are now aware that social functioning may be atypical in individuals presenting with a wide range of clinical disorders, far beyond those characteristically associated with frontal lobe deficits. Extending from the earliest conditions to be recognized as involving deficits in theory of mind (ToM), such as autistic spectrum disorder (ASD) and schizophrenia, we now believe that some of the most common psychiatric disorders with a primary diagnosis involving affect dysregulation, and patient groups most widely recognized for their movement disorder, can experience difficulties with social cognition. Studying these clinical groups is an invaluable complementary approach to research throughout the lifespan within the typically developing population.

This relatively rapid expansion in research has led to a proliferation of development in assessments and measures for social cognition, some of which were originally used in typically developing populations (e.g., children). The range of aspects of social cognition that can be assessed include recognition of facial expressions and vocal emotion, empathy and emotion contagion, more abstract reasoning about one's own and other people's cognitive (e.g., beliefs, intentions) or affective (e.g., emotions) mental states, understanding of humor and non-literal communicative intent, identification of deception, cooperative decision making, moral judgment, and more. As the field has evolved, our conceptualization of the limits of what can be classified as social cognitive skills will continue to develop. For example, we may now consider emotion identification (1), insight (2), mind reading motivation (3), social anxiety (4), and imitation ability (5) to be important factors relevant to the assessment of social cognition.

Now is the time to further our understanding of social cognition and its intricate relationship with mental health through wider application of instruments in the most carefully designed and rigorously controlled studies. However, when faced with such an abundance of potential measures, it is important for studies to be well considered in terms of selected tasks and method of assessment. The format of different tasks and assessments vary considerably and what is most appropriate for one patient group may lead to difficulties in interpretation or reliability (due to, e.g., incidental effects or confounding variables) when administered within another. In addition, certain measures may be more favorable in relation to selection for use in longitudinal studies or randomized controlled trials.

The aim of this review paper is to first identify the most frequently used social cognitive measures within neuropsychiatric populations (spanning disorders that may be considered psychiatric and/or neurological) in order to highlight the range of options available to researchers. Practical issues relating to task administration and interpretation will be presented. To further assist researchers in their utilization of the most appropriate tools for investigating social cognition within neuropsychiatry, the advantages and limitations of the most popular existing measures will then be explored. Finally, key areas for development will be discussed, including the gaps in knowledge ready to be filled by future innovative studies.

\section{METHOD}

To focus on the use of social cognitive measures in psychiatric populations, the phase one search (Web of Science; October 2018) sought to identify relevant review papers to cover as much of the published literature as possible. The search required the study title to contain "social cognition" or "theory of mind" or "empathy", and for the topic to include "psychiatr*". This generated 1,733 records in Web of Science and Medline. After selecting the topic of Psychiatry, and restricting date start to 1998 and English language only, 157 articles were identified (Table 1). The abstracts of these papers were manually checked to ensure relevance. A total of 109 papers were excluded from further review due to either not discussing a psychiatric group (these were often studies involving healthy populations such as students that applied clinical measures or discussed potential clinical implications), not reviewing relevant tasks or assessments (i.e., hypothesis/theory/model papers or single studies), or not listing specific tasks/assessments (note that categories are not mutually exclusive). Disorders that may be considered neuropsychiatric (spanning both neurological and psychiatric disciplines) were included in order to cover as much relevant literature as possible.

The 48 review and/or meta-analytic papers identified in phase one were examined to extract a list of social cognitive assessments to perform more specific searches for the most popular measures in phase two. Many measures were only referred to by just a few individual review papers (Results, Table 2). A list of 12 of the most commonly used measures to assess social cognition was constructed, based on a specific measure being explicitly referred to by more than $10 \%$ of the reviewed papers. To confirm that these were frequently used measures, individual searches were conducted using each of the 12 tasks in the short-list. Searches were carried out in Web of Science using a combination of the task name where possible (e.g., "sally anne task," "strange stories," "animations task", etc.) or clear task descriptors ("intention task" and "comic" or "cartoon") plus "social cognition." The numbers of papers retrieved per task ranged from 8 to 88 . Papers that were not original studies or reviews were excluded, as were papers not in English, duplicates, and those that did not discuss data pertaining to/or evaluation points related to the task in question. Where they were not directly yielded within a search, relevant original papers from the developers of the measure were used to supplement the data. Information was sought in relation to the task source and description, administration, psychometric properties, key findings in psychiatric populations, and strengths or limitations. 
TABLE 1 | Reviews and meta-analyses exploring social cognition in neuropsychiatric populations.

\begin{tabular}{|c|c|c|c|}
\hline Authors & Year & Journal & Disorders included \\
\hline Di Martino and Castellanos (6) & 2003 & Ann. N. Y. Acad. Sci. & Pervasive developmental disorders \\
\hline Couture et al. (7) & 2006 & Schizophr. Bull. & Schizophrenia \\
\hline Brüne and Brüne-Cohrs (8) & 2006 & Neurosci. Biobehav. Rev. & Multiple \\
\hline Sprong et al. (9) & 2007 & Br. J. Psychiatr. & Schizophrenia \\
\hline Pickup (10) & 2008 & Psychopathol. & Schizophrenia \\
\hline Uekermann and Daum (11) & 2008 & Addiction & Substance misuse \\
\hline Bora et al. (12) & 2009 & Acta Psychiatrica Scand. & Schizophrenia bipolar disorder \\
\hline Freedman and Stuss (13) & 2011 & J. Neurol. Sci. & Parkinson's disease \\
\hline Uekermann et al. (14) & 2010 & Neurosci. Biobehav. Rev. & Attention deficit hyperactivity disorder \\
\hline Adenzato et al. (15) & 2010 & Neuropsychologia & Frontotemporal dementia \\
\hline Korkmaz (16) & 2011 & Pediatr. Res. & Neurodevelopmental disorders \\
\hline Bragado Jimenez and Taylor (17) & 2012 & Schizophr. Res. & Schizophrenia \\
\hline Kemp et al. (18) & 2012 & Ageing Res. Rev. & Neurodegen \\
\hline Samame et al. (19) & 2012 & Acta Psychiatrica Scand. & Bipolar disorder \\
\hline Poletti et al. (20) & 2012 & Neurosci. Biobehav. Rev. & Neurodegenerative disorders \\
\hline Samame (21) & 2013 & Psychiatry Res. & Bipolar disorder \\
\hline Kucharska-Pietura and Mortimer (22) & 2013 & CNS Drugs & Schizophrenia \\
\hline Schreiter et al. (23) & 2013 & J. Affect. Dis. & Depression \\
\hline Roepke et al. (24) & 2013 & Front. Neurosci. & Borderline personality disorder \\
\hline Thoma et al. $(25,26)$ & 2013 & Neurosci. Biobehav. Rev. & Multiple \\
\hline Bora and Pantelis (27) & 2013 & Schizophr. Res. & Schizophrenia \\
\hline De Jong et al. (28) & 2013 & Eur. Psychiatry & Bulimia nervosa \\
\hline Cerami and Cappa (29) & 2013 & Neurol. Sci. & Frontotemporal dementia \\
\hline Giovagnoli (30) & 2014 & Epilepsy Behav. & Epilepsy \\
\hline Martin et al. (31) & 2014 & Genes Brain Behav. & Schizophrenia \\
\hline Weightmann et al. (32) & 2014 & Front. Psychiatr. & Depression \\
\hline Henry et al. (33) & 2014 & Neuropsychologia & Frontotemporal dementia \\
\hline Schurz et al. (34) & 2014 & Neurosci. Biobehav. Rev. & Multiple \\
\hline Mercedes Perez-Roriguez (35) & 2015 & Neuropsychopharmacol. & Mood disorders, schizophrenia \\
\hline Bora et al. (36) & 2015 & Behav. Brain Res. & Parkinson's disease \\
\hline Bora et al. (37) & 2015 & J. Neurol. Neurosurg. Psychiatry & Frontotemporal dementia, Alzheimer's disease \\
\hline Bora and Pantelis (38) & 2016 & Schizophr. Res. & Schizophrenia bipolar disorder \\
\hline Bora et al. (39) & 2016 & Psychol. Med. & Bipolar disorder \\
\hline Bora and Berk (40) & 2016 & J. Affect. Dis. & Depression \\
\hline Bora and Köse (41) & 2016 & Int. J. Eat. Disord. & Anorexia nervosa, bulimia nervosa \\
\hline Cotter et al. (42) & 2016 & Neurology & Multiple sclerosis \\
\hline Bora et al. (43) & 2016 & Behav. Brain Res. & Huntington's disease \\
\hline Bonfils et al. (44) & 2016 & Schizophr. Res. & Substance misuse \\
\hline Happé and Conway (45) & 2016 & Curr. Op. Pediatr. & Autistic spectrum disorders \\
\hline Bora et al. (46) & 2016 & Neuropsychol Rev & Multiple sclerosis \\
\hline Bora (47) & 2017 & Schizophr. Res. & Schizophrenia \\
\hline Bora and Zorlu (48) & 2017 & Addiction & Substance misuse \\
\hline Eddy (49) & 2018 & Prog, Neuropsychopharmacol. Biol. Psychiatry & Schizophrenia, Tourette syndrome \\
\hline Keech et al. (50) & 2018 & Psychoneuroendocrinol. & Neurodevelopmental disorders \\
\hline Wang et al. (51) & 2018 & Neurosci. Biobehav. Rev. & Multiple \\
\hline Fortier et al. (52) & 2018 & Revue Neurol. & Neurodegenerative disorders \\
\hline Rokita et al. (53) & 2018 & Eur Psychiatr & Multiple \\
\hline Eddy and Cook (54) & 2018 & Prog. Neuropsychopharmacol. Biol. Psychiatry & Multiple \\
\hline
\end{tabular}

\section{RESULTS}

\section{Identified Measures}

Table 2 lists the assessments identified from the phase one search. The most frequently applied measures used either verbal (usually written) or visual (image) forms of presentation, and were typically used to assess recognition of emotions/mental states from facial features (Ekman Pictures of Facial Affect, Reading the Mind in the Eyes task), self-rated empathy (Interpersonal Reactivity Index), understanding of other's cognitive mental states such as beliefs and intentions including communicative intentions (Strange Stories, Sally Anne Task, Intentions Comic
Strip Task, Hinting Task), or both other's cognitive and affective mental states including understanding of sarcasm and socially inappropriate or socially competitive emotions [Faux Pas Task, Yoni Task, Animations Task, Movie for the Assessment of Social Cognition (MASC), The Assessment of Social Inference Test (TASIT)]. Measures of everyday social functioning are also included in Table 2. A few emotion regulation questionnaires, attention tasks involving emotional stimuli (e.g., face in the crowd task), and socially competitive games (e.g., prisoner's dilemma, ultimatum game) were mentioned in the reviewed papers, but have not been considered here as they are less pure assessments of social cognition. 
TABLE 2 | Measures used to assess social cognition including scales for social functioning.

Measure name/description

Link/Reference

Task format

Skills assessed

(See key)

Referenced in over $20 \%$ of search papers

Pictures of Facial Affect

Ekman and Friesen (55)

Reading the Mind in the Eyes Test

Baron-Cohen et al. (56)

Visual

$A$

Faux Pas Task

Stone et al. (57)

Verbal

Interpersonal Reactivity Index

Davis (58)

Scale

Referenced in at least $10 \%$ of search papers

Hinting Task

Strange Stories

Intention inference comic strip

Sally Anne Task (or similar first- and second-

order belief tasks)

\begin{tabular}{|c|c|c|c|}
\hline $\begin{array}{l}\text { Animations Task } \\
\text { Yoni Task }\end{array}$ & $\begin{array}{l}\text { Abell et al. (66) } \\
\text { Shamay-Tsoory and Aharon-Peretz (67) }\end{array}$ & Visual & $\mathrm{CA}$ \\
\hline $\begin{array}{l}\text { The Assessment of Social Inference Test } \\
\text { Movie for the Assessment of Social Cognition }\end{array}$ & $\begin{array}{l}\text { McDonald et al. (68) } \\
\text { Dziobek et al. (69) }\end{array}$ & Audiovisual & \\
\hline
\end{tabular}

Movie for the Assessment of Social Cognition

\begin{tabular}{|c|c|c|c|}
\hline $\begin{array}{l}\text { Emotion Quotient (Cambridge Behaviour Scales) } \\
\text { Levels of Emotional Awareness Scale }\end{array}$ & $\begin{array}{l}\text { Baron-Cohen et al. (70) } \\
\text { Lane et al. (71) }\end{array}$ & Scale & A \\
\hline Facial Emotion Recognition Test & Anderson et al. (72) & Visual & \\
\hline Facial Emotion and Perception test & Langenecker et al. (73) & & \\
\hline Facial Expressions of Emotion FEEST & Surguladze et al. (74) & & \\
\hline Spy test & Hala et al. (75) & & C \\
\hline
\end{tabular}

False belief and deception task

Pragmatic Story Comprehension Task

False belief and false photo vignettes

False photo task

Conflicting beliefs and emotions

Violation of social norms task

Joke stories

\section{Friend-foe judgment}

Interpersonal perception task

Social Cue Recognition Test and Situational

features recognition task

Interpersonal perception task

Facial emotion identification task, Facial

emotion discrimination test, Vocal emotion

identification task

Bell-Lysaker emotion recognition test

Videotape affect perception test

Aprosodia battery

Florida Affect Battery

Comprehensive affect testing system

Emotional communication

Mayer-Salovey-Caruso emotional intelligence

test

Heider and Simmell animations

Picture sequencing

Visual jokes

Cartoons

Humorous cartoons
Corcoran et al. (59)

Happé (60)

Sarfati et al. $(61,62)$

Wimmer and Perner (63)

e.g., Baron-Cohen et al. (64); Baron Cohen (65)

Referenced in 5 to $10 \%$ of search papers

\section{Referenced in up to $5 \%$ of search papers}

Frith and Corcoran (76)

Langdon and Coltheart (77)

Saxe and Kanwisher (78)

Zaitchik (79)

Shaw et al. (80)

Berthoz et al. (81)

Uekermann et al. (82)

Watanabe et al. (83)

Audiovisual

C

C A

Visual

C

Costanzo and Archer (84)

Corrigan et al. (85)

Sergi et al. (86)

Kerr and Neale (87)

Audiovisual

A

Bell et al. (88)

Bellack et al. (89)

Blonder et al. (90)

Bowers et al. (91)

Froming et al. (92)

Schneider et al. $(93,94)$

Mayer et al. (95)

Visual (and verbal)

C A

Heider and Simmell (96)

Visual

Langdon and Coltheart (97)

Thompson et al. (98)

Snowden et al. (99)

Eddy et al. (100) 
TABLE 2 | Continued

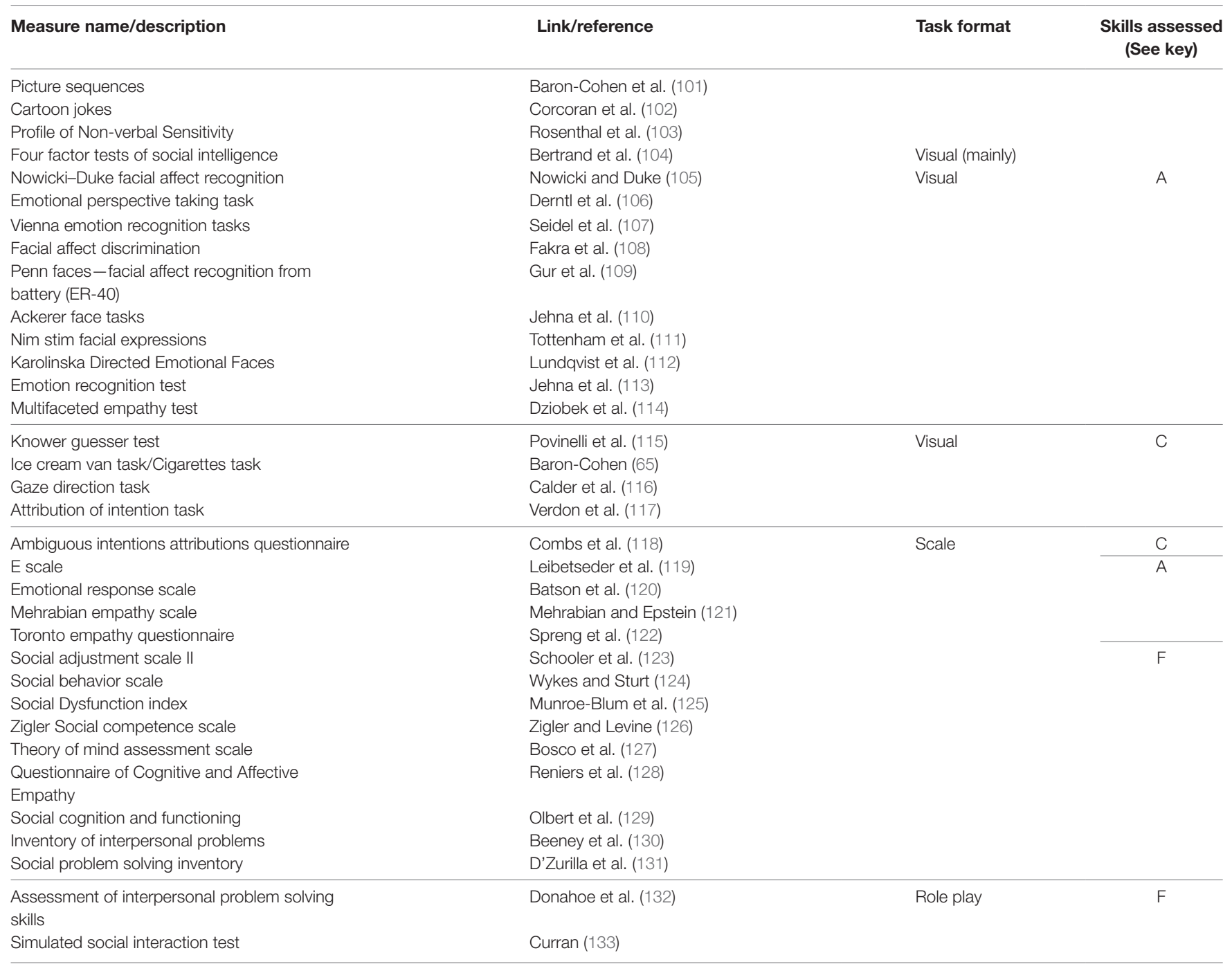

C, Only/primarily assesses understanding of cognitive mental states; A, Only/primarily assesses understanding of emotions/affective mental states; F, explores functioning across a range of everyday situations.

\section{Description of the Most Popular Measures}

The 12 most popular tasks referred to in at least $10 \%$ of the review papers are now each described in turn (with the Sally Anne Task selected to represent the false belief task paradigm). Key findings in neuropsychiatric populations are also discussed. It was beyond the scope of this review to give a detailed account of the social cognitive profiles of such a range of neuropsychiatric disorders, although Table 1 provides a list of publications to provide the reader with relevant review papers.

\section{Sally Anne Task}

False belief tasks assess the ability to understand that a character holds an incorrect belief, typically about the location of an object (unexpected transfer type task) or the nature of an object (deceptive box type task). One of the earliest tasks to be developed within the false belief paradigm was the Sally Anne Task (63). This task was traditionally used in cognitive developmental research, in the form of a puppet show. The character Sally puts a ball in one of two locations and then leaves the scene. In her absence, another character (Anne) moves the ball to the other location and also leaves the scene, before Sally returns. Participants are asked where Sally will look for the ball, with a control question about the ball's actual location. Do they appreciate her lack of knowledge or do they perhaps mistakenly confuse their own knowledge for hers and expect her to access the current location? Some studies using this task with very young children took measures of eye movement towards the different locations in order to assess implicit belief processing and their results suggest that children spend more time looking at the correct answer from around age 3 years, although the correct answer is usually only provided verbally from age 4 years (134).

The task has been presented as videos during, e.g., fMRI studies $(135,136)$, and cultural adaptions have been created [e.g., Ref. (137)]. An important update was a version without "referential pull”, which was used to explore children's ability when the real location of the ball was not salient $(137,138)$. Studies in psychiatry 
have used spoken, written, and line drawing versions (139). Deficits have been reported in disorders such as Alzheimer's disease (140) as well as $\operatorname{ASD}(101,141)$.

\section{Strange Stories}

The Strange Stories (142) were designed to provide a sensitive measure of mental state reasoning that may circumvent the use of compensation strategies in populations with ASD (143). Happés original instrument contained 24 test stories plus 6 control stories. Test stories contain statements involving pretence, sarcasm, persuasion, double bluff, deception, misunderstanding, and forgetting. For example, in one story depicting sarcasm, a story character is unappreciative when her mother brings her favorite meal: The mother states "Well that's very nice, isn't it! That's what I call politeness!” Stories are followed by two test questions to assess comprehension (e.g., Was what X said true)? and reasoning/ justification (e.g., Why did X say that)?. During questioning, participants are expected to explain the thoughts and feelings of characters in the stories, i.e., consider aspects of both cognitive and affective ToM, although the major focus is cognitive ToM. Although some studies simply awarded one point for the correct responses to each story, scoring can be graded in terms of a score of 0 (incorrect; no mention of cognitive or affective ToM), 1 (partially correct answer with some mention of cognitive or affective ToM), or 2 (complete correct response including reference to both cognitive and affective ToM) for each story [e.g., Ref. (144)]. Coding provided by Happé defines mental state references as, e.g., including reference to thoughts, feelings, desires, traits, or dispositions (142). Control stories describe events (e.g., the loss of a pair of glasses) and environmental conditions such as weather or a character's movements, asking the participant to make a judgment based on comprehending physical events (e.g., Where is the best place to look for the glasses)?. Total score is used.

A shorter set of 12 stories is sometimes used with children [e.g., Ref. (144)]. Film versions of the task have also been created (145, $146)$, and a few cultural adaptions and translations exist $(147,148)$. Many studies have reported impairment in psychiatric populations, such as ASD (149-153), high functioning autism or pervasive developmental disorder (154-156), epilepsy (157-160), bipolar disorder (161), children with social communication disorder (162), psychosis/schizophrenia (163, 164), and Alzheimer's disease (165). However, other studies report no impairment in samples with ASD (166), borderline personality disorder (167), and medial prefrontal damage (168).

\section{The Yoni Task}

This task is a visual computerized cartoon-type task that tests the ability to judge first-order and second-order affective and cognitive mental state attributions based on simple verbal instructions and eye-gaze cues (67). It was designed to make minimal language and executive functioning demands and was first used in patients with brain lesions (67), followed by those with schizophrenia (169), and then forensic samples (170). There are a total of 98 trials (32 first-order and 66 second-order). The central character "Yoni" ("Gianni" in the Italian version) is always surrounded by four color images in each corner of the screen, which take the form of items from semantic categories such as fruit or animals, or faces. Participants are asked to choose the image that Yoni is referring to based on a sentence appearing on the screen and cues such as direction of gaze and facial expression. Trials assess affective ToM ("Yoni likes..."), cognitive ToM ("Yoni is thinking of..."), or physical states for the control condition ("Yoni is close to..."). First-order trials focus on Yoni's mental state, while secondorder trials also involve taking into account the mental state of another on-screen face (e.g., "Yoni is thinking of the chair that ... wants"). Each item is scored 1 if the answer was correct and 0 if the answer was wrong. Many studies use a subset of trials (e.g., 24 affective, 24 cognitive, and 16 physical). Another version of this task (171) includes trials where characters hold socially competitive emotions, such that participants are asked to identify the character that Yoni is jealous of or gloating over. A combination of facial expressions of Yoni and the other character can be used to make this judgment.

A wide range of patient groups have already been found to report impairment on at least some aspect of the Yoni Task, suggesting that this is a versatile and sensitive measure. They include samples with Parkinson's disease $(172,173)$, mild cognitive impairment (173), schizophrenia (174, 175), first-episode psychosis (176), bipolar disorder (174), depression (174), obsessive-compulsive disorder (177), epilepsy (178), Huntington's disease (179), and Tourette syndrome (100). The task has revealed selective deficits in some patient groups on ToM trials only with performance on control trials being spared [e.g., in Parkinson's disease: Ref. (172); schizophrenia: Ref. (175)].

\section{Animations Task}

Sometimes referred to as the "Frith-Happé Animations Task", this measure can be used to assess the attribution of cognitive mental states and emotions, and was originally developed for use in $\operatorname{ASD}(66,180)$. The task comprises 12 short (35-45 s) videoclips (plus a few practice clips) that feature pairs of animated geometric stimuli (i.e., red and blue triangle shapes). There are four trials within each of three conditions: random (e.g., drifting movement of the triangles), simple goal-directed movement (e.g., the triangles bounce off each other as if fighting), complex interaction, or ToM type (e.g., one triangle appears to push and coax another repeatedly out of a central box, each triangle reacting in a varied way to the other's movements). Participants are asked to watch the animation and describe what they see, with the experimenter avoiding any specific cues or questions that may lead the response, allowing the assessment of implicit mental state reasoning (181). However, when adapted for use in fMRI studies, a forced-choice response set will be used, whereby participants have to categorize each video-clip as containing (a) no interaction/random, (b) simple interaction/goaldirected movement, or (c) mental-state-related/complex social interaction.

Behavioral scoring is fairly complex, and each response is rated for length, appropriateness, and intentionality. Coding is provided by the developers and will ideally be carried out by multiple blinded raters. Deficits have already been uncovered in Tourette syndrome (182), Huntington's disease (183, 184), somatoform disorder (185), Asperger's syndrome, and 
schizophrenia $(186,187)$. Hypermentalizing has been revealed in some disorders based on responses to the random movement component of this task (e.g., Tourette syndrome: 182).

\section{Intention Comic Strip Task}

The intention inference comic strip task developed by Sarfati et al. (61) provides a useful non-verbal measure of the ability to understand cognitive mental states in the form of intentions in order to predict character behavior. This validated task (188) originally contained 30 short stories depicting a character engaged in an intentional behavior (e.g., preparing a bath for a baby) in the form of a short sequence of line drawings. Participants are asked to choose the correct ending of the story from among three pictures. The stories were designed to depict simple first-order intentional behavior, with effort made to avoid emotional situations or expressions, social interaction between figures, behavior underpinned by beliefs, and higher-order mental states. This can therefore be considered a relatively pure measure of intention understanding.

The task has been modified in order to be used successfully in psychophysiological studies $(189,190)$ and fMRI experiments (191), and the stories can be categorized into attribution of intention, physical causality with characters, and physical causality with objects only. As yet, it does not appear to have been used far beyond populations with schizophrenia $(61,62$, $188,189,192)$, and studies indicate that disorganized symptoms may be most predictive of impairment in these patients [e.g., Ref. (192)].

\section{Pictures of Facial Affect}

The Pictures of Facial Affect (55) comprise a classic test of human facial emotion recognition. The six core basic emotions (happiness, sadness, anger, surprise, fear, and disgust) are depicted across the 60 monochrome photograph stimuli (10 of each). Standard presentation is that stimuli are presented for $5 \mathrm{~s}$, after which the subject has to choose which emotion label best describes the emotion shown. The total score ranges from 0 to 60 , with subscores for each emotion. This task forms a subtest within The Facial Expressions of Emotion-Stimuli and Tests (FEEST) (193). Other related tests are the emotional hexagon and caricatures task, which contain variations in emotional intensity, and neutral expressions can be included in the stimulus set (see Ref. 194 for a review). The pictures of facial affect have been used frequently in fMRI studies [e.g., Refs. $(195,196)]$ and as an outcome measure in clinical trials (197).

Some studies have attempted to develop control tasks $(150,151)$, modified the original stimuli set to add additional emotions (198), or employed a forced-choice yes/no format [e.g., Ref. (199)]. The Ekman faces have been used in a wide range of studies including as an imitation task [e.g., Ref. (200)], as a control task (e.g., Ref. 201), and in psychophysiological investigations (202). Deficits can be apparent in patients with multiple sclerosis (203), frontotemporal dementia (204-206), schizophrenia (207-210), ASD [Refs. (150, 151, 211) and forensic: Ref. (212)], amyotrophic lateral sclerosis $(195,213)$, epilepsy (214-216), brain tumor (217), Parkinson's disease (218), Prader-Willi syndrome (219), substance use disorder
(220), bipolar disorder, and depression $(221,222)$. Clinical groups may show selective impairment on individual emotions, including patients with Parkinson's disease [e.g., Ref. (218)] and epilepsy [e.g., Ref. (214)].

\section{The Assessment of Social Inference Test}

TASIT (223) was created in order to provide an ecologically valid measure of both emotion recognition and ToM. It takes the form of a set of video-clips featuring characters involved in everyday social situations, providing cues such as facial expression, vocal intonation and prosody, other non-verbal gestures, and context, in addition to the verbal script. There are three parts. Part 1 focuses on detecting the emotions portrayed from the six basic emotions plus neutral (scored 0-28). Part 2, Social Inference Minimal, contains 15 vignettes where speakers make sincere and sarcastic remarks. Four forced-choice questions are asked to investigate understanding of character intentions, beliefs/emotions, and intended meanings (scored 0-60). This includes making inferences based on second-order beliefs and recognizing simple and paradoxical sarcasm. Part 3, Social Inference Maximum, is similar to Part 2 but contains 16 vignettes with additional cues to help interpret speaker meaning, such as an additional spoken exchange between the characters implying a character's belief.

Both forms [Form A: Ref. (224); Form B: Ref. (225)] possess favorable psychometric properties, with moderate to high testretest and other forms of reliability (estimates range from 0.74 to 0.88$)$ (223). In relation to its potential use in clinical trials, it appears relatively insensitive to practice effects (223). The two forms are useful for counterbalancing in trials [e.g., Refs. (226, 227)] and the TASIT has been utilized in fMRI experiments (228, 229). Shorter versions are also sometimes used [e.g., Ref. (230)]. It has been used to demonstrate social cognitive impairment in Alzheimer's disease $(231,232)$, frontotemporal dementia (206, 233, 234), semantic dementia (235), schizophrenia (236-238), first-episode psychosis (239), attention deficit-hyperactivity disorder (240), depression (241), ASD (242), bipolar disorder (209), Huntington's disease (243), traumatic brain injury (68, 244), multiple sclerosis (245), neurofibromitosis (246), agenesis of the corpus callosum (247), and groups featuring substance misuse $(248,249)$.

\section{Movie for the Assessment of Social Cognition}

The MASC $(150,151)$ centers on a 15 -min-long film showing a group of people having a dinner party. As the film progresses, it pauses regularly, and participants answer multiple-choice questions (total $=46$ ) that relate to characters' thoughts, feelings, and intention, in certain scenes. The film contains examples of irony, sarcasm, social norms, inappropriate behavior, insinuations, and ambiguous non-verbal exchanges. Forcedchoice answers can be categorized as correct attribution of ToM, overmentalizing errors (excessive or unnecessary use of mental state attribution), and undermentalizing errors (lack of mental state attribution when it would be appropriate), or a total absence of mental state inference, i.e., inappropriate physical causality attributions. There are also six control questions. Sometimes, focus is on verbal items (e.g., understanding of figurative speech), 
and sometimes, it is on non-verbal items (e.g., interpretation of body language).

The MASC has been translated into languages including Italian $(250,251)$. It has been employed in a few previous clinical trials [e.g., Refs. (252, 253)]. Significant impairments have been reported in individuals with schizophrenia $(254,255)$ [also firstdegree relatives: Refs. (256, 257)], depression (258), ASD (69, 150, 151, 231, 259-261), high social anxiety (262), borderline personality disorder $(250,263,264)$, bipolar disorder (265, 266), anorexia nervosa (267), and substance misuse $(268,269)$. However, no such difficulties were revealed in other studies that involved patients with remitted bipolar disorder (270), obsessive-compulsive disorder (271), borderline personality disorder (272), or depression (273). Different aspects of the tasks can be associated with particular kinds of clinical symptoms in disorders such as schizophrenia [e.g., Ref. (255)].

\section{The Hinting Task}

The Hinting Task (59) assesses the understanding of indirect speech requests through the presentation of 10 vignettes depicting everyday social interactions that could be read by or read out loud to the participant. Each vignette ends with a remark that can be interpreted as a hint. For example, "Rebecca's birthday is approaching. She says to her Dad, 'I love animals, especially dogs'. What does Rebecca really mean when she says this? What does Rebecca want her dad to do?" Participants have to identify the intended meaning of the remark and understand the character's true desire. If the answer to the initial question is correct, the participant is given a score of 2. If a correct answer is given after additional questioning, a score of 1 can be given. The task has been found to have strong psychometric properties [e.g., Ref. (274)]; however, many participants get a perfect score (275).

A North American version of The Hinting Task has been developed (276) and the task has been translated into many languages including Dutch (277), Brazilian Portuguese (278), Spanish (279), and Korean (280). An auditory version has been created containing trials with and without prosody (276), and multiple versions have been created to help overcome any risk of practice effect $(281,282)$, which has enabled utilization as an outcome measure in many clinical trials (197, 283-285). Some patient groups exhibit difficulty with the Hinting Task including those with schizophrenia/psychosis (104, 274, 285-296) including ultra high-risk (98) and first-episode (297) samples, groups exhibiting substance misuse $(298,299)$, and patients with bipolar disorder $(264,300,301)$. However, other clinical studies involving patients with first-episode psychosis (302), bipolar disorder (293), or Tourette syndrome (303) revealed no differences to healthy controls.

\section{Reading the Mind in the Eyes Task}

Baron-Cohen et al. (304) developed the Reading the Mind in the Eyes Test (RMET: https://www.autismresearchcentre.com/ arc_tests), which measures the ability to discriminate mental states from photographs of pairs of human eyes. A revised version was produced slightly later (56) aiming to ensure that the target words and foils possessed comparable emotional qualities.
There is one practice item plus 36 grayscale edited photographs featuring males (19) and females (17), each image surrounded by four mental state terms (e.g., bored, arrogant, flustered, and preoccupied). The participant must choose the word that best describes what the individual in the picture is thinking or feeling. Correct responses based on expert consensus are provided by Baron-Cohen et al. (56) and scores can range from 0 to 36 . A glossary of the mental state terms is provided for participants during testing. Baron-Cohen et al. suggest the task involves an unconscious, automatic, and rapid matching process between stored memories of similar expressions with a lexicon of mental state terms.

Although the revised version has been shown to have good validity and test-retest reliability $(305,306)$, perhaps up to 10 items from the original test can have ceiling or floor effects (307, 308). Similarly, a separate control task using the same stimuli but for which subjects are asked to judge the sex of the person leads to responses approaching ceiling (56). More recent studies have therefore attempted to develop alternative control tasks, usually involving selecting age for the same set of stimuli [e.g., Refs. (308, 309)], although few studies have matched the tasks for difficulty [e.g., Refs. $(310,311)$ ]. There is also a child version with 28 items (56). Many versions of the task have been developed for use with speakers of Chinese, Turkish (312), German (313), Italian [Ref. (314); also for children: Ref. (315)], Spanish (305), Brazilian Portuguese (316), French (317), and Persian (318). This task has been utilized very widely in many fMRI studies $(310,311$, 319-324) and as an outcome measure in clinical experimental trials (227, 325-334). Atypical performance can be detected in association with childhood adverse experiences $(335,336)$ and patient groups with schizophrenia (210, 337-342), Parkinson's disease (343), bipolar disorder and depression (344, 345), methamphetamine users with psychosis (346), frontotemporal dementia (347), ASD (348, 349), epilepsy (350), Huntington's disease $(183,184,351,352)$, Tourette syndrome (100), attention deficit-hyperactivity disorder (353), and cerebellar tumor (354). However, some clinical samples demonstrate no impairment [bipolar disorder: Ref. (355); high functioning autism: Ref. (356); depression: Ref. (258); cocaine use: Ref. (253); schizotypy: Refs. $(357,358)]$ or potentially enhanced performance in comparison to healthy controls [depression: Ref. (359); borderline personality disorder: Ref. (360); neglected children: Ref. (361)]. Efforts have been made to identify selective impairments on the task in relation to the valence of items and considering neutral items may lead to further insight into conditions such as borderline personality disorder [e.g., Ref. (360)] and social anxiety (262), but individual items aren't well matched for difficulty.

\section{Faux Pas Task}

This story-based task was developed as a measure of more advanced ToM in children $(57,362)$, but there is also a version typically used with adults. There are 10 faux pas (test) stories and 10 non-faux-pas-containing (control) stories. Test stories describe one of the characters making an unintentional statement that is likely to negatively affect another character's feelings (e.g., Kim has made an apple pie for her uncle, and as she carries out the pie to him, he remarks that he loves pies, except apple 
ones). The participant must recognize the lack of awareness or mistaken belief of the speaker (cognitive mental state: it's not an apple pie) and the upset of the other character (affective ToM: disappointment or offense). The task therefore assesses understanding of both cognitive and affective mental states. Older participants are first asked "Did anyone say something they shouldn't have said, or something awkward?" If a faux pas is indicated, this is followed by questions relating to who, and why. After this, there is the question tapping into understanding of emotional mental state ("Why shouldn't he/she have said it or why was it awkward?") and the check for understanding of the unintentional aspect of the faux pas ("Why do you think he/she said it?"). In addition to the comprehension questions, there is a final more explicit check of the understanding of the speaker's false belief ("Did Uncle Tom know the pie was an apple pie?"). For control stories, questioning follows the same pattern, but only one comprehension question is asked and the more explicit false belief question is not present. Scores for test stories range from 0 to 2 based on complete or partial understanding, but control stories are scored from 0 to 1 , resulting in a maximum possible score of 60 .

The popularity of this task is such that versions have been produced in languages such as German (363), Hebrew (364), Japanese (365), Chinese (366), and Italian (367). It has been employed in clinical trials [e.g., Refs. $(197,368)$ ] and neurophysiological studies (369), and has been presented with illustrations to help control for working memory demand (370). Deficits in understanding faux pas can be found in epilepsy (especially temporal lobe epilepsy) (157, 159, 338, 371-376), substance misuse (377), Parkinson's disease (378, 379), multiple sclerosis $(380,381)$, schizophrenia $(175,176,382-$ $388)$, bipolar disorder $(389,390)$, ASD (391), attention deficithyperactivity disorder $(392,393)$, Tourette syndrome $(100,303$, 394), Huntington's disease $(351,352)$, depression $(174,395)$, frontotemporal dementia $(36,396,397)$, personality disorder (398), anorexia nervosa (399), temporal lobe damage (400), caudate lesion (401), brain tumor (402), myotonic dystonia (403), and frontal lobe damage [(168, 404, 405); but see Ref. (406)]. Patients with Turner syndrome (407), borderline PD (408), obsessivecompulsive disorder (409), or autobiographical memory deficit (410) appear less likely to demonstrate impairments. Some neuropsychiatric groups show atypical responses to control trials [e.g., Tourette syndrome: Eddy et al. (303) and ASD: Ref. (391)].

\section{Interpersonal Reactivity Index}

The Interpersonal Reactivity Index is a 28 -item multidimensional scale typically thought to assess both cognitive and affective aspects of empathy (IRI) (58). The cognitive aspects assessed include Perspective Taking (PT) and Fantasy (F) subscales. PT involves imagining other people's perspectives, whereas the $\mathrm{F}$ subscale taps into tendencies towards empathizing with fictional characters (e.g., in films or books). Emotional aspects of empathy are measured via the subscales Personal Distress (PD), which asks about the respondent's reactions when witnessing another person's distress, and Empathic Concern (EC), a measure of concern towards others' emotions and experiences (58). Each item is rated using a five-point Likert scale from "does not describe me well" to "describes me very well." Internal consistency is high, Cronbach's $\alpha=0.85$ (58), with good test-retest reliability as well as convergent validity with other measures of empathy (411). Although many previous studies combine subscales to provide two separate measures of cognitive and affective empathy, some factor structure studies question the validity of the PD subscale $(412,413)$ and the F subscale (414) as valid measures of empathy. Other studies support validity $(415,416)$ and test-retest reliability $(417)$.

There is a child version of the task (418) and versions have been developed in Dutch (419), Italian (420), Chinese (421), French (422), Japanese (423), Spanish (424), and German (425). There is also a proxy version [e.g., Ref. (426)]. The IRI has been used in many trials related to social cognition (427) (e.g., 329, 427-429) and neurophysiological studies $(430,431)$, in combination with MRI data (432-437), and appears to be predictive of performance on other tasks of social cognition (438-440). Atypical scores may arise in association with schizotypy (441), schizophrenia (256, 442-448), epilepsy $(449,450)$, ASD (156), Huntington's disease (183, 184), Tourette syndrome (183), Alzheimer's disease and mild cognitive impairment (451), frontotemporal dementia (452-454), post-traumatic stress disorder $(455,456)$, attention deficit-hyperactivity disorder (393), anorexia nervosa (457), Parkinson's disease $(458,459)$, depression (273), traumatic brain injury (460), aphasia (461), multiple sclerosis (462), complex regional pain (463), and substance misuse (464). No significant difference to controls have also been found in other samples of patients with substance misuse $(25,26,465)$, schizophrenia (466), first-episode psychosis (467), and first-degree relatives of patients with schizophrenia $(468,469)$.

\section{Strengths and Limitations of the Most Popular Measures}

Identified strengths and limitations of these more popular tasks are shown in Table 3.

\section{DISCUSSION}

\section{Evaluation of Existing Measures Task Characteristics and Applications}

Overall, it is almost difficult to identify a psychiatric (or neurological) disorder that has not been associated with abnormalities on at least one of the four most popular measures (RMET, IRI, Faux Pas Task, and Pictures of Facial Affect). However, the more popular measures have been applied most frequently in populations with schizophrenia or ASD, and there have been markedly fewer studies in conditions such as obsessive-compulsive disorder, attention deficit-hyperactivity disorder, eating disorders, or specific anxiety disorders. A scattering of studies in this review employed the measures in borderline personality disorder [but see Ref. (571)], substance use populations, and rarer genetic and neurological syndromes. Few previous studies have explored these tasks in younger populations with psychiatric diagnoses, although this area may now be receiving greater interest [see Ref. (572)]. Furthermore, while studies in a few disorders (e.g., schizophrenia) have attempted to explore the relationship between social 
TABLE 3 | Strengths and limitations of more popular social cognitive assessments used in neuropsychiatric populations.

\begin{tabular}{|c|c|c|}
\hline Measure & Strengths & Limitations \\
\hline Sally Anne Task & $\begin{array}{l}\text { - Can be used with children } \\
\text { - Tests understanding of both first- and second-order belief } \\
\text { - False belief tasks in general are established tests of ToM } \\
\text { available in a variety of forms } \\
\text { - Relatively pure measure of cognitive ToM }\end{array}$ & $\begin{array}{l}\text { - Not originally designed for adults } \\
\text { - Executive functions affect performance }(93,94,139) \\
\text { - Format of presentation will also influence performance } \\
(139,470)\end{array}$ \\
\hline Strange Stories & $\begin{array}{l}\text { - Validity, e.g., correlated with measures of relational } \\
\text { - } \text { Associated with social competence in epilepsy (157) } \\
\text { - Includes control-type "physical" stories } \\
\text { - Insight offered by multiple scoring techniques including } \\
\text { number of mental states attributed, appropriateness and } \\
\text { - } \text { quality (149) }\end{array}$ & $\begin{array}{l}\text { - Performance is affected by reading comprehension (155), } \\
\text { IQ (153, 163, 471-473), and executive function }(145,161 \text {, } \\
\text { 163) } \\
\text { - General inferential ability, social norms, and autobiographical } \\
\text { memory may influence performance (474) } \\
\text { - Typical children don't reach ceiling (474) } \\
\text { - Different studies use different length versions } \\
\text { - Lack of vocal cues limits ecological validity (146) } \\
\text { - Physical (control) stories are not well matched (152) } \\
\text { - Age effects }(145,475)\end{array}$ \\
\hline The Yoni Task & $\begin{array}{l}\text { - Tests both cognitive and affective mental states, and first- } \\
\text { and second-order belief } \\
\text { - Visual task which could reduce working memory demand } \\
\text { - Ease of presentation and can be used well with children (175) } \\
\text { - Validity supported by correlations with, e.g., false belief tasks } \\
\text { (67) } \\
\text { - Affective trials can be related to quality of life measure in } \\
\text { - Parkinson's disease (172) } \\
\text { - The authors also developed a related task to assess } \\
\text { understanding of socially competitive emotions }\end{array}$ & $\begin{array}{l}\text { - Executive functions }(175,176,454) \text { and IQ can affect } \\
\text { performance }(176,454) \\
\text { - It is not clear if these factors differentially influence the cognitive } \\
\text { and affective aspects, i.e., that the demands of all trials are } \\
\text { comparable } \\
\text { - Simply relying on eye gaze direction may help answer some } \\
\text { trials, although there are some control trials with eye gaze } \\
\text { straight ahead }\end{array}$ \\
\hline Animations Task & $\begin{array}{l}\text { - Can be used to reveal both hypo- and hyper-mentalizing } \\
\text { - Can assess spontaneous mental state reasoning, therefore } \\
\text { has good ecological validity, and may be more challenging } \\
\text { and sensitive than some other tasks } \\
\text { - Non-facial as well as non-verbal stimuli } \\
\text { - Multiple scores meaning complex patterns of performance } \\
\text { and selective deficits can be identified } \\
\text { - Can be related to social, school, and occupational } \\
\text { functioning in schizophrenia (476) } \\
\text { - Responses can be scored for length as a control }\end{array}$ & $\begin{array}{l}\text { - Complex scoring and transcription required, a need for multiple } \\
\text { raters } \\
\text { - The clips are short: standardized instructions are required in } \\
\text { relation to the number of viewings to permit } \\
\text { - Experimenter must avoid providing cues as to the nature of the } \\
\text { task } \\
\text { - Verbal abilities from speech to vocabulary will influence } \\
\text { response quality (e.g., 186) and visual attention may affect } \\
\text { - Performance } \\
\text { - Possible gender effect (186) } \\
\text { length or complexity }\end{array}$ \\
\hline $\begin{array}{l}\text { Intentions Comic Strip } \\
\text { Task }\end{array}$ & $\begin{array}{l}\text { - Avoids verbal demands, which makes it accessible across } \\
\text { cultures and enhances the purity of the measure } \\
\text { - Useful for fMRI experiments (e.g., 191) } \\
\text { - Contains useful control conditions }\end{array}$ & $\begin{array}{l}\text { - Possible ceiling effect in controls (478) } \\
\text { - Used in few clinical groups overall } \\
\text { - Studies have yet to explore the contribution of, e.g., executive } \\
\text { functions to task performance }\end{array}$ \\
\hline
\end{tabular}

- Factor analysis supports the validity of the three conditions (477)

- Taps implicit reasoning

- Fairly pure measure of cognitive ToM

Pictures of Facial Affect - Can be used to reveal emotion specific deficits

- Suitable for use with children (479)

- May be a sensitive measure in terms of tracking disorder state (e.g., 210)

- Performance can indicate carer burden (480)

- Includes neutral trials can offer particular insight (481)

- Validity supported by associations with other social cognitive tasks (223)

- Not originally designed for adults

- Executive functions affect performance $(93,94,139)$

presentation will also influence performance

Performance is affected by reading comprehension (155), IQ $(153,163,471-473)$, and executive function $(145,161$,

memory may influence performance (474)

- Typical children don't reach ceiling (474)

- Different studies use different length versions

- Lack of vocal cues limits ecological validity (146)

- Physical (control) stories are not well matched (152)

performance $(176,454)$

- It is not clear if these factors differentially influence the cognitive comparable

- Simply relying on eye gaze direction may help answer some trials, although there are some control trials with eye gaze straight ahead

Complex scoring and transcription required, a need for multiple raters

s are required in

as to the nature of the response quality (e.g., 186) and visual attention may affect performance

sible gender effect (186) length or complexity

- Used in few clinical groups overall functions to task performance

- Only assesses recognition of basic emotions and mainly negative emotions

- Motor contribution unknown

- Associated with global cognition or education $(238,482)$ and IQ $(211,216)$

- Interpretation is complex as performance could be impaired by self-awareness (483), problems with motor simulation, or memory

- Possible gender (484) and age effects $(479,485,486)$

- Time-limited format may lead to guessing (222)

- Little ethnic variation in stimuli, grayscale, old fashioned (479)

- Ecologically validity is limited by the use of static images

- Possible effects of field of presentation (487) 
TABLE 3 | Continued

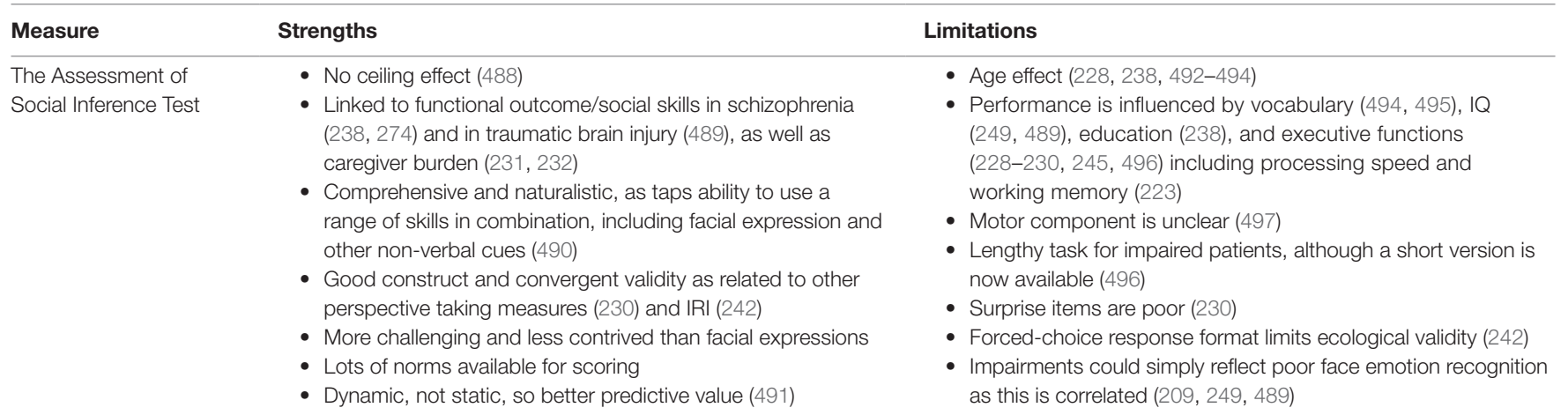

Movie for the

Assessment of Social Cognition

Hinting Task

Reading the Mind in the Eyes Test

Faux Pas Task
- Dynamic, not static, so better predictive value (491)

- Indexes frontal lobe volume loss in fronto-temporal dementia (234)

- Good psychometrics (223)

- Can detect both hypo- and hyper-mentalizing

- Tests understanding of both cognitive and affective mental state reasoning and fine-grained assessment that can revea selective deficits $(69,259)$

- Reliable in adolescents $(260,498)$

- Good psychometrics (250) including internal consistency and reliability $(263,273)$

- Ecologically valid (267)

- Not related to verbal IQ (69)

- Validity supported by correlations with other social cognitive tasks $(150,151,260,499)$ but not always correlated with other social cognitive tasks (273)

- Not affected by culture or social desirability $(150,151)$

- Takes less than 10 min to administer (278)

- Strong test-retest reliability and good internal consistency (500)

- Not associated with IQ $(294,503)$

- Validity supported by correlation with spoken prosody (504) and correlates with other social cognitive tasks, e.g., emotion recognition (505)

- Related to social functioning in schizophrenia $(274,506)$

- Not associated with referential thinking in general $(507,508)$

- Validity supported by strong association with other social cognitive measures, e.g., Hinting task (506), IRI-PT (515) but perhaps only a weak correlation with autism spectrum quotient (516)

- No ceiling in controls, can examine positive, negative, and neutral trials separately (e.g., 382-384) and use RT to offer insight $(382-384,517)$

- Scores remain stable over time (518)

- Short administration time (typically 10-15 min)

- Can use across cultures (349) and many existing translations

- Not just basic emotion recognition (519)

- Associated with social factors such as maternal functioning (520), social isolation (506), and clinical change in psychosis (521)

- Test-retest reliability is fairly good for the child version of RMET and one study demonstrated no learning effects (522).

- Used to test cognitive and affective ToM, with multiple layers of difficulty, and fine-grained analysis possible

- Control stories are included and can indicate hypermentalizing as well as hypo-mentalizing

- Mimics real life

- Associated with other social cognitive tasks and quality of life in epilepsy (373)

- Can adapt to other cultures (137)

- Associated with prosody deficit/indirect speech understanding $(540,541)$ and RMET performance in some studies (542) but not others $(543,544)$

- Associated with carer behavior ratings (545) and mixed findings for social functioning in schizophrenia $(366,546)$
- Depression, $I Q$, and executive functions can affect performance $(255,265,501)$

- Age effects $(265,270,499)$

- Uses only second-person perspective and participant is observer (499), should add self-referent aspect (271)

- Long time to administer and score-45-70 min (150, 151)

- Use of contextual cues could mask a deficit (468)

- Stress can affect performance (502)

- Need trained raters $(69,259)$

- Doesn't tap implicit social cognition (250)

- Further psychometric analysis would be helpful

- Potential ceiling effect $(274,275,300)$

- Only assesses cognitive ToM

- Poor test-retest reliability and practice effect (274)

- Highly dependent on verbal comprehension (293) and associated with IQ (509)

- Executive function may affect performance (504, 510-514), especially processing speed and memory (297)

- Age effect (301)

- Gender effects are debated (361, 515, 518, 523-525)

- Performance is associated with visuospatial skills (512), reading (526), autobiographical memory (527), IQ (528-532), and executive function (533; my papers; 298, 534)

- Debate as to whether stress affects performance $(502,535)$

- Age effects $(160,523,536)$

- Cronbach's alpha can be low $(312,537)$

- The stimuli were restricted to only Caucasians in the original task, and a gender confound as the males are older, less attractive, and more negative (538)

- Ecological validity is also weakened by static images, specificity of cues and forced-choice response format

- Better control tasks are needed (539)

- Debate over whether the task measures cognitive or affective ToM, or empathy, or emotion recognition (261)

- Some items have floor or ceiling effects

- A verbal task that makes cognitive demands beyond mental state reasoning (474)

- Accuracy may reflect use social norms and scripts, not just online reasoning about mental states, making this a "top-down" task (547)

- Associated with education (548) and IQ (549), and executive function can affect performance (339, 378, 382-385, 546, 550, 551)

- Scoring differences across studies (160) and some responses are difficult to score

- The cognitive and affective questions may not be of comparable difficulty

- Controls don't always perform at ceiling

- Antipsychotic medications may affect performance (552)

- Little psychometric data 
TABLE 3 | Continued

\begin{tabular}{|c|c|c|}
\hline Measure & Strengths & Limitations \\
\hline $\begin{array}{l}\text { Interpersonal Reactivity } \\
\text { Index }\end{array}$ & $\begin{array}{l}\text { - A multidimensional measure that can be used to assess } \\
\text { - } \text { Fagnitive and affective empathy: multidimensional } \\
\text { - High convergent and discriminant validity (553) } \\
\text { - Often associated with other social cognitive tasks (e.g., 341) } \\
\text { - Psychophysiological data support the difference between } \\
\text { cognitive and affective aspects (430) } \\
\text { - Stable over time in schizophrenia (554) } \\
\text { - Predicts functional capacity/psychosocial functioning in } \\
\text { schizophrenia (555, 556) and psychosocial function in bipolar } \\
\text { disorder (557) as well as being associated with carer burden } \\
\text { (231, } 232,461) \\
\text { - Proxy version available and scores can be correlated, e.g., } \\
\text { between parents and their adolescent children (558). }\end{array}$ & $\begin{array}{l}\text { - Not associated with other empathy measures (559) } \\
\text { - Self-report means potential for bias and difficulties due to } \\
\text { insight or anosagnosia (541) } \\
\text { - Social desirability can be a problem, e.g., in forensic populations } \\
\text { (560), so more objective measures are needed (561) } \\
\text { - Cognitive and affective subscales and combinations have } \\
\text { questionable validity (562) and the factor structure can be } \\
\text { challenged (563): the scale be less valid for affective empathy (564) } \\
\text { - The PD subscale has weakest internal consistency (565), plus } \\
\text { this subscale is self-oriented and neither it nor the F subscale } \\
\text { - Geasures true empathy (566) } \\
\text { - Scores effect (567-569) } \\
\text { - Age effect (570) }\end{array}$ \\
\hline
\end{tabular}

Limitations are raised by the author where no reference is given. Factors such as ceiling effects and the specificity of the measure could be considered both strengths and limitations. A ceiling effect in controls could mean a task can highlight a profound deficit in patients, but no ceiling effect may mean greater sensitivity, whereas task specificity can help to reveal a precise deficit to target with intervention, although a more global perspective on social cognitive performance may also be needed.

cognitive performance and core symptoms of disorders (e.g., signs of depression or psychosis, tics, etc.), this is infrequent and results can be equivocal.

In relation to task format, studies assessing facial emotion recognition are perhaps the most widespread. However, videobased tasks assessing the understanding of dynamic social exchanges and inappropriate behavior have recently become prevalent (e.g., MASC, TASIT), presumably given the advantages of dynamic over static stimuli in terms of ecological validity. Audiovisual tasks are rich and comprehensive in the form of assessment provided, but studies do acknowledge that they are more lengthy to administer and more complex to score and interpret. Many studies note the importance of including measures to assess understanding of both cognitive and affective mental states, but only a few of the more popular measures have the advantage of being able to reveal hyper- in addition to hypomentalizing (e.g., Faux Pas Task, Animations Task).

Task selection also demonstrates a tendency towards explicit assessment of social cognition. That is, questioning tends to imply the need to pay attention to mental states, although this may mean we fail to detect subtle impairments in application of ToM, which can be distinguished from ability per se. Of the 12 more popular tasks, the Animations Task is probably the only measure that can explore spontaneous attribution of mental states due to the ambiguous nature of questioning. Relationships between this task and functioning remain to be explored, and it has yet to be used widely in clinical samples. One potential drawback is that it is rather complex to score and verbal ability will impact performance; thus, groups with speech or language impairment need to be carefully examined.

Many of the most popular social cognitive tasks have been adapted for use in fMRI experiments, especially those that involve visual stimuli (e.g., RMET, Pictures of Facial Affect, and Intentions Comic Strip Task). However, in this case, behavioral responses are not always collected, or the method of questioning may differ when participants can only be assessed within a scanner. Combining behavioral and brain imaging data may have much to add when working with patient groups who have, e.g., communication limitations, and when attempting to determine the primary difficulties driving task performance differences to healthy controls.

\section{Common Limitations of Measures}

There are limitations in relation to interpretation of performance on the more popular measures in terms of seeking evidence of a social cognitive deficit per se. For example, while gender is one potential confound, age effects have been reported in relation to the majority of social cognitive tasks, and it will therefore be imperative to have a control group matched for this. Furthermore, interpretation requires an understanding of what typical performance should be, and not all tasks display ceiling effects in the typical population. Some tasks already have the advantage of established norms, including in a range of different clinical groups (e.g., TASIT). However, what is a typical response may still change over time, especially in relation to those tasks most influenced by cultural norms.

Other difficulties include potential confounds such as IQ, education, vocabulary, etc., and while many studies attempt to explore such characteristics in the samples they test, relationships are frequently unreliable and hard to interpret (e.g., should we expect some measures of IQ to be intrinsically related to social cognitive ability)?. In addition, although most popular social cognitive tasks include some control trials or questions to assess, e.g., memory or comprehension (e.g., Faux Pas Task, Strange Stories, TASIT, etc.), this is not the case for all, and it can be difficult to develop control conditions or tasks well matched for complexity or difficulty. For example, a few recent studies have aimed to address this problem with the RMET, developing age judgment versions of the task (309-311), and most recently, comparison tasks featuring non-human animal eyes (573). However, strategy may also influence performance, e.g., stored knowledge may be an alternative way of answering certain tasks rather than 
effortful mental state reasoning in terms of perspective taking or emotion simulation, and few studies have explored such possibilities in any depth.

More generally, this review has also highlighted challenges in terms of synthesizing results across studies due to variations in the presentation or administration of tasks and assessments. Many tasks have been revised over the years and even these most popular and established measures are not always administered in the form of the complete task, or scored consistently across studies. A few measures (e.g., the MASC) are more likely to avoid this kind of problem, but others (e.g., Hinting Task) may be read by one experimenter in a way that offers cues to performance that is not done by another. While some flexibility may appear to be needed when working around the limitations of individual patient groups, systematic administration and consistent reporting promote synthesis across studies and allow broader implications to be drawn.

Perhaps the most important limitation identified is the relatively under-explored relationship between social cognitive task performance and other scales assessing both self- and other-rated report of social cognitive ability. This is particularly important in those groups that may lack insight (e.g., dementia, Huntington's disease, personality disorders, etc.). The IRI has been applied extensively, but this is a self-report measure of PT, and may not provide the broadest indication of behaviors during everyday social interaction. It is interesting to note that while according to the literature, a range of social functioning scales appear to have been developed (Table 2), hardly any of these scales appear to have been used repeatedly in neuropsychiatric populations. It is not clear whether developers were simply unaware of other measures in existence, were unable to access them, or felt there were existing limitations. Underutilization of existing measures of everyday functioning restricts the ability to evaluate more specific neuropsychological tasks. For example, an abundance of studies have reported impairments on the RMET in a wide range of psychiatric conditions, but relatively few studies have attempted to link task scores to real world function. What do these lab-type tasks add beyond functioning scales? Perhaps in some cases they can help us identify the more precise problems that lead to broader behavioral problems, while advancing our understanding of neuropsychological mechanisms. Correlational studies may shed further light on the precise individual skills involved in these popular measures and help identify (or further develop) the best tasks and measures for use in cognitive rehabilitation trials.

\section{Recommendations}

As can be seen from Table 2, a wide range of measures are available. Some measures have yet to be applied in specific psychiatric groups; hence, addressing these gaps could be insightful. Specific confounds (e.g., IQ and age effects) should be considered based on the likely characteristics of the patient group in question and appropriate controls should be identified where possible. Some tasks may be particularly sensitive in high functioning patient groups. For example, the Animations Task has revealed subtle impairments in Tourette syndrome (303) while the Yoni Task is one of the very few measures known to have revealed impairment in obsessive compulsive disorder (177) and first-episode psychosis (176). A flurry of attention has focused on the possibility that some measures of social cognition may track with disease state or identify early conversion in disorders such as psychosis [e.g., Ref. (297)], frontotemporal dementia (234), or Huntington's disease $(183,184)$, but further research is required.

The compromise in assessment selection is likely to rest in the balance between the comprehensiveness of the measure and ease of interpretation of performance. The Hinting Task, Intention Comic Strip Task, and Sally Anne-type false belief tasks are rather pure measures of cognitive ToM and perhaps easier to interpret than some other measures. On the other hand, measures such as the TASIT and MASC are more comprehensive and the involvement of dynamic visual cues and context means superior ecological validity. If a task can also detect a difference in the tendency to spontaneously attribute mental states (e.g., Animations Task) or detect hypermentalizing as well as hypo-mentalizing (e.g., Faux Pas Task), this could also be seen as a significant advantage.

If few measures can be included within a study (e.g., due to time constraints) but both cognitive and affective ToM should be assessed, the Yoni Task seems to be a very sensitive visual "allaround" task, whereas the Faux Pas Task is a good "verbal only" all-around task. In terms of ease of administration, previous studies have suggested that the Hinting Task, RMET, Strange Stories, and the Yoni Task are all fairly easy to administer and score. Those tasks that make fewer verbal demands may be particularly useful in clinical populations with more general cognitive problems such as people with dementia. This could include the Intention Comic Strip Task and the Yoni Task. Those tasks involving more abstract reasoning (e.g., second-order belief questions) will involve more working memory demand. Standardized recorded materials or visual stimuli to accompany verbal tasks would also be helpful. Studies could even explore variation in performance of patients across multiple task formats [e.g., Ref. (574)]. It seems to be a sensible approach to develop visual accompaniments for verbal tasks that can help remove confounds with, e.g., working memory. However, development of these additional materials will have to be carefully considered in terms of what additional cues are being provided (e.g., emotional facial expressions).

Ultimately, there will be a trade-off between empirical control and ecological validity. Controlling for the many confounds likely to influence patient studies is important, but we should not lose sight of the point that we rarely interpret social stimuli in isolation or outside of sociocultural context. Some tasks are clearly influenced by social norms and convention (e.g., Hinting task, Faux Pas Task, and tasks involving non-literal language and humor), whereas others seem to tap into more basic abilities (e.g., visual emotion recognition). This is certainly worth bearing in mind. Sometimes, multiple strategies can be used and testing cannot always control for this. Therefore, more extensive questioning around how participants have approached a task, and related factors such as motivation and metacognition, should be the norm. 
Routine inclusion of dimensional clinical assessments is the way forward, and this should be extended to include measures of emotional reactivity. When answering a task question about how a given character would react in a given situation, and using oneself as a simulation piece to try and generate a mental state that would be felt in that situation, this would only give an accurate answer if one would indeed respond the same way. For the Faux Pas Task, it may be important to ask how the patients themselves would feel in that situation, as well as asking them to explain how someone else is likely to feel. Few studies ask the respondent to explicitly imagine being in the perspective of another, and this may offer insight into performance on tasks such as the Faux Pas Task, where incorrect responses could reflect a general emotional insensitivity rather than a specific perspectivetaking deficit. Sometimes, the difficulty may lie in holding conflicting perspectives in mind rather than simply matching another's emotion, or the distinction between self and other versus self-other blending (49). While emotion recognition measures assess blending, false belief tasks are a good example of a measure that involves self-other distinction due to the need to hold in mind conflicting perspectives. Furthermore, it can be helpful to have other kinds of cognitive perspectivetaking measures included in an experiment as control tasks. For example, it has been shown that in Huntington's disease (HD), performance on a basic object spatial PT task was related to performance on the RMET (352). Task deficits can reflect egocentric tendencies in general (e.g., 575) rather than just simply difficulties in understanding other people's mental states, and experimental design should take this into consideration.

A few studies [e.g., in schizophrenia: Refs. (382-384)] have highlighted the importance of insight and a potential relationship between this and social cognition. Self-ratings (or proxy ratings of, e.g., empathy) are rarely explored in terms of a relationship with scores on these social cognitive popular tasks, but the pattern of performance on a scale such as the IRI could aid interpretation of other social cognitive tasks, e.g., high PD scores could be associated with an aversive reaction to emotional stimuli, affecting attention focus and impairing performance (49). However, self-rated measures may be of limited use when working with groups with potential insight issues or who may exhibit social desirability effects [e.g., Ref. (560)].

In summary, researchers should consider the range of skills they want to assess when selecting a task, in addition to any likely administration limitations, and the potential confounds that may affect interpretation within the patient group in question. They should consider multiple presentation formats and tasks that can tap application as well as ability per se, and consider assessment of general cognitive and emotional status as well as seeking a combination of objective and subjective data around everyday social function. Clinical samples should be well characterized. An additional consideration for clinical trials is potential practice effect, and some popular tasks are already available in multiple forms (e.g., TASIT and Hinting Task) to help avoid this difficulty.

\section{Conclusions and Future Directions}

Despite the wealth of previous research, some factors that could significantly impact performance on social cognitive tasks have received little attention. These include those that will influence the majority of patient studies, such as potential medication effects, and those that may interact with affective or motor factors such as ease of eye contact and visual attention more generally. We rarely ask patients how they felt about a task, or their performance, and this in itself may prove informative. We also need to improve the detail and clarity in data reporting to support greater synthesis across study findings and help to clarify the precise underpinnings of deficits in those more complex and heterogenous patient groups as research evidence mounts. Cross-disorder comparison studies are rare, but comparing multiple patient groups within the same study using the same social cognitive tasks could offer useful insight into etiology and neurodevelopmental relationships between disorders (49).

Another important aim for future research will be to develop more well-matched control tasks to allow the identification of selective deficits where possible, as well as identify ecologically valid measures of real-world social functioning. New measures should aim to help differentiate between problems with ability versus differences in application as in some cases there may be subtle deficits that simply cannot be detected by the more contrived and explicit measures. More measures are always needed in the form of cultural adaptions, as well as counterpart measures to address proxy perspective when possible: the aim is to assess social factors after all, and studies rarely consider social cognition as a two-way process in their approach to assessment. There are currently few roleplay-type assessments available, and further development in this area could be advantageous.

Longitudinal studies well help disentangle developmental effects and identify those measures that remain stable over time and those that may track with disease. This will, in turn, inform the creation of additional tasks for use in clinical and rehabilitative trials. But before we even begin to design interventional studies and assess outcome, we need to have a clear picture about what we mean when we refer to dysfunctional social cognition. This may, in turn, necessitate the development of more disease-specific measures that can account for what can reasonably be expected for individuals living with varied patterns of neuropsychiatric symptoms. Ultimately, the best approaches to the assessment of social cognition will be seeking to match the depth, complexity, and dynamicity of the human experience that we endeavor to explain.

\section{AUTHOR CONTRIBUTIONS}

CME is the sole author of this manuscript. 


\section{REFERENCES}

1. Ospina LH, Shanahan M, Perez-Rodriguez MM, Chan CC, Clari R, Burdick KE. Alexithymia predicts poorer social and everyday functioning in schizophrenia and bipolar disorder. Psychiatry Res (2019) 273:218-26. doi: 10.1016/j.psychres.2019.01.033

2. Konstantakopoulos G, Ploumpidis D, Oulis P, Patrikelis P, Nikitopoulou S, Papadimitriou GN, et al. The relationship between insight and theory of mind in schizophrenia. Schizophr Res (2014) 152(1):217-22. doi: 10.1016/j. schres.2013.11.022

3. Carpenter JM, Green MC, Vacharkulksemsuk T. Beyond perspectivetaking: mind-reading motivation. Motiv Emot (2016) 40:358. doi: 10.1007/ s11031-016-9544-z

4. Pile V, Haller SPW, Hiu CF, Lau JYF. Young people with higher social anxiety are less likely to adopt the perspective of another: data from the director task. J Behav Ther Exp Psychiatry (2017) 55:41-8. doi: 10.1016/j.jbtep.2016.11.002

5. Spengler S, von Cramon DY, Brass M. Resisting motor mimicry: control of imitation involves processes central to social cognition in patients with frontal and temporo-parietal lesions. Soc Neurosci (2010) 5(4):401-16. doi: $10.1080 / 17470911003687905$

6. Di Martino A, Castellanos FX. Functional neuroimaging of social cognition in pervasive developmental disorders. Ann N Y Acad Sci (2003) 1008:25660. doi: 10.1196/annals.1301.027

7. Couture SM, Penn DL, Roberts DL. The functional significance of social cognition in schizophrenia: a review. Schizophr Bull (2006) S1:S44-63. doi: 10.1093/schbul/sbl029

8. Brüne M, Brüne-Cohrs U. Theory of mind-evolution, ontogeny, brain mechanisms and psychopathology. Neurosci Biobehav Rev (2006) 30(4):43755. doi: 10.1016/j.neubiorev.2005.08.001

9. Sprong M, Schothorst P, Vos E, Hox J, van Engeland H. Theory of mind in schizophrenia: meta-analysis. Br J Psychiatry (2007) 191:5-13. doi: 10.1192/ bjp.bp.107.035899

10. Pickup GJ. Relationship between Theory of Mind and executive function in schizophrenia: a systematic review. Psychopathology (2008) 41(4):206-13. doi: 10.1159/000125554

11. Uekermann J, Daum I. Social cognition in alcoholism: a link to prefrontal cortex dysfunction? Addiction (2008) 103(5):726-35. doi: 10.1111/j.1360-0443.2008.02157.x

12. Bora E, Yucel M, Pantelis C. Theory of mind impairment in schizophrenia: metaanalysis. Schizophr Res (2009) 109(1-3):1-9. doi: 10.1016/j.schres.2008.12.020

13. Freedman M, Stuss DT. Theory of Mind in Parkinson's disease. J Neurol Sci (2011) 310:225-7. doi: 10.1016/j.jns.2011.06.004

14. Uekermann J, Kraemer M, Abdel-Hamid M, Schimmelmann BG, Hebebrand J, Daum I, et al. Social cognition in attention-deficit hyperactivity disorder (ADHD). Neurosci Biobehav Rev (2010) 34(5):734-43. doi: 10.1016/j. neubiorev.2009.10.009

15. Adenzato M, Cavallo M, Enrici I. Theory of mind ability in the behavioural variant of frontotemporal dementia: an analysis of the neural, cognitive, and social levels. Neuropsychologia (2010) 48(1):2-12. doi: 10.1016/j. neuropsychologia.2009.08.001

16. Korkmaz B. Theory of mind and neurodevelopmental disorders of childhood. Pediatr Res (2011) 5(2):101R-08R. doi: 10.1203/PDR.0b013e318212c177

17. Bragado-Jimenez MD, Taylor PJ. Empathy, schizophrenia and violence: a systematic review. Schizophr Res (2012) 141(1):83-90. doi: 10.1016/j. schres.2012.07.019

18. Kemp J, Després O, Sellal F, Dufour A. Theory of Mind in normal ageing and neurodegenerative pathologies. Ageing Res Rev (2012) 11(2):199-219. doi: 10.1016/j.arr.2011.12.001

19. Samamé C, Martino DJ, Strejileivich SA. Social cognition in euthymic bipolar disorder: systematic review and meta-analytic approach. Acta Psychiatr Scand (2012) 125(4):266-80. doi: 10.1111/j.1600-0447.2011.01808.x

20. Poletti M, Enrici I, Adenzato M. Cognitive and affective Theory of Mind in neurodegenerative diseases: neuropsychological, neuroanatomical and neurochemical levels. Neurosci Biobehav Rev (2012) 36(9):2147-264. doi: 10.1016/j.neubiorev.2012.07.004

21. Samamé C. Social cognition throughout the three phases of bipolar disorder: a state-of-the-art overview. Psychiatry Res (2013) 210(3):1275-86. doi: 10.1016/j.psychres.2013.08.012
22. Kucharska-Pietura K, Mortimer A. Can antipsychotics improve social cognition in patients with schizophrenia? CNS Drugs (2013) 27(5):335-43. doi: 10.1007/s40263-013-0047-0

23. Schreiter S, Pijnenborg GH, Aan Het Rot M. Empathy in adults with clinical or subclinical depressive symptoms. J Affect Disord (2013) 150(1):1-16. doi: 10.1016/j.jad.2013.03.009

24. Roepke S, Vater A, Preißler S, Heekeren HR, Dziobek I. Social cognition in borderline personality disorder. Front Neurosci (2013) 6:195. doi: 10.3389/ fnins.2012.00195

25. Thoma P, Friedmann C, Suchan B. Empathy and social problem solving in alcohol dependence, mood disorders and selected personality disorders. Neurosci Biobehav Rev (2013a) 37(3):448-70. doi: 10.1016/j. neubiorev.2013.01.024

26. Thoma P, Winter N, Juckel G, Roser P. Mental state decoding and mental state reasoning in recently detoxified alcohol-dependent individuals. Psychiatry Res (2013b) 205(3):232-40. doi: 10.1016/j.psychres.2012.08.042

27. Bora E, Pantelis C. Theory of mind impairments in first-episode psychosis, individuals at ultra-high risk for psychosis and in first-degree relatives of schizophrenia: systematic review and meta-analysis. Schizophr Res (2013) 144(1-3):31-6. doi: 10.1016/j.schres.2012.12.013

28. De Jong H, Van den Eynde F, Broadbent H, Kenyon MD, Lavender A, Startup H, et al. Social cognition in bulimia nervosa: a systematic review. Eur Psychiatry (2013) 28(1):1-6. doi: 10.1016/j.eurpsy.2011.07.002

29. Cerami C, Cappa SF. The behavioral variant of frontotemporal dementia: linking neuropathology to social cognition. Neurol Sci (2013) 34(8):1267-74. doi: 10.1007/s10072-013-1317-9

30. Giovagnoli AR. Cognition, behavior, and the role of epilepsy \& behavior in advancing knowledge about epilepsy. Epilepsy Behav (2014) 40:105-6. doi: 10.1016/j.yebeh.2014.09.012

31. Martin AK, Robinson G, Dzafic I, Reutens D, Mowry B. Theory of mind and the social brain: implications for understanding the genetic basis of schizophrenia. Genes Brain Behav (2014) 13(1):104-17. doi: 10.1111/gbb.12066

32. Weightman MJ, Air TM, Baune BT. A review of the role of social cognition in major depressive disorder. Front Psychiatry (2014) 5:179. doi: 10.3389/ fpsyt.2014.00179

33. Henry JD, Phillips LH, von Hippel C. A meta-analytic review of theory of mind difficulties in behavioural-variant frontotemporal dementia. Neuropsychologia (2014) 56:53-62. doi: 10.1016/j.neuropsychologia.2013.12.024

34. Schurz M, Radua J, Aichhorn M, Richlan F, Perner J. Fractionating theory of mind: a meta-analysis of functional brain imaging studies. Neurosci Biobehav $\operatorname{Rev}$ (2014) 42:9-34. doi: 10.1016/j.neubiorev.2014.01.009

35. Mercedes Perez-Roriguez M, Mahon K, Russo M, Ungar AK, Burdick KE. Oxytocin and social cognition in affective disorders. Eur Neuropsychopharmacol (2015) 25:265-82. doi: 10.1016/j.euroneuro.2014.07.012

36. Bora E, Walterfang M, Velakoulis D. Theory of mind in Parkinson's disease: a meta-analysis. Behav Brain Res (2015b) 292:515-20. doi: 10.1016/j. bbr.2015.07.012

37. Bora E, Walterfang M, Velakoulis D. Theory of mind in behavioural-variant frontotemporal dementia and Alzheimer's disease: a meta-analysis. J Neurol Neurosurg Psychiatry (2015a) 86(7):714-9. doi: 10.1136/jnnp-2014-309445

38. Bora E, Pantelis C. Social cognition in schizophrenia in comparison to bipolar disorder: a meta-analysis. Schizophr Res (2016) 175(1-3):72-8. doi: 10.1016/j.schres.2016.04.018

39. Bora E, Bartholomeusz C, Pantelis C. Meta-analysis of Theory of Mind (ToM) impairment in bipolar disorder. Psychol Med (2016a) 46(2):253-64. doi: 10.1017/S0033291715001993

40. Bora E, Berk M. Theory of mind in major depressive disorder: a metaanalysis. J Affect Disord (2016) 191:49-55. doi: 10.1016/j.jad.2015.11.023

41. Bora E, Köse S. Meta-analysis of theory of mind in anorexia nervosa and bulimia nervosa: a specific impairment of cognitive perspective taking in anorexia nervosa? Int J Eat Disord (2016) 49(8):739-40. doi: 10.1002/ eat. 22572

42. Cotter J, Firth J, Enzinger C, Kontopantelis E, Yung AR, Elliott R, et al. Social cognition in multiple sclerosis: a systematic review and meta-analysis. Neurology (2016) 87(16):1727-36. doi: 10.1212/WNL.0000000000003236

43. Bora E, Velakoulis D, Walterfang M. Social cognition in Huntington's disease: a meta-analysis. Behav Brain Res (2016c) 297:131-40. doi: 10.1016/j. bbr.2015.10.001 
44. Bonfils KA, Lysaker PH, Minor KS, Salyers MP. Affective empathy in schizophrenia: a meta-analysis. Schizophr Res (2016) 175:109-17. doi: 10.1016/j.schres.2016.03.037

45. Happé F, Conway JR. Recent progress in understanding skills and impairments in social cognition. Curr Opin Pediatr (2016) 28(6):736-42. doi: 10.1097/MOP.0000000000000417

46. Bora E, Özakbaş S, Velakoulis D, Walterfang M. Social cognition in multiple sclerosis: a meta-analysis. Neuropsychol Rev (2016b) 26(2):160-72. doi: 10.1007/s11065-016-9320-6

47. Bora E. Relationship between insight and theory of mind in schizophrenia: a meta-analysis. Schizophr Res (2017) 190:11-7. doi: 10.1016/j.schres. 2017.03.029

48. Bora E, Zorlu N. Social cognition in alcohol use disorder: a meta-analysis. Addiction (2017) 112(1):40-8. doi: 10.1111/add.13486

49. Eddy CM. Social cognition and self-other distinctions in neuropsychiatry: insights from schizophrenia and Tourette syndrome. Prog Neuropsychopharmacol Biol Psychiatry (2018) 82:69-85. doi: 10.1016/j.pnpbp.2017.11.026

50. Keech B, Crowe S, Hocking DR. Intranasal oxytocin, social cognition and neurodevelopmental disorders: a meta-analysis. Psychoneuroendocrinol (2018) 87:9-19. doi: 10.1016/j.psyneuen.2017.09.022

51. Wang Y, Metoki A, Alm KH, Olson IR. White matter pathways and social cognition. Neurosci Biobehav Rev (2018) 90:350-70. doi: 10.1016/j. neubiorev.2018.04.015

52. Fortier J, Besnard J, Allain P. Theory of mind, empathy and emotion perception in cortical and subcortical neurodegenerative diseases. Rev Neurol (Paris) (2018) 174(4):237-46. doi: 10.1016/j.neurol.2017.07.013

53. Rokita KI, Dauvermann MR, Donohoe G. Early life experiences and social cognition in major psychiatric disorders: a systematic review. Eur Psychiatry (2018) 53:123-33. doi: 10.1016/j.eurpsy.2018.06.006

54. Eddy CM, Cook JL. Emotions in action: the relationship between motor function and social cognition across multiple clinical populations. Prog Neuropsychopharmacol Biol Psychiatry (2018) 86:229-44. doi: 10.1016/j. pnpbp.2018.05.021

55. Ekman P, Friesen WV. Pictures of facial affect. Palo Alto: Consulting Psychologists (1976).

56. Baron-Cohen S, Wheelwright S, Hill J, Raste Y, Plumb I. The "Reading the Mind in the Eyes" Test revised version: a study with normal adults, and adults with Asperger syndrome or high-functioning autism. J Child Psychol Psychiatry (2001) 42:241-51. doi: 10.1017/S0021963001006643

57. Stone VE, Baron-Cohen S, Knight RT. Frontal lobe contributions to theory of mind. J Cogn Neurosci (1998) 10:640-56. doi: 10.1162/089892998562942

58. Davis MH. Measuring individual differences in empathy: evidence for a multidimensional approach. J Pers Soc Psychol (1983) 44(1):113-26. doi: 10.1037//0022-3514.44.1.113

59. Corcoran R, Mercer G, Frith CD. Schizophrenia, symptomatology and social inference: investigating "theory of mind" in people with schizophrenia. Schizophr Res (1995) 17(1):5-13. doi: 10.1016/0920-9964(95)00024-G

60. Happé FGE. An shamay: understanding of story characters' thoughts and feelings by able autistic, mentally handicapped and normal children and adults. J Autism Dev Disord (1994) 24:129-54. doi: 10.1007/BF02172093

61. Sarfati Y, Hardy-Bayle MC, Besche C, Widlocher D. Attribution of intentions to others in people with schizophrenia: a non-verbal exploration with comic strips. Schizophr Res (1997a) 25(3):199-209. doi: 10.1016/ S0920-9964(97)00025-X

62. Sarfati Y, Hardy-Baylé MC, Nadel J, Chevalier JF, Widlocher D. Attribution of mental states to others by schizophrenic patients. Cogn Neuropsychiatry (1997b) 2:1-17. doi: 10.1080/135468097396388

63. Wimmer H, Perner J. Beliefs about beliefs: representation and constraining function of wrong beliefs in young children's understanding of deception. Cognition (1983) 13:103-28. doi: 10.1016/0010-0277(83)90004-5

64. Baron-Cohen S, Leslie AM, Frith U. Does the autistic child have a "theory of mind"? Cognition (1985) 21(1):37-46. doi: 10.1016/0010-0277(85)90022-8

65. Baron-Cohen S. The autistic child's theory of mind: a case of specific developmental delay. J Child Psychol Psychiatry (1989) 30(2):285-97. doi: 10.1111/j.1469-7610.1989.tb00241.x

66. Abell F, Happé F, Frith U. Do triangles play tricks? Attribution of mental states to animated shapes in normal and abnormal development. Cogn Dev (2000) 15:1-16. doi: 10.1016/S0885-2014(00)00014-9
67. Shamay-Tsoory SG, Aharon-Peretz J. Dissociable prefrontal networks for cognitive and affective theory of mind: a lesion study. Neuropsychologia (2007) 45:3054-67. doi: 10.1016/j.neuropsychologia.2007.05.021

68. McDonald S, Flanagan S, Rollins J, Kinch J. TASIT: a new clinical tool for assessing social perception after traumatic brain injury. J Head Trauma Rehabil (2003) 18:219-38. doi: 10.1097/00001199-200305000-00001

69. Dziobek I, Fleck S, Kalbe E, Rogers K, Hassenstab J, Brand M, et al. Introducing MASC: a movie for the assessment of social cognition. J Autism Dev Disord (2006a) 36:623-36. doi: 10.1007/s10803-006-0107-0

70. Baron-Cohen S, Richler J, Bisarya D, Gurunathan N, Wheelwright S. The systemizing quotient: an investigation of adults with Asperger syndrome or high-functioning autism, and normal sex differences. Philos Trans $R$ Soc Lond B Biol Sci (2003) 358(1430):361-74. doi: 10.1098/rstb.2002.1206

71. Lane RD, Quinlan DM, Schwartz GE, Walker PA, Zeitlin SB. The Levels of Emotional Awareness Scale: a cognitive-developmental measure of emotion. J Pers Assess (1990) 55(1-2):124-34. doi: 10.1080/00223891.1990.9674052

72. Anderson IM, Shippen C, Juhasz G, Chase D, Thomas E, Downey D, et al. State-dependent alteration in face emotion recognition in depression. $\mathrm{Br} \mathrm{J}$ Psychiatry (2011) 198(4):302-8. doi: 10.1192/bjp.bp.110.078139

73. Langenecker SA, Bieliauskas LA, Rapport LJ, Zubieta JK, Wilde EA, Berent S. Face emotion perception and executive functioning deficits in depression. J Clin Exp Neuropsychol (2005) 27(3):320-33. doi: 10.1080/13803390490490515720

74. Surguladze SA, Young AW, Senior C, Brebon G, Travis MJ, Phillips ML. Recognition accuracy and response bias to happy and sad facial expressions in patients with major depression. Neuropsychology (2004) 18:212-8. doi: 10.1037/0894-4105.18.2.212

75. Hala S, Chandler M, Fritz AS. Fledgling theories of mind: deception as a marker of three-year-olds' understanding of false belief. Child Dev (1991) 62(1):83-97. doi: 10.1111/j.1467-8624.1991.tb01516.x

76. Frith CD, Corcoran R. Exploring 'theory of mind' in people with schizophrenia. Psychol Med (1996) 26(3):521-30. doi: 10.1017/ S0033291700035601

77. Langdon R, Coltheart M. Recognition of metaphor and irony in young adults: the impact of schizotypal personality traits. Psychiatry Res (2004) 125(1):9-20. doi: 10.1016/j.psychres.2003.10.005

78. Saxe R, Kanwisher N. People thinking about thinking people. The role of the temporo-parietal junction in "theory of mind". Neuroimage (2003) 19(4):1835-42. doi: 10.1016/S1053-8119(03)00230-1

79. Zaitchik D. When representations conflict with reality: the preschooler's problem with false beliefs and "false" photographs. Cognition (1990) 35(1):41-68. doi: 10.1016/0010-0277(90)90036-J

80. Shaw P, Lawrence EJ, Radbourne C. The impact of early and late damage to the human amygdala on 'Theory of Mind' reasoning. Brain (2004) 127:153548. doi: 10.1093/brain/awh168

81. Berthoz S, Armony JL, Blair RJ, Dolan RJ. An fMRI study of intentional and unintentional (embarrassing) violations of social norms. Brain (2002) 125(8):1696-708. doi: 10.1093/brain/awf190

82. Uekermann J, Channon S, Winkel K, Schlebusch P, Daum I. Theory of mind, humour processing and executive functioning in alcoholism. Addiction (2007) 102(2):232-40. doi: 10.1111/j.1360-0443.2006.01656.x

83. Watanabe T, Kuroda M, Kuwabara H, Aoki Y, Iwashiro N, Tatsunobu N, et al. Clinical and neural effects of six-week administration of oxytocin on core symptoms of autism. Brain (2015) 138(11):3400-12. doi: 10.1093/brain/ awv249

84. Costanzo M, Archer D. Interpreting the expressive behavior of others: the Interpersonal Perception Task. J Nonverbal Behav (1989) 13(4):225-45. doi: 10.1007/BF00990295

85. Corrigan PW, Buican B, Toomey R. Construct validity of two tests of social cognition in schizophrenia. Psychiatry Res (1996) 63(1):77-82. doi: 10.1016/0165-1781(96)02897-1

86. Sergi M, Green M, Widmark C, Reist C, Erhart S, Braff D, et al. Social cognition and neurocognition: effects of risperidone, olanzapine, and haloperidol. Am J Psychiatry (2007) 1164(10):1585-92. doi: 10.1176/appi. ajp.2007.06091515

87. Kerr SL, Neale JM. Emotion perception in schizophrenia: specific deficit or further evidence of generalized poor performance? J Abnorm Psychol (1993) 102(2):312-8. doi: 10.1037//0021-843X.102.2.312 
88. Bell M, Bryson G, Lysaker P. Positive and negative affect recognition in schizophrenia: a comparison with substance abuse and normal control subjects. Psychiatry Res (1997) 73(1-2):73-82. doi: 10.1016/S0165-1781(97)00111-X

89. Bellack AS, Blanchard JJ, Mueser KT. Cue availability and affect perception in schizophrenia. Schizophr Bull (1996) 22(3):535-44. doi: 10.1093/ schbul/22.3.535

90. Blonder LX, Bowers D, Heilman KM. The role of the right hemisphere in emotional communication. Brain (1991) 114(3):1115-27. doi: 10.1093/ brain/114.3.1115

91. Bowers D, Blonder L, Heilman K. The Florida affect battery. Gainesville, FL: University of Florida Brain Institute (1998).

92. Froming K, Levy M, Schaffer S, Ekman P. The comprehensive affect testing system. Psychology Software Inc. (2006). doi: 10.1037/t06823-000

93. Schneider D, Lam R, Bayliss AP, Dux PE. Cognitive load disrupts implicit theory-of-mind processing. Psychol Sci (2012a) 23(8):842-7. doi: $10.1177 / 0956797612439070$

94. Schneider D, Regenbogen C, Kellermann T, Finkelmeyer A, Kohn N, Derntl B, et al. Empathic behavioral and physiological responses to dynamic stimuli in depression. Psychiatry Res (2012b) 200(2-3):294-305. doi: 10.1016/j.psychres.2012.03.054

95. Mayer JD, Salovey P, Caruso DR, Sitarenios G. Measuring emotional intelligence with the MSCEIT V2.0. Emotion (2003) 3(1):97-105. doi: 10.1037/1528-3542.3.1.97

96. Heider F, Simmel M. An experimental study of apparent behaviour. Am J Psychol (1944) 57:243-59. doi: 10.2307/1416950

97. Langdon R, Coltheart M. Mentalising, schizotypy, and schizophrenia. Cognition (1999) 71:43-71. doi: 10.1016/S0010-0277(99)00018-9

98. Thompson A, Papas A, Bartholomeusz C, Allott K, Amminger GP, Nelson B, et al. Social cognition in clinical "at risk" for psychosis and first episode psychosis populations. Schizophr Res (2012) 141(2-3):204-9. doi: 10.1016/j. schres.2012.08.007

99. Snowden JS, Austin NA, Sembi S, Thompson JC, Craufurd D, Neary D. Emotion recognition in Huntington's disease and frontotemporal dementia. Neuropsychologia (2008) 46(11):2638-49. doi: 10.1016/j. neuropsychologia.2008.04.018

100. Eddy CM, Mitchell IJ, Beck SR, Cavanna AE, Rickards H. Social reasoning in Tourette syndrome. Cogn Neuropsychiatry (2011) 16(4):326-47. doi: 10.1080/13546805.2010.538213

101. Baron-Cohen S, Leslie AM, Frith U. Mechanical, behavioural and intentional understanding of picture stories in autistic children. Br J Dev Psychol (1986) 4(2):113-25. doi: 10.1111/j.2044-835X.1986.tb01003.x

102. Corcoran R, Cahill C, Frith CD. The appreciation of visual jokes in people with schizophrenia: a study of 'mentalizing' ability. Schizophr Res (1997) 24(3):319-27. doi: 10.1016/S0920-9964(96)00117-X

103. Rosenthal R, Hall JA, DiMatteo MR, Rogers PL, Archer D. Sensitivity to nonverbal communication: The PONS test. Baltimore, Maryland: The Johns Hopkins University Press (1979). doi: 10.1016/B978-0-12-761350-5.50012-4

104. Bertrand MC, Sutton H, Achim AM, Malla AK, Lepage M. Social cognitive impairments in first episode psychosis. Schizophr Res (2007) 95(1-3):12433. doi: $10.1016 /$ j.schres.2007.05.033

105. Nowicki S, Duke MP. Individual differences in the nonverbal communication of affect: the Diagnostic Analysis of Nonverbal Accuracy Scale. J Nonverbal Behav (1994) 18(1):9-35. doi: 10.1007/BF02169077

106. Derntl B, Seidel EM, Schneider F, Habel U. How specific are emotional deficits? A comparison of empathic abilities in schizophrenia, bipolar and depressed patients. Schizophr Res (2012) 142(1-3):58-64. doi: 10.1016/j. schres.2012.09.020

107. Seidel EM, Habel U, Finkelmeyer A, Schneider F, Gur RC, Derntl B. Implicit and explicit behavioral tendencies in male and female depression. Psychiatry Res (2010) 177(1-2):124-30. doi: 10.1016/j.psychres.2010.02.001

108. Fakra E, Salgado-Pineda P, Besnier N, Azorin JM, Blin O. Risperidone versus haloperidol for facial affect recognition in schizophrenia: findings from a randomised study. World J Biol Psychiatry (2009) 10:719-28. doi: $10.1080 / 15622970701432536$

109. Gur RC, Sara R, Hagendoorn M, Marom O, Hughett P, Macy L, et al. A method for obtaining 3-dimensional facial expressions and its standardization for use in neurocognitive studies. J Neurosci Methods (2002) 115(2):137-43. doi: 10.1016/S0165-0270(02)00006-7
110. Jehna M, Neuper C, Petrovic K, Wallner-Blazek M, Schmidt R, Fuchs S, et al. An exploratory study on emotion recognition in patients with a clinically isolated syndrome and multiple sclerosis. Clin Neurol Neurosurg (2010) 112(6):482-4. doi: 10.1016/j.clineuro.2010.03.020

111. Tottenham N, Tanaka JW, Leon AC, McCarry T, Nurse M, Hare TA, et al. The NimStim set of facial expressions: judgments from untrained research participants. Psychiatry Res (2009) 168(3):242-9. doi: 10.1016/j. psychres.2008.05.006

112. Lundqvist D, Flykt A, Öhman A. The Karolinska Directed Emotional Faces $(K D E F)$. Stockholm: Department of Neurosciences Karolinska Hospital (1998). doi: 10.1037/t27732-000

113. Jehna M, Langkammer C, Wallner-Blazek M, Neuper C, Loitfelder M, Ropele S, et al. Cognitively preserved MS patients demonstrate functional differences in processing neutral and emotional faces. Brain Imaging Behav (2011) 5(4):241-51. doi: 10.1007/s11682-011-9128-1

114. Dziobek I, Rogers K, Fleck S, Bahnemann M, Heekeren HR, Wolf OT, et al. Dissociation of cognitive and emotional empathy in adults with Asperger syndrome using the Multifaceted Empathy Test (MET). J Autism Dev Disord (2008) 38(3):464-73. doi: 10.1007/s10803-007-0486-x

115. Povinelli DJ, Nelson KE, Boysen ST. Inferences about guessing and knowing by chimpanzees (Pan troglodytes). J Comp Psychol (1990) 104(3):203-10. doi: $10.1037 / / 0735-7036.104 .3 .203$

116. Calder AJ, Lawrence AD, Keane J, Scott SK, Owen AM, Christoffels I, et al. Reading the mind from eye gaze. Neuropsychologia (2002) 40(8):1129-38. doi: 10.1016/S0028-3932(02)00008-8

117. Verdon CM, Fossati P, Verny M, Dieudonné B, Teillet L, Nadel J. Social cognition: an early impairment in dementia of the Alzheimer type. Alzheimer Dis Assoc Disord (2007) 21(1):25-30. doi: 10.1097/WAD.0b013e318032487a

118. Combs DR, Penn DL, Wicher M, Waldheter E. The Ambiguous Intentions Hostility Questionnaire (AIHQ): a new measure for evaluating hostile social-cognitive biases in paranoia. Cogn Neuropsychiatry (2007) 12(2):12843. doi: $10.1080 / 13546800600787854$

119. Leibetseder M, Laireiter A-R, Köller T. Structural analysis of the E-scale. Pers Indiv Diff (2007) 42:547-61. doi: 10.1016/j.paid.2006.08.002

120. Batson CD, O'Quin K, Fultz J, Vanderplas M, Isen AM. Influence of selfreported distress and empathy on egoistic versus altruistic motivation to help. J Pers Soc Psychol (1983) 453:706-18. doi: 10.1037//0022-3514.45.3.706

121. Mehrabian A, Epstein N. A measure of emotional empathy. J Pers (1972) 40:525-43. doi: 10.1111/j.1467-6494.1972.tb00078.x

122. Spreng RN, McKinnon MC, Mar RA, Levine B. The Toronto Empathy Questionnaire: scale development and initial validation of a factor-analytic solution to multiple empathy measures. J Pers Assess (2009) 91(1):62-71. doi: $10.1080 / 00223890802484381$

123. Schooler N, Hogarty G, Weissman MM. "Social adjustment scale II (SAS II)". In: Hargreaves WA, Attkisson CC, Sorenson JE, editors. Resource Materials for Community Mental Health Program Evaluators. DHEW Publication No. (ADM) 79-328. Superintendent of Documents, Government Printing Office, 1979 (1979).

124. Wykes T, Sturt E. The measurement of social behaviour in psychiatric patients: an assessment of the reliability and validity of the SBS schedule. $\mathrm{Br}$ J Psychiatry (1986) 148:1-11. doi: 10.1192/bjp.148.1.1

125. Munroe-Blum H, Collins E, McCleary L, Nuttall S. The social dysfunction index (SDI) for patients with schizophrenia and related disorders. Schizophr Res (1996) 20(1-2):211-9. doi: 10.1016/0920-9964(96)88527-6

126. Zigler E, Levine J. Premorbid competence in schizophrenia: what is being measured? J Consult Clin Psychol (1981) 49(1):96-105. doi: 10.1037//0022-006X.49.1.96

127. Bosco FM, Capozzi F, Colle L, Marostica P, Tirassa M. Theory of mind deficit in subjects with alcohol use disorder: an analysis of mindreading processes. Alcohol Alcohol (2014) 49(3):299-307. doi: 10.1093/alcalc/agt148

128. Reniers RL, Corcoran R, Drake R, Shryane NM, Völlm BA. The QCAE: a Questionnaire of Cognitive and Affective Empathy. J Pers Assess (2011) 93(1):84-95. doi: 10.1080/00223891.2010.528484

129. Olbert CM, Penn DL, Reise SP, Horan WP, Kern RS, Lee J, et al. Assessment of attachment in psychosis: a psychometric cause for concern. Psychiatry Res (2016) 246:77-83. doi: 10.1016/j.psychres.2016.09.020

130. Beeney JE, Stepp SD, Hallquist MN, Scott LN, Wright AG, Ellison WD, et al. Attachment and social cognition in borderline personality disorder: 
specificity in relation to antisocial and avoidant personality disorders. Pers Disord (2015) 6(3):207-15. doi: 10.1037/per0000110

131. D’Zurilla TJ, Nezu AM, Maydeu-Olivares T. Social Problem-Solving Inventory Revised (SPSI-R): Manual. North Tonawanda, New York: Multi-Health Systems (2002).

132. Donahoe CP, Carter MJ, Bloem WD, Hirsch GL, Laasi N, Wallace CJ. Assessment of interpersonal problem-solving skills. Psychiatry (1990) 53:329-39. doi: 10.1080/00332747.1990.11024517

133. Curran JP. "A procedure for the assessment of social skills: the simulated Social Interactions Test". In: Curran JP, Monti PM, editors. Social skills training: A practical handbook for assessment and treatment. Guilford Press (1982). p. 313-47.

134. Clements WA, Perner J. Implicit understanding of belief. Cogn Dev (1994) 9:377-95. doi: 10.1016/0885-2014(94)90012-4

135. Naughtin CK, Horne K, Schneider D, Venini D, York A, Dux PE. Do implicit and explicit belief processing share neural substrates? Hum Brain Mapp (2017) 38(9):4760-72. doi: 10.1002/hbm.23700

136. Schneider D, Slaughter VP, Becker SI, Dux PE. Implicit false-belief processing in the human brain. Neuroimage (2014) 101:268-75. doi: 10.1016/j.neuroimage.2014.07.014

137. Mehta UM, Thirthalli J, Naveen Kumar C, Mahadevaiah M, Rao K, Subbakrishna DK, et al. Validation of Social Cognition Rating Tools in Indian Setting (SOCRATIS): a new test-battery to assess social cognition. Asian J Psychiatr (2011) 4(3):203-9. doi: 10.1016/j.ajp.2011.05.014

138. Perner J, Rendl B, Garnham A. Objects of desire, thought and reality: problems of anchoring discourse referents in development. Mind Lang (2007) 22:475-513. doi: 10.1111/j.1468-0017.2007.00317.x

139. Wellman HM, Cross D, Watson J. Meta-analysis of theory-of-mind development: the truth about false belief. Child Dev (2001) 72:655-84. doi: 10.1111/1467-8624.00304

140. van Buijsen M, Hendriks A, Ketelaars M, Verhoeven L. Assessment of theory of mind in children with communication disorders: role of presentation mode. Res Dev Disabil (2011) 32(3):1038-45. doi: 10.1016/j.ridd.2011.01.036

141. Takenoshita S, Terada S, Yokota O, Kutoku Y, Wakutani Y, Nakashima M, et al. Sally-Anne test in patients with Alzheimer's Disease Dementia. J Alz Dis (2018) 61(3):1029-36.

142. Aoki Y, Yahata N, Watanabe T, Takano Y, Kawakubo Y, Kuwabara H, et al. Oxytocin improves behavioural and neural deficits in inferring others' social emotions in autism. Brain (2014) 137(11):3073-86. doi: 10.1093/brain/ awu231

143. Rajendran G, Mitchell P. Cognitive theories of Autism. Dev Review (2007) 27: $224-60$.

144. O’Hare AE, Bremner L, Nash M, Happé F, Pettigrew LM. A clinical assessment tool for advanced theory of mind performance in 5 to 12 year olds. J Autism Dev Disord (2009) 39(6):916-28. doi: 10.1007/s10803-009-0699-2

145. Johansson Nolaker E, Murray K, Happé F, Charlton RA. Cognitive and affective associations with an ecologically valid test of theory of mind across the lifespan. Neuropsychology (2018) 32(6):754-63. doi: 10.1037/neu0000464

146. Murray K, Johnston K, Cunnane H, Kerr C, Spain D, Gillan N, et al. A new test of advanced theory of mind: the "Strange Stories Film Task' captures social processing differences in adults with autism spectrum disorders. Autism Res (2017) 10(6):1120-32. doi: 10.1002/aur.1744

147. Perez-Zapata D, Slaughter V, Henry JD. Cultural effects on mindreading. Cognition (2016) 146:410-4. doi: 10.1016/j.cognition.2015.10.018

148. Mazzola V, Camaioni L. Strane Storie: Versione italiana a cura di Mazzola $e$ Camaioni. Roma: Dipartimento di Psicologia dinamica e clinica, UniversitaLa Sapienza (2002).

149. Kaland N, Callesen K, Møller-Nielsen A, Mortensen EL, Smith L. Performance of children and adolescents with Asperger syndrome or highfunctioning autism on advanced theory of mind tasks. J Autism Dev Disord (2008) 38(6):1112-23. doi: 10.1007/s10803-007-0496-8

150. Lahera G, Boada L, Pousa E, Mirapeix I, Morón-Nozaleda G, Marinas L, et al. Movie for the Assessment of Social Cognition (MASC): Spanish validation. J Autism Dev Disord (2014a) 44(8):1886-96. doi: 10.1007/s10803-014-2061-6

151. Lahera G, Herrera S, Fernández C, Bardón M, de los Ángeles V, FernándezLiria A. Familiarity and face emotion recognition in patients with schizophrenia. Compr Psychiatry (2014b) 55(1):199-205. doi: 10.1016/j. comppsych.2013.06.006
152. David N, Gawronski A, Santos NS, Huff W, Lehnhardt FG, Newen A, et al. Dissociation between key processes of social cognition in autism: impaired mentalizing but intact sense of agency. J Autism Dev Disord (2008) 38(4):593-605. doi: 10.1007/s10803-007-0425-x

153. Henderson HA, Zahka NE, Kojkowski NM, Inge AP, Schwartz CB, Hileman CM, et al. Self-referenced memory, social cognition, and symptom presentation in autism. J Child Psychol Psychiatry (2009) 50(7):853-61. doi: 10.1111/j.1469-7610.2008.02059.x

154. Roeyers H, Buysse A, Ponnet K, Pichal B. Advancing advanced mindreading tests: empathic accuracy in adults with a pervasive developmental disorder. J Child Psychol Psychiatry (2001) 42(2):271-8. doi: 10.1017/ S0021963001006680

155. McIntyre NS, Oswald TM, Solari EJ, Zajic MC, Lerro LE, Hughes C, et al. Social cognition and reading comprehension in children and adolescents with autism spectrum disorders or typical development. Res Autism Spectrum Disord (2018) 54:9-20. doi: 10.1016/j.rasd.2018.06.004

156. Rogers K, Dziobek I, Hassenstab J, Wolf OT, Convit A. Who cares? Revisiting empathy in Asperger syndrome. J Autism Dev Disord (2007) 37(4):709-15. doi: 10.1007/s10803-006-0197-8

157. Stewart E, Catroppa C, Gill D, Webster R, Lawson J, Mandalis A, et al. Theory of Mind and social competence in children and adolescents with genetic generalised epilepsy (GGE): relationships to epilepsy severity and antiepileptic drugs. Seizure (2018) 60:96-104. doi: 10.1016/j.seizure.2018.06.015

158. Lew AR, Lewis C, Lunn J, Tomlin P, Basu H, Roach J, et al. Social cognition in children with epilepsy in mainstream education. Dev Med Child Neurol (2015) 57(1):53-9. doi: 10.1111/dmcn.12613

159. Giorgi FS, Guida M, Caciagli L, Pagni C, Pizzanelli C, Bonanni E, et al. Social cognition in juvenile myoclonic epilepsy. Epilepsy Res (2016) 128:61-7. doi: 10.1016/j.eplepsyres.2016.10.017

160. Stewart E, Catroppa C, Lah S. Theory of Mind in patients with epilepsy: a systematic review and meta-analysis. Neuropsychol Rev (2016) 26(1):3-24. doi: 10.1007/s11065-015-9313-x

161. Bodnar A, Rybakowski JK. Mentalization deficit in bipolar patients during an acute depressive and manic episode: association with cognitive functions. Int J Bipolar Disord (2017) 5(1):38. doi: 10.1186/s40345-017-0107-3

162. Freed J, McBean K, Adams C, Lockton E, Nash M, Law J. Performance of children with social communication disorder on the Happé Strange Stories: physical and mental state responses and relationship to language ability. J Commun Disord (2015) 55:1-14. doi: 10.1016/j.jcomdis.2015.03.002

163. Hur JW, Byun MS, Shin NY, Shin YS, Kim SN, Jang JH, et al. General intellectual functioning as a buffer against theory-of-mind deficits in individuals at ultra-high risk for psychosis. Schizophr Res (2013) 149(1-3):83-7. doi: 10.1016/j.schres.2013.06.019

164. Stanford AD, Messinger J, Malaspina D, Corcoran CM. Theory of Mind in patients at clinical high risk for psychosis. Schizophr Res (2011) 131(1-3): 11-7. doi: 10.1016/j.schres.2011.06.005

165. Castelli I, Pini A, Alberoni M, Liverta-Sempio O, Baglio F, Massaro D, et al. Mapping levels of theory of mind in Alzheimer's disease: a preliminary study. Aging Ment Health (2011) 15(2):157-68. doi: 10.1080/ 13607863.2010.513038

166. Schuwerk T, Vuori M, Sodian B. Implicit and explicit Theory of Mind reasoning in autism spectrum disorders: the impact of experience. Autism (2015) 19(4):459-68. doi: 10.1177/1362361314526004

167. Górska D, Marszał M. [Mentalization and theory of mind in borderline personality organization: exploring the differences between affective and cognitive aspects of social cognition in emotional pathology]. Psychiatr Pol (2014) 48(3):503-13.

168. Umeda S, Mimura M, Kato M. Acquired personality traits of autism following damage to the medial prefrontal cortex. Soc Neurosci (2010) 5(1):19-29. doi: 10.1080/17470910902990584

169. Shamay-Tsoory SG, Aharon-Peretz J, Levkovitz Y. The neuroanatomical basis of affective mentalizing in schizophrenia: comparison of patient with schizophrenia and patients with localized prefrontal lesions. Schizophr Res (2007a) 90:274-83. doi: 10.1016/j.schres.2006.09.020

170. Shamay-Tsoory SG, Harari H, Aharon-Peretz J, Levkovitz Y. The role of the orbitofrontal cortex in affective theory of mind deficits in criminal offenders with psychopathic tendencies. Cortex (2010) 46:668-77. doi: 10.1016/j. cortex.2009.04.008 
171. Shamay-Tsoory SG, Tibi-Elhanany Y, Aharon-Peretz J. The green-eyed monster and malicious joy: the neuroanatomical bases on envy and gloating (schadenfreude). Brain (2007b) 130:1663-78. doi: 10.1093/brain/awm093

172. Bodden ME, Mollenhauer B, Trenkwalder C, Cabanel N, Eggert KM, Unger MM, et al. Affective and cognitive theory of mind in patients with Parkinson's disease. Parkinsonism Relat Disord (2010) 16(7):466-70. doi: 10.1016/j.parkreldis.2010.04.014

173. Rossetto F, Castelli I, Baglio F, Massaro D, Alberoni M, Nemni R, et al. Cognitive and affective theory of mind in mild cognitive impairment and Parkinson's disease: preliminary evidence from the Italian version of the Yoni Task. Dev Neuropsychol (2018) 43(8):764-80. doi: 10.1080/87565641.2018.1529175

174. Wang YG, Wang YQ, Chen SL, Zhu CY, Wang K. Theory of mind disability in major depression with or without psychotic symptoms: a componential view. Psychiatry Res (2008) 161(2):153-61. doi: 10.1016/j.psychres.2007.07.018

175. Li D, Li X, Yu F, Chen X, Zhang L, Li D, et al. Comparing the ability of cognitive and affective Theory of Mind in adolescent onset schizophrenia. Neuropsychiatr Dis Treat (2017) 13:937-45. doi: 10.2147/NDT.S128116

176. Ho KK, Lui SS, Hung KS, Wang Y, Li Z, Cheung EF, et al. Theory of mind impairments in patients with first-episode schizophrenia and their unaffected siblings. Schizophr Res (2015) 166(1-3):1-8. doi: 10.1016/j. schres.2015.05.033

177. Liu W, Fan J, Gan J, Lei H, Niu C, Chan RCK, et al. Disassociation of cognitive and affective aspects of theory of mind in obsessive-compulsive disorder. Psychiatry Res (2017) 255:367-72. doi: 10.1016/j.psychres.2017.06.058

178. Hu Y, Jiang Y, Hu P, Ma H, Wang K. Impaired social cognition in patients with interictal epileptiform discharges in the frontal lobe. Epilepsy Behav (2016) 57(A):46-54. doi: 10.1016/j.yebeh.2016.01.027

179. Adjeroud N, Besnard J, El Massioui N, Verny C, Prudean A, Scherer C, et al. Theory of mind and empathy in preclinical and clinical Huntington's disease. Soc Cogn Affect Neurosci (2016) 11(1):89-99. doi: 10.1093/scan/nsv093

180. White SJ, Coniston D, Rogers R, Frith U. Developing the Frith-Happé animations: a quick and objective test of theory of mind for adults with autism. Autism Res (2011) 4:149-54. doi: 10.1002/aur.174

181. Castelli F, Frith C, Happe F, Frith U. Autism, Asperger syndrome andbrain mechanisms for the attribution of mental states to animated shapes. Brain (2002) 125:1839-1849.

182. Eddy CM, Cavanna AE. Triangles, tricks and tics: hyper-mentalizing in response to animated shapes in Tourette syndrome. Cortex (2015) 71:68-75. doi: 10.1016/j.cortex.2015.06.003

183. Eddy CM, Rickards HE. Theory of mind can be impaired prior to motor onset in Huntington's disease. Neuropsychology (2015a) 29(5):792-8. doi: $10.1037 /$ neu0000190

184. Eddy CM, Rickards HE. Interaction without intent: the shape of the social world in Huntington's disease. Soc Cogn Affect Neurosci (2015b) 10(9):122835. doi: $10.1093 /$ scan/nsv012

185. Subic-Wrana C, Beutel ME, Knebel A, Lane RD. Theory of mind and emotional awareness deficits in patients with somatoform disorders. Psychosom Med (2010) 72(4):404-11. doi: 10.1097/PSY.0b013e3181d35e83

186. Lugnegård T, Unenge Hallerbäck M, Hjärthag F, Gillberg C. Social cognition impairments in Asperger syndrome and schizophrenia. Schizophr Res (2013) 143(2-3):277-84. doi: 10.1016/j.schres.2012.12.001

187. Horan WP, Nuechterlein KH, Wynn JK, Lee J, Castelli F, Green MF. Disturbances in the spontaneous attribution of social meaning in schizophrenia. Psychol Med (2009) 39(4):635-43. doi: 10.1017/ S0033291708003838

188. BrunetE, Sarfati Y, Hardy-Baylé MC, Decety J. Abnormalities of brain function during a nonverbal theory of mind task in schizophrenia. Neuropsychologia (2003) 41(12):1574-82. doi: 10.1016/S0028-3932(03)00119-2

189. Vistoli D, Brunet-Gouet E, Lemoalle A, Hardy-Baylé MC, Passerieux C. Abnormal temporal and parietal magnetic activations during the early stages of theory of mind in schizophrenic patients. Soc Neurosci (2011) 6(3):31626. doi: 10.1080/17470919.2010.530870

190. Vistoli D, Passerieux C, El Zein M, Clumeck C, Braun S, Brunet-Gouet E. Characterizing an ERP correlate of intentions understanding using a sequential comic strips paradigm. Soc Neurosci (2015) 10(4):391-407. doi: 10.1080/17470919.2014.1003272

191. Völlm BA, Taylor AN, Richardson P, Corcoran R, Stirling J, McKie S, et al. Neuronal correlates of theory of mind and empathy: a functional magnetic resonance imaging study in a nonverbal task. Neuroimage (2006) 29(1):90-8. doi: 10.1016/j.neuroimage.2005.07.022

192. Sarfati Y, Hardy-Baylé MC, Brunet E, Widlocher D. Investigating theory of mind in schizophrenia: influence of verbalization in disorganized and non-disorganized patients. Schizophr Res (1999) 37:183-90. doi: 10.1016/ S0920-9964(98)00154-6

193. Young A, Perrett D, Calder A, Sprengelmeyer R, Ekman P. Facial expressions of emotion stimuli and tests (FEEST). Bury St Edmunds, England: Thames Valley Test Company (2002).

194. Montagne B, Kessels RP, De Haan EH, Perrett DI. The Emotion Recognition Task: a paradigm to measure the perception of facial emotional expressions at different intensities. Percept Mot Skills (2002) 104(2):589-98. doi: 10.2466/ pms.104.2.589-598

195. Aho-Özhan HE, Keller J, Heimrath J, Uttner I, Kassubek J, Birbaumer N, et al. Perception of emotional facial expressions in amyotrophic lateral sclerosis (ALS) at behavioural and brain metabolic level. PLoS One (2016) 11(10):e0164655. doi: 10.1371/journal.pone.0164655

196. Kumfor F, Irish M, Hodges JR, Piguet O. Discrete neural correlates for the recognition of negative emotions: insights from frontotemporal dementia. PLoS One (2013) 8(6):e67457. doi: 10.1371/journal.pone.0067457

197. Vázquez-Campo M, Maroño Y, Lahera G, Mateos R, García-Caballero A. e-Motional Training ${ }^{\circledR}$ : pilot study on a novel online training program on social cognition for patients with schizophrenia. Schizophr Res Cogn (2016) 4:10-7. doi: 10.1016/j.scog.2015.11.007

198. Moritz S, Woznica A, Andreou C, Köther U. Response confidence for emotion perception in schizophrenia using a Continuous Facial Sequence Task. Psychiatry Res (2012) 200(2-3):202-7. doi: 10.1016/j.psychres.2012. 07.007

199. Tsoi DT, Lee KH, Khokhar WA, Mir NU, Swalli JS, Gee KA, et al. Is facial emotion recognition impairment in schizophrenia identical for different emotions? A signal detection analysis. Schizophr Res (2008) 99(1-3):263-9. doi: 10.1016/j.schres.2007.11.006

200. Falkenberg I, Bartels M, Wild B. Keep smiling! Facial reactions to emotional stimuli and their relationship to emotional contagion in patients with schizophrenia. Eur Arch Psychiatry Clin Neurosci (2008) 258(4):245-53. doi: 10.1007/s00406-007-0792-5

201. Purcell DG, Stewart AL, Skov RB. It takes a confounded face to pop out of a crowd. Perception (1996) 25(9):1091-1108.

202. Komlósi S, Csukly G, Stefanics G, Czigler I, Bitter I, Czobor P. Fearful face recognition in schizophrenia: an electrophysiological study. Schizophr Res (2013) 149(1-3):135-40. doi: 10.1016/j.schres.2013.06.044

203. Realmuto S, Dodich A, Meli R, Canessa N, Ragonese P, Salemi G, et al. Moral cognition and multiple sclerosis: a neuropsychological study. Arch Clin Neuropsychol (2018) 34(3):319-26. doi: 10.1093/arclin/acy047

204. Gossink F, Schouws S, Krudop W, Scheltens P, Stek M, Pijenburg Y, et al. Social Cognition Differentiates Behavioral Variant Frontotemporal Dementia From Other Neurodegenerative Diseases and Psychiatric Disorders. J Geriatric Psychiatry (2018) 26(5):569-79.

205. Cerami C, Dodich A, Iannaccone S, Marcone A, Lettieri G, Crespi C, et al. Right limbic FDG-PET hypometabolism correlates with emotion recognition and attribution in probable behavioral variant of frontotemporal dementia patients. PLoS One (2015) 10(10):e0141672. doi: 10.1371/journal. pone. 0141672

206. Savage SA, Lillo P, Kumfor F, Kiernan MC, Piguet O, Hodges JR. Emotion processing deficits distinguish pure amyotrophic lateral sclerosis from frontotemporal dementia. Amyotroph Lateral Scler Frontotemporal Degener (2014) 15(1-2):39-46. doi: 10.3109/21678421.2013.809763

207. Carra G, Nicolini G, Lax A, Bartoli F, Castellano F, Chiorazzi A, et al. Facial emotion recognition in schizophrenia: An exploratory study on the role of comorbid alcohol and substance use disorders and COMT Val158Met. Hum Psychopharmacol Clin Exp (2017) 32(6):e2630.

208. Gultekin G, Yuksek E, Tevfik K, Alper B, Tuba Ocek B, Alaattin D. Differential effects of clozapine and risperidone on facial emotion. Psychiatry Clin Psychopharm (2017) 27(1):19-23. doi: 10.1080/24750573.2017.1293242

209. Rowland JE, Hamilton MK, Vella N, Lino BJ, Mitchell PB, Green MJ. Adaptive associations between social cognition and emotion regulation are absent in schizophrenia and bipolar disorder. Front Psychol (2013) 3:607. doi: 10.3389/fpsyg.2012.00607 
210. Balogh N, Egerházi A, Berecz R, Csukly G. Investigating the state-like and trait-like characters of social cognition in schizophrenia: a short term follow-up study. Schizophr Res (2014) 159(2-3):499-505. doi: 10.1016/j. schres.2014.08.027

211. Stanfield AC, Philip RCM, Whalley H, Romaniuk L, Hall J, Johnstone EC, et al. Dissociation of brain activation in autism and schizotypal personality disorder during social judgments. Schizophr Bull (2017) 43(6):1220-8. doi: $10.1093 / \mathrm{schbul} / \mathrm{sbx} 083$

212. Robinson L, Spencer MD, Thomson LD, Stanfield AC, Owens DG, Hall J, et al. Evaluation of a screening instrument for autism spectrum disorders in prisoners. PLoS One (2012) 7(5):e36078. doi: 10.1371/journal.pone. 0036078

213. Crespi C, Cerami C, Dodich A, Canessa N, Arpone M, Iannaccone S, et al. Microstructural white matter correlates of emotion recognition impairment in amyotrophic lateral sclerosis. Cortex (2014) 53:1-8. doi: 10.1016/j. cortex.2014.01.002

214. Realmuto S, Zummo L, Cerami C, Agrò L, Dodich A, Canessa N, et al. Social cognition dysfunctions in patients with epilepsy: evidence from patients with temporal lobe and idiopathic generalized epilepsies. Epilepsy Behav (2015) 47:98-103. doi: 10.1016/j.yebeh.2015.04.048

215. Wendling AS, Steinhoff BJ, Bodin F, Staack AM, Zentner J, Scholly J, et al. Selective amygdalohippocampectomy versus standard temporal lobectomy in patients with mesiotemporal lobe epilepsy and unilateral hippocampal sclerosis: post-operative facial emotion recognition abilities. Epilepsy Res (2015) 111:26-32. doi: 10.1016/j.eplepsyres.2015.01.002

216. Amlerova J, Cavanna AE, Bradac O, Javurkova A, Raudenska J, Marusic P. Emotion recognition and social cognition in temporal lobe epilepsy and the effect of epilepsy surgery. Epilepsy Behav (2014) 36:86-9. doi: 10.1016/j. yebeh.2014.05.001

217. Campanella F, Shallice T, Ius T, Fabbro F, Skrap M. Impact of brain tumour location on emotion and personality: a voxel-based lesion-symptom mapping study on mentalization processes. Brain (2014) 137(9):2532-45. doi: 10.1093/brain/awu183

218. Lawrence AD, Goerendt IK, Brooks DJ. Impaired recognition of facial expressions of anger in Parkinson's disease patients acutely withdrawn from dopamine replacement therapy. Neuropsychologia (2007) 45(1):65-74. doi: 10.1016/j.neuropsychologia.2006.04.016

219. Whittington J, Holland T. Recognition of emotion in facial expression by people with Prader-Willi syndrome. J Intellect Disabil Res (2011) 55(1):7584. doi: $10.1111 / j .1365-2788.2010 .01348 . x$

220. Šprah L, Novak T. Neurocognitive assessment of alcohol inpatients during recovery from alcoholism. Slov Med J (2008) 77(SII).

221. Soeiro-de-Souza MG, Bio DS, David DP, Rodrigues dos Santos D, Jr., Kerr DS, Gattaz WF, et al. COMT Met (158) modulates facial emotion recognition in bipolar I disorder mood episodes. J Affect Disord (2012) 136(3):370-6. doi: 10.1016/j.jad.2011.11.021

222. Robinson LJ, Gray JM, Burt M, Ferrier IN, Gallagher P. Processing of facial emotion in bipolar depression and euthymia. J Int Neuropsychol Soc (2015) 21(9):709-21. doi: 10.1017/S1355617715000909

223. McDonald S, Bornhofen C, Shum D, Long E, Saunders C, Neulinger K. Reliability and validity of The Awareness of Social Inference Test (TASIT): a clinical test of social perception. Disabil Rehabil (2006) 28(24):1529-42. doi: 10.1080/09638280600646185

224. Flanagan S, McDonald S, Rollins J. The awareness of social inference test revised: Manual. Sydney: Pearson Education Ltd. (2002).

225. McDonald S, Flanagan S, Rollins J. The Awareness of Social Inference TestRevised (TASIT-R). Sydney: Pearson Education Ltd. (2011).

226. Pinkham AE, Harvey PD, Penn DL. Social cognition psychometric evaluation: results of the final validation study. Schizophr Bull (2018) 44(4):737-48. doi: 10.1093/schbul/sbx117

227. Woolley JD, Arcuni PA, Stauffer CS, Fulford D, Carson DS, Batki S, et al. The effects of intranasal oxytocin in opioid-dependent individuals and healthy control subjects: a pilot study. Psychopharmacology (Berl) (2016) 233(13):2571-80. doi: 10.1007/s00213-016-4308-8

228. McDonald S, Dalton KI, Rushby JA, Landin-Romero R. Loss of white matter connections after severe traumatic brain injury (TBI) and its relationship to social cognition. Brain Imaging Behav (2018a) 13(3):819-29. doi: 10.1007/ s11682-018-9906-0
229. McDonaldS, RushbyJA, Dalton KI, Allen SK, Parks N. The role of abnormalities in the corpus callosum in social cognition deficits after traumatic brain injury. Soc Neurosci (2018c) 13(4):471-9. doi: 10.1080/17470919.2017.1356370

230. Honan CA, McDonald S, Sufani C, Hine DW, Kumfor F. The awareness of social inference test: development of a shortened version for use in adults with acquired brain injury. Clin Neuropsychol (2016) 30(2):243-64. doi: 10.1080/13854046.2015.1136691

231. Martinez G, Alexandre C, Mam-Lam-Fook C, Bendjemaa N, Gaillard R, Garel P, et al. Corrigendum to "Phenotype continuum between autism and schizophrenia: evidence from the Movie for the Assessment of the social cognition (MASC)". Schizophr Res (2018a) 193:489. doi: 10.1016/j. schres.2017.12.013

232. Martinez M, Multani N, Anor CJ, Misquitta K, Tang-Wai DF, Keren R, et al. Emotion detection deficits and decreased empathy in patients with Alzheimer's disease and Parkinson's disease affect caregiver mood and burden. Front Aging Neurosci (2018b) 10:120. doi: 10.3389/fnagi.2018.00120

233. Kumfor F, Honan C, McDonald S, Hazelton JL, Hodges JR, Piguet O. Assessing the "social brain" in dementia: Applying TASIT-S. Cortex (2017) 93:166-77. doi: 10.1016/j.cortex.2017.05.022

234. Kipps CM, Nestor PJ, Acosta-Cabronero J, Arnold R, Hodges JR. Understanding social dysfunction in the behavioural variant of frontotemporal dementia: the role of emotion and sarcasm processing. Brain (2009) 132(3):592-603. doi: 10.1093/brain/awn314

235. Rankin KP, Salazar A, Gorno-Tempini ML, Sollberger M, Wilson SM, Pavlic D, et al. Detecting sarcasm from paralinguistic cues: anatomic and cognitive correlates in neurodegenerative disease. Neuroimage (2009) 47(4):2005-15. doi: 10.1016/j.neuroimage.2009.05.077

236. Bratton H, O'Rourke S, Tansey L, Hutton P. Social cognition and paranoia in forensic inpatients with schizophrenia: a cross-sectional study. Schizophr Res (2017) 184:96-102. doi: 10.1016/j.schres.2016.12.004

237. Rocca P, Galderisi S, Rossi A, Bertolino A, Rucci P, Gibertoni D, et al. Disorganization and real-world functioning in schizophrenia: results from the multicenter study of the Italian Network for Research on Psychoses. Schizophr Res (2016) 201:105-12. doi: 10.1016/j.schres.2018.06.003

238. Sparks A, McDonald S, Lino B, O'Donnell M, Green MJ. Social cognition, empathy and functional outcome in schizophrenia. Schizophr Res (2010) 122(1-3):172-8. doi: 10.1016/j.schres.2010.06.011

239. Bliksted V, Videbech P, Fagerlund B, Frith C. The effect of positive symptoms on social cognition in first-episode schizophrenia is modified by the presence of negative symptoms. Neuropsychology (2017) 31(2):209-19. doi: 10.1037/ neu0000309

240. Ludlow AK, Garrood A, Lawrence K, Gutierrez R. Emotion recognition from dynamic emotional displays in children with ADHD. J Soc Clin Psychol (2014) 33(5):413-27. doi: 10.1521/jscp.2014.33.5.413

241. Ladegaard N, Larsen ER, Videbech P, Lysaker PH. Higher-order social cognition in first-episode major depression. Psychiatry Res (2014) 216(1):3743. doi: 10.1016/j.psychres.2013.12.010

242. Mathersul D, McDonald S, Rushby JA. Understanding advanced theory of mind and empathy in high-functioning adults with autism spectrum disorder. J Clin Exp Neuropsychol (2013) 35(6):655-68. doi: 10.1080/13803395.2013.809700

243. Philpott AL, Andrews SC, Staios M, Churchyard A, Fisher F. Emotion Evaluation and Social Inference Impairments in Huntington's Disease. J Huntington's Dis (2016) 5(2):175-83.

244. McDonald S, Fisher A, Flanagan S. When diplomacy fails: difficulty understanding hints following severe traumatic brain injury. Aphasiology (2016) 30(7):801-14. doi: 10.1080/02687038.2015.1070948

245. Genova HM, Cagna CJ, Chiaravalloti ND, DeLuca J, Lengenfelder J. Dynamic assessment of social cognition in individuals with multiple sclerosis: a pilot study. J Int Neuropsychol Soc (2016) 22(1):83-8. doi: 10.1017/ S1355617715001137

246. Pride NA, Korgaonkar MS, Barton B, Payne JM, Vucic S, North KN. The genetic and neuroanatomical basis of social dysfunction: lessons from neurofibromatosis type 1. Hum Brain Mapp (2014) 35(5):2372-82. doi: $10.1002 / \mathrm{hbm} .22334$

247. Symington SH, Paul LK, Symington MF, Ono M, Brown WS. Social cognition in individuals with agenesis of the corpus callosum. Soc Neurosci (2010) 5(3):296-308. doi: 10.1080/17470910903462419 
248. Vik PW, Williams C, Dasher N, Van Wyk P. Alcohol use, drinking consequences, and sensitivity to social cues among college women. Addict Behav (2014) 39(6):1106-12. doi: 10.1016/j.addbeh.2014.03.011

249. McDonald S, Darke S, Kaye S, Torok M. Deficits in social perception in opioid maintenance patients, abstinent opioid users and non-opioid users. Addiction (2013a) 108(3):566-74. doi: 10.1111/add.12040

250. Fossati A, Borroni S, Dziobek I, Fonagy P, Somma A. Thinking about assessment: further evidence of the validity of the movie for the assessment of social cognition as a measure of mentalistic abilities. Psychoanalytic Psychol (2018) 35(1):127-41. doi: 10.1037/pap0000130

251. Isernia S, Baglio F, d'Arma A, Groppo E, Marchetti A, Massaro D. Social mind and long-lasting disease: focus on affective and cognitive theory of mind in multiple sclerosis. Front Psychol (2019) 10:218. doi: 10.3389/ fpsyg.2019.00218

252. Wingenfeld K, Kuehl LK, Dziobek I, Roepke S, Otte C, Hinkelmann K. Effects of mineralocorticoid receptor blockade on empathy in patients with major depressive disorder. Cogn Affect Behav Neurosci (2016) 16(5):902-10. doi: 10.3758/s13415-016-0441-4

253. Wingenfeld K, Kuehl LK, Janke K, Hinkelmann K, Dziobek I, Fleischer J, et al. Enhanced emotional empathy after mineralocorticoid receptor stimulation in women with borderline personality disorder and healthy women. Neuropsychopharmacology (2014) 39(8):1799-804. doi: 10.1038/ npp.2014.36

254. Vaskinn A, Andersson S, Østefjells T, Andreassen OA, Sundet K. Emotion perception, non-social cognition and symptoms as predictors of theory of mind in schizophrenia. Compr Psychiatry (2018) 85:1-7. doi: 10.1016/j. comppsych.2018.05.002

255. Fretland RA, Andersson S, Sundet K, Andreassen OA, Melle I, Vaskinn A. Theory of mind in schizophrenia: error types and associations with symptoms. Schizophr Res (2015) 162:42-6. doi: 10.1016/j.schres.2015.01.024

256. Montag C, Brockmann EM, Lehmann A, Müller DJ, Rujescu D, Gallinat J. Association between oxytocin receptor gene polymorphisms and self-rated "empathic concern" in schizophrenia. PLoS One (2012a) 7(12):e51882. doi: 10.1371/journal.pone.0051882

257. Montag C, Neuhaus K, Lehmann A, Krüger K, Dziobek I, Heekeren HR, et al. Subtle deficits of cognitive theory of mind in unaffected first-degree relatives of schizophrenia patients. Eur Arch Psychiatry Clin Neurosci (2012b) 262(3):217-26. doi: 10.1007/s00406-011-0250-2

258. Wolkenstein L, Schönenberg M, Schirm E, Hautzinger M. I can see what you feel, but I can't deal with it: impaired theory of mind in depression. J Affect Disord (2011) 132(1-2):104-11. doi: 10.1016/j.jad.2011.02.010

259. Dziobek I, Fleck S, Rogers K, Wolf OT, Convit A. The 'amygdala theory of autism' revisited: linking structure to behavior. Neuropsychologia (2006b) 44:1891-9. doi: 10.1016/j.neuropsychologia.2006.02.005

260. Müller N, Baumeister S, Dziobek I, Banaschewski T, Poustka L. Validation of the movie for the assessment of social cognition in adolescents with ASD: fixation duration and pupil dilation as predictors of performance. J Autism Dev Disord (2016) 46(9):2831-44. doi: 10.1007/s10803-016-2828-z

261. Oakley BFM, Brewer R, Bird G, Catmur C. Theory of mind is not theory of emotion: a cautionary note on the Reading the Mind in the Eyes Test. J Abnorm Psychol (2016) 125(6):818-23. doi: 10.1037/abn0000182

262. Lenton-Brym AP, Moscovitch DA, Vidovic V, Nilsen E, Friedman O. Theory of mind ability in high socially anxious individuals. Anxiety Stress Coping (2018) 31(5):487-99. doi: 10.1080/10615806.2018.1483021

263. Sharp C, Pane H, Ha C, Venta A, Patel AB, Sturek J, et al. Theory of mind and emotion regulation difficulties in adolescents with borderline traits. J Am Acad Child Adolesc Psychiatry (2011) 50(6):563-73.e1. doi: 10.1016/j. jaac.2011.01.017

264. Preißler S, Dziobek I, Ritter K, Heekeren HR, Roepke S. Social cognition in borderline personality disorder: evidence for disturbed recognition of the emotions, thoughts, and intentions of others. Front Behav Neurosci (2010) 4:182. doi: 10.3389/fnbeh.2010.00182

265. Santos JM, Pousa E, Soto E, Comes A, Roura P, Arrufat FX, et al. Theory of mind in euthymic bipolar patients and first-degree relatives. J Nerv Ment Dis (2017) 205(3):207-12. doi: 10.1097/NMD.0000000000000595

266. Montag C, Ehrlich A, Neuhaus K, Dziobek I, Heekeren HR, Heinz A, et al. Theory of mind impairments in euthymic bipolar patients. J Affect Disord (2010) 123(1-3):264-9. doi: 10.1016/j.jad.2009.08.017
267. Brockmeyer T, Pellegrino J, Münch H, Herzog W, Dziobek I, Friederich HC. Social cognition in anorexia nervosa: specific difficulties in decoding emotional but not nonemotional mental states. Int J Eat Disord (2016) 49(9):883-990. doi: 10.1002/eat.22574

268. Maurage P, D'Hondt F, de Timary P, Mary C, Franck N, Peyroux E. Dissociating affective and cognitive theory of mind in recently detoxified alcohol-dependent individuals. Alcohol Clin Exp Res (2016) 40(9):1926-34. doi: $10.1111 /$ acer. 13155

269. Preller KH, Hulka LM, Vonmoos M, Jenni D, Baumgartner MR, Seifritz E, et al. Impaired emotional empathy and related social network deficits in cocaine users. Addict Biol (2014) 19(3):452-66. doi: 10.1111/adb.12070

270. Feyerabend J, Lüttke S, Grosse-Wentrup F, Wolter S, Hautzinger M, Wolkenstein L. Theory of mind in remitted bipolar disorder: younger patients struggle in tasks of higher ecological validity. J Affect Disord (2018) 231:32-40. doi: 10.1016/j.jad.2018.01.026

271. Buhlmann U, Wacker R, Dziobek I. Inferring other people's states of mind: comparison across social anxiety, body dysmorphic, and obsessivecompulsive disorders. J Anxiety Disord (2015) 34:107-13. doi: 10.1016/j. janxdis.2015.06.003

272. Ritter K, Dziobek I, $\beta$ ssler S, Rüter A, Vater A, Fydrich T, et al. Lack of empathy in patients with narcissistic personality disorder. Psychiatry Res (2011) 187(1-2):241-7. doi: 10.1016/j.psychres.2010.09.013

273. Wilbertz G, Brakemeier EL, Zobel I, Härter M, Schramm E. Exploring preoperational features in chronic depression. J Affect Disord (2010) 124(3):262-9. doi: 10.1016/j.jad.2009.11.021

274. Pinkham AE, Penn DL, Green MF, Harvey PD. Social cognition psychometric evaluation: results of the initial psychometric study. Schizophr Bull (2016) 42(2):494-504. doi: 10.1093/schbul/sbv056

275. Davidson CA, Lesser R, Parente LT, Fiszdon JM. Psychometrics of social cognitive measures for psychosis treatment research. Schizophr Res (2018) 193:51-7. doi: 10.1016/j.schres.2017.06.018

276. Greig TC, Byrson GJ, Bell MD. Theory of mind performance in schizophrenia: diagnostic, symptom, and neuropsychological correlates. J Nerv Ment Dis (2004) 192:12-8. doi: 10.1097/01.nmd.0000105995.67947.fc

277. Janssen I, Krabbendam L, Jolles J, van Os J. Alterations in theory of mind in patients with schizophrenia and non-psychotic relatives. Acta Psychiatr Scand (2003) 108:110-7. doi: 10.1034/j.1600-0447.2003.00092.x

278. Sanvicente-Vieira B, Brietzke E, Grassi-Oliveira R. Translation and adaptation of Theory of Mind tasks into Brazilian Portuguese. Trends Psychiatry Psychother (2012) 34:178-85. doi: 10.1590/S2237-60892012000400003

279. Gil D, Fernández-Modamio M, Bengochea R, Arrieta M. Adaptation of the hinting task theory of the mind test to Spanish. Rev Psiquiatr Salud Ment (2012) 5:79-88. doi: 10.1016/j.rpsmen.2011.11.002

280. Hur DH, Park JH, Kwon SM, Kim YT, Kwon DH, Cho SN, et al. An investigation into theory of mind of schizophrenia using hinting task and eyes task. J Korean Biol Ther Psychiatry (2006) 12:215-23.

281. Marjoram D, Gardner C, Burns J, Miller P, Lawrie SM, Johnstone EC. Symptomatology and social inference: a theory of mind study of schizophrenia and psychotic affective disorder. Cogn Neuropsychiatry (2005a) 10:347-59. doi: 10.1080/13546800444000092

282. Marjoram D, Tansley H, Miller P, MacIntyre D, Owens DG, Johnstone EC, et al. A theory of mind investigation into the appreciation of visual jokes in schizophrenia. BMC Psychiatry (2005b) 5:12. doi: 10.1186/1471-244X-5-12

283. Lahera G, Benito A, Montes JM, Fernández-Liria A, Olbert CM, Penn DL. Social cognition and interaction training (SCIT) for outpatients with bipolar disorder. J Affect Disord (2013) 146(1):132-6. doi: 10.1016/j.jad.2012.06.032

284. Mizrahi R, Korostil M, Starkstein SE, Zipursky RB, Kapur S. The effect of antipsychotic treatment on Theory of Mind. Psychol Med (2007) 37(4):595601. doi: $10.1017 /$ S0033291706009342

285. Gil-Sanz D, Fernández-Modamio M, Bengochea-Seco R, Arrieta-Rodríguez M, Pérez-Fuentes G. Efficacy of the social cognition training program in a sample of outpatients with schizophrenia. Clin Schizophr Relat Psychoses (2016) 10(3):154-62.

286. Montreuil T, Bodnar M, Bertrand M-C, Malla AK, Joober R, Lepage M. Social cognitive markers of short-term clinical outcome in first-episode psychosis. Clin Schizophr Relat Disord (2010) 4(2):105-14.

287. Kanie A, Hagiya K, Ashida S, Pu S, Kaneko K, Mogami T, et al. New instrument for measuring multiple domains of social cognition: construct 
validity of the Social Cognition Screening Questionnaire (Japanese version). Psychiatry Clin Neurosci (2014) 68(9):701-11. doi: 10.1111/pcn.12181

288. Hagiya K, Sumiyoshi T, Kanie A, Pu S, Kaneko K, Mogami T, et al. Facial expression perception correlates with verbal working memory function in schizophrenia. Psychiatry Clin Neurosci (2015) 69(12):773-81. doi: 10.1111/ pcn. 12329

289. Popolo R, Dimaggio G, Luther L, Vinci G, Salvatore G, Lysaker PH. Theory of mind in schizophrenia: associations with clinical and cognitive insight controlling for levels of psychopathology. J Nerv Ment Dis (2016) 204(3):240-3. doi: 10.1097/NMD.0000000000000454

290. Ng R, Fish S, Granholm E. Insight and theory of mind in schizophrenia. Psychiatry Res (2015) 225(1-2):169-74. doi: 10.1016/j.psychres.2014.11.010

291. Fiszdon JM, Richardson R, Greig T, Bell MD. A comparison of basic and social cognition between schizophrenia and schizoaffective disorder. Schizophr Res (2007) 91(1-3):117-21. doi: 10.1016/j.schres.2006.12.012

292. Smeets-Janssen MM, Meesters PD, Comijs HC, Eikelenboom P, Smit JH, de Haan L, et al. Theory of Mind differences in older patients with earlyonset and late-onset paranoid schizophrenia. Int J Geriatr Psychiatry (2013) 28(11):1141-6. doi: 10.1002/gps.3933

293. Lahera G, Herrera S, Reinares M, Benito A, Rullas M, González-Cases J, et al. Hostile attributions in bipolar disorder and schizophrenia contribute to poor social functioning. Acta Psychiatr Scand (2015) 131(6):472-82. doi: 10.1111/ acps. 12399

294. Park S. A study on the theory of mind deficits and delusions in schizophrenic patients. Issues Ment Health Nurs (2018) 39(3):269-74. doi: 10.1080/01612840.2017.1378782

295. Weijers J, Fonagy P, Eurelings-Bontekoe E, Termorshuizen F, Viechtbauer W, Selten JP. Mentalizing impairment as a mediator between reported childhood abuse and outcome in nonaffective psychotic disorder. Psychiatry Res (2018) 259:463-9. doi: 10.1016/j.psychres.2017.11.010

296. Bertone MS, Diaz-Granados EA, Vallejos M, Muniello J. Differences in social cognition between male prisoners with antisocial personality or psychotic disorder. Int J Psychol Res (2011) 10(2):15-24. doi: 10.21500/20112084.2903

297. Lindgren M, Torniainen-Holm M, Heiskanen I, Voutilainen G, Pulkkinen U, Mehtälä T, et al. Theory of mind in a first-episode psychosis population using the Hinting Task. Psychiatry Res (2018) 263:185-92. doi: 10.1016/j. psychres.2018.03.014

298. Sanvicente-Vieira B, Kluwe-Schiavon B, Corcoran R, Grassi-Oliveira R. Theory of Mind impairments in women with cocaine addiction. J Stud Alcohol Drugs (2017) 78(2):258-67. doi: 10.15288/jsad.2017.78.258

299. Kim YT, Kwon DH, Chang Y. Impairments of facial emotion recognition and theory of mind in methamphetamine abusers. Psychiatry Res (2011) 186(1):80-4. doi: 10.1016/j.psychres.2010.06.027

300. Benito A, Lahera G, Herrera S, Muncharaz R, Benito G, Fernández-Liria A, et al. Deficits in recognition, identification, and discrimination of facial emotions in patients with bipolar disorder. Braz J Psychiatry (2013) 35(4):435-8. doi: 10.1590/1516-4446-2013-1086

301. Schenkel LS, Marlow-O'Connor M, Moss M, Sweeney JA, Pavuluri MN. Theory of mind and social inference in children and adolescents with bipolar disorder. Psychol Med (2008) 38(6):791-800. doi: 10.1017/ S0033291707002541

302. Morozova A, Garakh Z, Bendova M, Zaytseva Y. Comparative analysis of theory of mind tests in first episode psychosis patients. Psychiatr Danub (2017) 29(3):285-8.

303. Eddy CM, Mitchell IJ, Beck SR, Cavanna AE, Rickards HE. Impaired comprehension of nonliteral language in Tourette syndrome. Cogn Behav Neurol (2010) 23(3):178-84. doi: 10.1097/WNN.0b013e3181e61cb7

304. Baron-Cohen S, Jolliffe T, Mortimore C, Robertson M. Another advanced test of theory of mind: evidence from very high functioning adults with autism or Asperger syndrome. J Child Psychol Psychiatry (1997) 38(7):81322. doi: 10.1111/j.1469-7610.1997.tb01599.x

305. Fernández-Abascal EG, Cabello R, Fernández-Berrocal P, Baron-Cohen S. Test-retest reliability of the "reading the mind in the eyes" test: a one-year follow-up study. Molec Autism (2013) 4:33-9. doi: 10.1186/2040-2392-4-33

306. Vellante M, Baron-Cohen S, Melis M, Marrone M, Petretto DR, Masala C, et al. The "reading the mind in the eyes" test: systematic review of psychometric properties and a validation study in Italy. Cogn Neuropsychiatry (2013) 18:326-54. doi: 10.1080/13546805.2012.721728
307. Bull R, Phillips LH, Conway CA. The role of control functions in mentalizing: dual task studies of theory of mind and executive function. Cognition (2008) 107:663-72. doi: 10.1016/j.cognition.2007.07.015

308. Slessor G, Phillips LH, Bull R. Exploring the specificity of age-related differences in theory of mind tasks. Psychol Aging (2007) 22:639-43. doi: 10.1037/0882-7974.22.3.639

309. Moor BG, Macks ZA, Güroglu B, Rombouts SA, Molen MW, Crone EA. Neurodevelopmental changes of reading the mind in the eyes. Soc Cogn Affect Neurosci (2012) 7(1):44-52. doi: 10.1093/scan/nsr020

310. Eddy CM, Cavanna AE, Hansen PC. Empathy and aversion: the neural signature of mentalizing in Tourette syndrome. Psychol Med (2017) 47(3):507-17. doi: 10.1017/S0033291716002725

311. Eddy CM, Rickards HE, Hansen PC. Through your eyes or mine? The neural correlates of mental state recognition in Huntington's disease. Hum Brain Mapp (2018) 39(3):1354-66. doi: 10.1002/hbm.23923

312. Yildrim EA, Kasar M, Guduk M, Ates E, Kucukparlak I, Ozalmete EO. Investigation of the reliability of the "Reading the Mind in the Eyes Test" in a Turkish Population. Turk Psikiyatri Dergisi (2011) 22(3):177-86.

313. Pfaltz MC, Mcaleese S, Saladin A, Meyer AH, Stoecklin M, Dammann G, et al. The "Reading the Mind in the Eyes" test: test-retest reliability and preliminary psychometric properties of the German version. Int $J$ Adv Psychol (2013) 2:1-9.

314. Serafin M, Surian L. Il test degli occhi: uno strumento per valutare la "teoria della mente". Giornale Italiano di Psicologia (2004) 4:839-60.

315. Castelli I. La comprensione degli stati mentali dallo sguardo. In: Marchetti A, Valle A, editors. Il bambino e le relazioni sociali. Strumenti per educatori e insegnanti. Franco Angeli (2010). p. 58-82.

316. Sanvicente-Vieira B, Kluwe-Schiavon B, Wearick-Silva LE, Piccoli GL, Scherer L, Tonelli HA, et al. Revised Reading the Mind in the Eyes Test (RMET)-Brazilian version. Braz J Psychiatry (2014) 36(1):60-7. doi: 10.1590/1516-4446-2013-1162

317. Prevost M, Carrier M-E, Chowne G, Zelkowitz P, Joseph L, Gold I. The "Reading the Mind in the Eyes" test: validation of a French version and exploration of cultural variations in a multi-ethnic city. Cogn Neuropsychiatry (2014) 19:189-204. doi: 10.1080/13546805.2013.823859

318. Khorashad BS, Baron-Cohen S, Roshan GM, Kazemian M, Khazai L, Aghili Z, et al. The "Reading the Mind in the Eyes" Test: investigation of psychometric properties and test-retest reliability of the Persian version. J Autism Dev Disord (2015) 45:2651-66. doi: 10.1007/s10803-015-2427-4

319. Bos PA, Hofman D, Hermans EJ, Montoya ER, Baron-Cohen S, van Honk J. Testosterone reduces functional connectivity during the 'Reading the Mind in the Eyes' Test. Psychoneuroendocrinology (2016) 68:194-201. doi: 10.1016/j.psyneuen.2016.03.006

320. Baglio F, Castelli I, Alberoni M, Blasi V, Griffanti L, Falini A, et al. Theory of mind in amnestic mild cognitive impairment: an FMRI study. J Alzheimers Dis (2012) 29(1):25-37. doi: 10.3233/JAD-2011-111256

321. Castelli I, Baglio F, Blasi V, Alberoni M, Falini A, Liverta-Sempio O, et al. Effects of aging on mindreading ability through the eyes: an fMRI study. Neuropsychologia (2010) 48(9):2586-94. doi: 10.1016/j. neuropsychologia.2010.05.005

322. Yin $\mathrm{S}, \mathrm{Fu} \mathrm{C}, \mathrm{Chen} \mathrm{A}$. The structural and functional correlates underlying individual heterogeneity of reading the mind in the eyes. Biol Psychol (2018) 138:179-84. doi: 10.1016/j.biopsycho.2018.09.009

323. Chalah MA, Kauv P, Lefaucheur JP, Hodel J, Créange A, Ayache SS. Theory of mind in multiple sclerosis: a neuropsychological and MRI study. Neurosci Lett (2017) 658:108-13. doi: 10.1016/j.neulet.2017.08.055

324. Mascaro JS, Rilling JK, Tenzin Negi L, Raison CL. Compassion meditation enhances empathic accuracy and related neural activity. Soc Cogn Affect Neurosci (2013) 8(1):48-55. doi: 10.1093/scan/nss095

325. Martin AK, Huang J, Hunold A, Meinzer M. Sex mediates the effects of high-definition transcranial direct current stimulation on "Mind-Reading". Neuroscience (2017) 366:84-94. doi: 10.1016/j.neuroscience.2017.10.005

326. Berlim MT, McGirr A, Beaulieu MM, Turecki G. Theory of mind in subjects with major depressive disorder: is it influenced by repetitive transcranial magnetic stimulation? World J Biol Psychiatry (2012) 13(6):474-9. doi: 10.3109/15622975.2011.615861

327. Balikci K, Aydin O, Tas C, Danaci AE. Oxytocin and social cognition in patients with schizophrenia: comparison with healthy siblings and healthy 
controls. Psychiatry Clin Psychopharmacol (2018) 28(2):123-30. doi: 10.1080/24750573.2017.1387405

328. Woolley JD, Chuang B, Lam O, Lai W, O’Donovan A, Rankin KP, et al. Oxytocin administration enhances controlled social cognition in patients with schizophrenia. Psychoneuroendocrinology (2014) 47:116-25. doi: 10.1016/j.psyneuen.2014.04.024

329. Radke S, de Bruijn ER. Does oxytocin affect mind-reading? A replication study. Psychoneuroendocrinology (2015) 60:75-81. doi: 10.1016/j. psyneuen.2015.06.006

330. Weisman O, Pelphrey KA, Leckman JF, Feldman R, Lu Y, Chong A, et al. The association between $2 \mathrm{D}: 4 \mathrm{D}$ ratio and cognitive empathy is contingent on a common polymorphism in the oxytocin receptor gene (OXTR rs53576). Psychoneuroendocrinology (2015) 58:23-32. doi: 10.1016/j. psyneuen.2015.04.007

331. Kovács B, Kéri S. Off-label intranasal oxytocin use in adults is associated with increased amygdala-cingulate resting-state connectivity. Eur Psychiatry (2015) 30(4):542-7. doi: 10.1016/j.eurpsy.2015.02.010

332. MacDonald K, MacDonald TM, Brüne M, Lamb K, Wilson MP, Golshan S, et al. Oxytocin and psychotherapy: a pilot study of its physiological, behavioral and subjective effects in males with depression. Psychoneuroendocrinology (2013) 38(12):2831-43. doi: 10.1016/j.psyneuen.2013.05.014

333. Lucht MJ, Barnow S, Sonnenfeld C, Ulrich I, Grabe HJ, Schroeder W, et al. Associations between the oxytocin receptor gene (OXTR) and "mindreading" in humans-an exploratory study. Nord J Psychiatry (2013) 67(1):15-21. doi: 10.3109/08039488.2012.700731

334. Domes G, Heinrichs M, Michel A, Berger C, Herpertz SC. Oxytocin improves "mind-reading" in humans. Biol Psychiatry (2007) 61(6):731-3. doi: 10.1016/j.biopsych.2006.07.015

335. Koizumi M, Takagishi $\mathrm{H}$. The relationship between child maltreatment and emotion recognition. PLoS One (2014) 9(1):e86093. doi: 10.1371/journal. pone. 0086093

336. Schwaiger M, Heinrichs $M$, Kumsta R. Oxytocin administration and emotion recognition abilities in adults with a history of childhood adversity. Psychoneuroendocrinology (2019) 99:66-71. doi: 10.1016/j. psyneuen.2018.08.025

337. Navarra-Ventura G, Fernandez-Gonzalo S, Turon M, Pousa E, Palao D, Cardoner N, et al. Gender differences in social cognition: a crosssectional pilot study of recently diagnosed patients with schizophrenia and healthy subjects. Can J Psychiatry (2018) 63(8):538-46. doi: $10.1177 / 0706743717746661$

338. Zhang T, Chen L, Wang Y, Zhang M, Wang L, Xu X, et al. Impaired theory of mind in Chinese children and adolescents with idiopathic generalized epilepsy: association with behavioral manifestations of executive dysfunction. Epilepsy Behav (2018a) 79:205-12. doi: 10.1016/j.yebeh.2017.12.006

339. Zhang T, Cui H, Wei Y, Tang Y, Xu L, Tang X, et al. Progressive decline of cognition during the conversion from prodrome to psychosis with a characteristic pattern of the theory of mind compensated by neurocognition. Schizophr Res (2018b) 195:554-9. doi: 10.1016/j.schres.2017.08.020

340. Zhang T, Xu L, Cui H, Tang Y, Wei Y, Tang X, et al. Changes in correlation characteristics of time consumption and mind-reading performance in preonset and post-onset psychosis. Psychiatry Res (2018c) 262:168-14. doi: 10.1016/j.psychres.2018.02.008

341. Schiffer B, Pawliczek C, Müller BW, Wiltfang J, Brüne M, Forsting M, et al. Neural mechanisms underlying affective theory of mind in violent antisocial personality disorder and/or schizophrenia. Schizophr Bull (2017) 43(6):1229-39. doi: 10.1093/schbul/sbx012

342. Akgul O, Kucukcoban O, Binbay T, Bora E, Alptekin K, Akdede BB. Do clinical features relate to theory of mind, empathy and 2D:4D in schizophrenia? Psychiatry Clin Psychopharmacol (2017) 27(4):380-5. doi: 10.1080/24750573.2017.1373725

343. Tsuruya N, Kobayakawa M, Kawamura M. Is "reading mind in the eyes" impaired in Parkinson's disease? Parkinsonism Relat Disord (2011) 17(4):246-8. doi: 10.1016/j.parkreldis.2010.09.001

344. Espinós U, Fernández-Abascal EG, Ovejero M. What your eyes tell me: theory of mind in bipolar disorder. Psychiatry Res (2018) 262:536-41. doi: 10.1016/j.psychres.2017.09.039

345. Tay SA, Hulbert CA, Jackson HJ, Chanen AM. Affective and cognitive theory of mind abilities in youth with borderline personality disorder or major depressive disorder. Psychiatry Res (2017) 255:405-11. doi: 10.1016/j. psychres.2017.06.016

346. Uhlmann A, Ipser JC, Wilson D, Stein DJ. Social cognition and aggression in methamphetamine dependence with and without a history of psychosis. Metab Brain Dis (2018) 33(2):559-68. doi: 10.1007/s11011-017-0157-3

347. Schroeter ML, Pawelke S, Bisenius S, Kynast J, Schuemberg K, Polyakova $\mathrm{M}$, et al. A modified Reading the Mind in the Eyes Test predicts behavioral variant frontotemporal dementia better than executive function tests. Front Aging Neurosci (2018) 10:11. doi: 10.3389/fnagi.2018.00011

348. Saghir H, Dupuis A, Chau T, Kushki A. Atypical autonomic nervous system complexity accompanies social cognition task performance in ASD. Res Autism Spectrum Disord (2017) 39:54-62. doi: 10.1016/j.rasd.2017.04.004

349. Rudra A, Ram JR, Loucas T, Belmonte MK, Chakrabarti B. Bengali translation and characterisation of four cognitive and trait measures for autism spectrum conditions in India. Mol Autism (2016) 7:50. doi: 10.1186/ s13229-016-0111-y

350. Okruszek Ł, Bala A, Wordecha M, Jarkiewicz M, Wysokiński A, Szczepocka E, et al. Social cognition in neuropsychiatric populations: a comparison of theory of mind in schizophrenia and mesial temporal lobe epilepsy. Sci Rep (2017) 7(1):484. doi: 10.1038/s41598-017-00565-2

351. Eddy CM, Sira Mahalingappa S, Rickards H. Is Huntington's disease associated with deficits in Theory of Mind? Acta Neurol Scand (2012) 126(6):376-83.

352. Eddy CM, Sira Mahalingappa S, Rickards H. Putting things into perspective: the nature and impact of theory of mind impairments in Huntington's disease. Eur Arch Psychiatry Clin Neurosci (2014) 264:697-705.

353. Demirci E, Erdogan A. Is emotion recognition the only problem in ADHD? Effects of pharmacotherapy on face and emotion recognition in children with ADHD. Atten Defic Hyperact Disord (2016) 8(4):197-204. doi: 10.1007/ s12402-016-0201-x

354. Hoche F, Guell X, Sherman JC, Vangel MG, Schmahmann JD. Cerebellar contribution to social cognition. Cerebellum (2016) 15(6):732-43. doi: 10.1007/s12311-015-0746-9

355. Haag S, Haffner P, Quinlivan E, Brüne M, Stamm T. No differences in visual theory of mind abilities between euthymic bipolar patients and healthy controls. Int J Bipolar Disord (2016) 4(1):20. doi: 10.1186/s40345-016-0061-5

356. Vogindroukas I, Chelas EN, Petridis NE. Reading the Mind in the Eyes Test (Children's Version): a comparison study between children with typical development, children with high-functioning autism and typically developed adults. Folia Phoniatr Logop (2014) 66(1-2):18-24. doi: 10.1159/000363697

357. Gooding DC, Johnson M, Peterman JS. Schizotypy and altered digit ratios: a second look. Psychiatry Res (2010) 178(1):73-8. doi: 10.1016/j. psychres.2010.04.023

358. Ripoll LH, Zaki J, Perez-Rodriguez MM, Snyder R, Strike KS, Boussi A, et al. Empathic accuracy and cognition in schizotypal personality disorder. Psychiatry Res (2013) 210(1):232-41. doi: 10.1016/j.psychres.2013.05.025

359. Richman MJ, Unoka Z. Mental state decoding impairment in major depression and borderline personality disorder: meta-analysis. $\mathrm{Br} \mathrm{J}$ Psychiatry (2015) 207(6):483-9. doi: 10.1192/bjp.bp.114.152108

360. Fertuck EA, Jekal A, Song I, Wyman B, Morris MC, Wilson ST, et al. Enhanced 'Reading the Mind in the Eyes' in borderline personality disorder compared to healthy controls. Psychol Med (2009) 39(12):1979-88. doi: 10.1017/S003329170900600X

361. Rnic K, Sabbagh MA, Washburn D, Bagby RM, Ravindran A, Kennedy JL, et al. Childhood emotional abuse, physical abuse, and neglect are associated with theory of mind decoding accuracy in young adults with depression. Psychiatry Res (2018) 268:501-7. doi: 10.1016/j.psychres.2018.07.045

362. Baron-Cohen S, O'Riordan M, Stone V, Jones R, Plaisted K. Recognition of faux pas by normally developing children and children with Asperger syndrome or high-functioning autism. J Autism Dev Disord (1999) 29(5):407-418.

363. Schacher M, Winkler R, Grunwald T, Kraemer G, Kurthen M, Reed V, et al. Mesial temporal lobe epilepsy impairs advanced social cognition. Epilepsia (2006) 47:2141-6. doi: 10.1111/j.1528-1167.2006.00857.x

364. Shamay-Tsoory SG, Tomer R, Berger BD, Goldsher D, Aharon-Peretz J. Impaired "affective theory of mind" is associated with right ventromedial prefrontal damage. Cogn Behav Neurol (2005) 18(1):55-67. doi: 10.1097/01. wnn.0000152228.90129.99 
365. Kawamura M, Koyama S. Social cognitive impairment in Parkinson's disease. J Neurol (2007) 254(S4):IV49-53. doi: 10.1007/s00415-007-4008-8

366. Zhu CY, Lee TM, Li XS, Jing SC, Wang YG, Wang K. Impairments of social cues recognition and social functioning in Chinese people with schizophrenia. Psychiatry Clin Neurosci (2007) 61(2):149-58. doi: 10.1111/j.1440-1819.2007.01630.x

367. Liverta Sempio O, Marchetti A, Lecciso F. Faux pas: traduzione italiana. Milan: Theory of Mind Research Unit, Department of Psychology, Catholic University of the Sacred Heart (2005).

368. Guastella AJ, Ward PB, Hickie IB, Shahrestani S, Hodge MA, Scott EM, et al. Single dose of oxytocin nasal spray improves higher-order social cognition in schizophrenia. Schizophr Res (2015) 168(3):628-33. doi: 10.1016/j. schres.2015.06.005

369. Petroni A, Canales-Johnson A, Urquina H, Guex R, Hurtado E, Blenkmann A, et al. The cortical processing of facial emotional expression is associated with social cognition skills and executive functioning: a preliminary study. Neurosci Lett (2011) 505(1):41-6. doi: 10.1016/j.neulet.2011.09.062

370. Henry A, Tourbah A, Chaunu MP, Rumbach L, Montreuil M, Bakchine S. Social cognition impairments in relapsing-remitting multiple sclerosis. J Int Neuropsychol Soc (2011) 17(6):1122-31. doi: 10.1017/S1355617711001147

371. Li YH, Chiu MJ, Yeh ZT, Liou HH, Cheng TW, Hua MS. Theory of mind in patients with temporal lobe epilepsy. J Int Neuropsychol Soc (2013) 19(5):594-600. doi: 10.1017/S1355617713000143

372. Hennion S, Delbeuck X, Duhamel A, Lopes R, Semah F, Tyvaert L, et al. Characterization and prediction of theory of mind disorders in temporal lobe epilepsy. Neuropsychology (2015) 29(3):485-92. doi: 10.1037/neu0000126

373. Giovagnoli AR, Parente A, Villani F, Franceschetti S, Spreafico R. Theory of mind and epilepsy: what clinical implications? Epilepsia (2013) 54(9):163946. doi: 10.1111/epi.12255

374. Giovagnoli AR, Parente A, Didato G, Deleo F, Villani F. Expanding the spectrum of cognitive outcomes after temporal lobe epilepsy surgery: a prospective study of theory of mind. Epilepsia (2016) 57(6):920-30. doi: 10.1111/epi.13384

375. Wang WH, Shih YH, Yu HY, Yen DJ, Lin YY, Kwan SY, et al. Theory of mind and social functioning in patients with temporal lobe epilepsy. Epilepsia (2015) 56(7):1117-23. doi: 10.1111/epi.13023

376. Morou N, Papaliagkas V, Markouli E, Karagianni M, Nazlidou E, Spilioti $\mathrm{M}$, et al. Theory of Mind impairment in focal versus generalized epilepsy. Epilepsy Behav (2018) 88:244-50. doi: 10.1016/j.yebeh.2018.09.026

377. Cox S, Bertoux M, Turner JJD, Moss A, Locker K, Riggs K. Aspects of alcohol use disorder affecting social cognition as assessed using the Mini Social and Emotional Assessment (mini-SEA). Drug Alcohol Depend (2018) 187:16570. doi: 10.1016/j.drugalcdep.2018.03.004

378. Nobis L, Schindlbeck K, Ehlen F, Tiedt H, Rewitzer C, Duits AA, et al. Theory of mind performance in Parkinson's disease is associated with motor and cognitive functions, but not with symptom lateralization. J Neural Transm (Vienna). (2017) 124(9):1067-72. doi: 10.1007/s00702-017-1739-2

379. Péron J, Vicente S, Leray E, Drapier S, Drapier D, Cohen R, et al. Are dopaminergic pathways involved in theory of mind? A study in Parkinson's disease. Neuropsychologia (2009) 47(2):406-14. doi: 10.1016/j. neuropsychologia.2008.09.008

380. Henry A, Tourbahi A, Chaunu MP, Bakchine S, Montreuil M. Social cognition abilities in patients with different multiple sclerosis subtypes. J Int Neuropsychol Soc (2017) 23(8):653-64. doi: 10.1017/S1355617717000510

381. Charvet LE, Cleary RE, Vazquez K, Belman AL, Krupp LB. US Network for Pediatric MS. Social cognition in pediatric-onset multiple sclerosis (MS). Mult Scler (2014) 20(11):1478-84. doi: 10.1177/1352458514526942.

382. Zhang Q, Li X, Parker GJ, Hong XH, Wang Y, Lui SS, et al. Theory of mind correlates with clinical insight but not cognitive insight in patients with schizophrenia. Psychiatry Res (2016a) 237:188-95. doi: 10.1016/j. psychres.2016.01.044

383. Zhang T, Tang Y, Cui H, Lu X, Xu L, Liu X, et al. Theory of mind impairments in youth at clinical high risk of psychosis. Psychiatry (2016b) 79(1):40-55. doi: 10.1080/00332747.2015.1123592

384. Zhang T, Yi Z, Li H, Cui H, Tang Y, Lu X, et al. Faux pas recognition performance in a help-seeking population at clinical high risk of psychosis. Eur Arch Psychiatry Clin Neurosci (2016c) 266(1):71-8. doi: 10.1007/ s00406-015-0615-z
385. Huepe D, Riveros R, Manes F, Couto B, Hurtado E, Cetkovich M, et al. The relationship of clinical, cognitive and social measures in schizophrenia: a preliminary finding combining measures in probands and relatives. Behav Neurol (2012) 25(2):137-50. doi: 10.1155/2012/194159

386. Shur S, Shamay-Tsoory SG, Levkovitz Y. Integration of emotional and cognitive aspects of theory of mind in schizophrenia and its relation to prefrontal neurocognitive performance. Cogn Neuropsychiatry (2008) 13(6):472-90. doi: 10.1080/13546800802490034

387. Hasson-Ohayon I, Avidan-Msika M, Mashiach-Eizenberg M, Kravetz S, Rozencwaig S, Shalev H, et al. Metacognitive and social cognition approaches to understanding the impact of schizophrenia on social quality of life. Schizophr Res (2015) 161(2-3):386-91. doi: 10.1016/j.schres.2014.11.008

388. Herold R, Feldmann A, Simon M, Tényi T, Kövér F, Nagy F, et al. Regional gray matter reduction and theory of mind deficit in the early phase of schizophrenia: a voxel-based morphometric study. Acta Psychiatr Scand (2009) 119(3):199-208. doi: 10.1111/j.1600-0447.2008.01297.x

389. Caletti E, Paoli RA, Fiorentini A, Cigliobianco M, Zugno E, Serati M, et al. Neuropsychology, social cognition and global functioning among bipolar, schizophrenic patients and healthy controls: preliminary data. Front Hum Neurosci (2013) 7:661. doi: 10.3389/fnhum.2013.00661

390. Samamé C, Martino DJ, Strejilevich SA. An individual task meta-analysis of social cognition in euthymic bipolar disorders. J Affect Disord (2015) 173:146-53. doi: 10.1016/j.jad.2014.10.055

391. Zalla T, Sav A-M, Stopin A, Ahade S, Leboyer M. Faux pas detection and intentional action in Asperger syndrome. a replication on a French sample. J Autism Dev Disord (2009) 39:373-82. doi: 10.1007/s10803-008-0634-y

392. Mary A, Slama H, Mousty P, Massat I, Capiau T, Drabs V, et al. Executive and attentional contributions to Theory of Mind deficit in attention deficit/ hyperactivity disorder (ADHD). Child Neuropsychol (2016) 22(3):345-65. doi: 10.1080/09297049.2015.1012491

393. Maoz H, Tsviban L, Gvirts HZ, Shamay-Tsoory SG, Levkovitz Y, Watemberg N, et al. Stimulants improve theory of mind in children with attention deficit/hyperactivity disorder. J Psychopharmacol (2014) 28(3):2129. doi: 10.1177/0269881113492030

394. Channon S, Drury H, Gafson L, Stern J, Robertson MM. Judgements of social inappropriateness in adults with Tourette's syndrome. Cogn Neuropsychiatry (2012) 17(3):246-61. doi: 10.1080/13546805.2011.590689

395. Cao Y, Zhao QD, Hu LJ, Sun ZQ, Sun SP, Yun WW, et al. Theory of mind deficits in patients with esophageal cancer combined with depression. World J Gastroenterol (2013) 19(19):2969-73. doi: 10.3748/wjg.v19.i19.2969

396. Torralva T, Roca M, Gleichgerrcht E, Bekinschtein T, Manes F. A neuropsychological battery to detect specific executive and social cognitive impairments in early frontotemporal dementia. Brain (2009) 132(5):1299309. doi: 10.1093/brain/awp041

397. Torralva T, Kipps CM, Hodges JR, Clark L, Bekinschtein T, Roca M, et al. The relationship between affective decision-making and theory of mind in the frontal variant of fronto-temporal dementia. Neuropsychologia (2007) 45(2):342-9. doi: 10.1016/j.neuropsychologia.2006.05.031

398. Ruiz-Tagle A, Costanzo E, De Achával D, Guinjoan S. Social cognition in a clinical sample of personality disorder patients. Front Psychiatry (2015) 6:75. doi: 10.3389/fpsyt.2015.00075

399. Tapajóz Pereira de Sampaio F, Soneira S, Aulicino A, Allegri RF. Theory of mind in eating disorders and their relationship to clinical profile. Eur Eat Disord Rev (2013) 21(6):479-87. doi: 10.1002/erv.2247

400. Xi C, Zhu Y, Zhu C, Song D, Wang Y, Wang K. Deficit of theory of mind after temporal lobe cerebral infarction. Behav Brain Funct (2013) 9:15. doi: 10.1186/1744-9081-9-15

401. Kemp J, Berthel MC, Dufour A, Després O, Henry A, Namer IJ, et al. Caudate nucleus and social cognition: neuropsychological and SPECT evidence from a patient with focal caudate lesion. Cortex (2013) 49(2):559-71. doi: 10.1016/j.cortex.2012.01.004

402. Goebel S, Mehdorn HM, Wiesner CD. Social cognition in patients with intracranial tumors: do we forget something in the routine neuropsychological examination? J Neurooncol (2018) 140(3):687-96. doi: 10.1007/s11060-018-3000-8

403. Kobayakawa M, Tsuruya N, Kawamura M. Theory of mind impairment in adult-onset myotonic dystrophy type 1. Neurosci Res (2012) 72(4):341-6. doi: 10.1016/j.neures.2012.01.005 
404. Xi C, Zhu Y, Niu C, Zhu C, Lee TM, Tian Y, et al. Contributions of subregions of the prefrontal cortex to the theory of mind and decision making. Behav Brain Res (2011) 221(2):587-93. doi: 10.1016/j.bbr.2010.09.031

405. Lee TM, Ip AK, Wang K, Xi CH, Hu PP, Mak HK, et al. Faux pas deficits in people with medial frontal lesions as related to impaired understanding of a speaker's mental state. Neuropsychologia (2010) 48(6):1670-76. doi: 10.1016/j.neuropsychologia.2010.02.012

406. Jonker FA, Jonker C, Scheltens P, Scherder EJ. The role of the orbitofrontal cortex in cognition and behavior. Rev Neurosci (2015) 26(1):1-11. doi: 10.1515/revneuro-2014-0043

407. Anaki D, Zadikov-Mor T, Gepstein V, Hochberg Z. Normal performance in non-visual social cognition tasks in women with Turner syndrome. Front Endocrinol (Lausanne). (2018) 9:171. doi: 10.3389/fendo.2018.00171

408. Anupama V, Bhola P, Thirthalli J, Mehta UM. Pattern of social cognition deficits in individuals with borderline personality disorder. Asian J Psychiatr (2018) 33:105-12. doi: 10.1016/j.ajp.2018.03.010

409. Mavrogiorgou P, Bethge M, Luksnat S, Nalato F, Juckel G, Brüne M. Social cognition and metacognition in obsessive-compulsive disorder: an explorative pilot study. Eur Arch Psychiatry Clin Neurosci (2016) 266(3):20916. doi: 10.1007/s00406-016-0669-6

410. Ciaramelli E, Bernardi F, Moscovitch M. Individualized Theory of Mind (iToM): when memory modulates empathy. Front Psychol (2013) 4:4. doi: 10.3389/fpsyg.2013.00004

411. Davis MH. A multidimensional approach to individual differences in empathy. JSAS Catal Select Doc Psychol (1980) 10:685.

412. Cliffordson C. The hierarchical structure of empathy: dimensional organization and relations to social functioning. Scand J Psychol (2002) 43:49-59. doi: $10.1111 / 1467-9450.00268$

413. Pulos S, Elison J, Lennon R. The hierarchical structure of the Interpersonal Reactivity Index. Soc Behav Pers (2004) 32:355-9. doi: 10.2224/ sbp.2004.32.4.355

414. Baldner C, McGinley JJ. Correlational and exploratory factor analyses (EFA) of commonly used empathy questionnaires: New insights. Motiv. Emot. (2014) 38(5):727-744.

415. Gilet A-L, Mella N, Studer J, Gruehn D, Labouvie-Vief G. Assessing dispositional empathy in adults: a French validation of the Interpersonal Reactivity Index (IRI). Can J Behav Sci Can Des Sci Du Comport (2013) 45:42-8. doi: $10.1037 / \mathrm{a} 0030425$

416. Maria Fernandez A, Dufey M, Kramp U. Testing the psychometric properties of the Interpersonal Reactivity Index (IRI) in Chile empathy in a different cultural context. Eur J Psychol Assess (2011) 27:179-85. doi: 10.1027/1015-5759/a000065

417. Johnson MH. Executive function and developmental disorders: the flip side of the coin. Trends Cogn Sci (2012) 16(9):454-7. doi: 10.1016/j. tics.2012.07.001

418. Garton A, Gringart E. The development of a scale to measure empathy in 8- and 9-year old children. Australian J Education Dev Psychol (2005) 5:17-25.

419. De Corte K, Buysse A, Verhofstadt L, Roeyers H, Ponnet K. Measuring empathic tendencies: reliability and validity of the Dutch version of the interpersonal reactivity index. Psychologica Belgica (2007) 47(4):235-60. doi: $10.5334 / \mathrm{pb}-47-4-235$

420. Albiero P, Ingoglia S, Lo Coco A. Contributo alladattamento italiano dell'Interpersonal Reactivity Index. Test Psicometria Metodologia (2006) 13:107-25.

421. Huang X, Li W, Sun B, Chen H, Davis MH. The validation of the interpersonal reactivity index for Chinese teachers from primary and middle schools. J Psychoeducational Assess (2012) 30(2):194-204. doi: $10.1177 / 0734282911410588$

422. Guttman HA, Laporte L. Empathy in families of women with borderline personality disorder, anorexia nervosa, and a control group. Fam Process (2000) 39(3):345-58. doi: 10.1111/j.1545-5300.2000.39306.x

423. Aketa H. Structure and measurement of empathy: Japanese version of Davis's interpersonal reactivity index (IRI-J). Psychol Rep Sophia Univ (1999) 23:19-31.

424. Pérez-Albéniz A, de Paúl J, Etxeberría J, Montes MP, Torres E. Adaptación de Interpersonal Reactivity Index (IRI) al español [Spanish adaptation of the Interpersonal Reactivity Index]. Psicothema (2003) 15(2):267-72.
425. Paulus C. Der Saarbrücker Persönlichkeitsfragebogen SPF (IRI) zur messung von empathie: Psychometrische Evaluation der deutschen Version des Interpersonal Reactivity Index. (2009). http://psydok.psycharchives.de/ jspui/handle/20.500.11780/3343

426. Carr AR, Mendez MF. Affective empathy in behavioral variant frontotemporal dementia: a meta-analysis. Front Neurol (2018) 9:417. doi: 10.3389/fneur.2018.00417

427. Halverson T, Jarskog LF, Pedersen C, Penn D. Effects of oxytocin on empathy, introspective accuracy, and social symptoms in schizophrenia: a 12-week twice-daily randomized controlled trial. Schizophr Res (2019) 204:178-82. doi: 10.1016/j.schres.2018.09.013

428. Lin IF, Kashino M, Ohta H, Yamada T, Tani M, Watanabe H, et al. The effect of intranasal oxytocin versus placebo treatment on the autonomic responses to human sounds in autism: a single-blind, randomized, placebo-controlled, crossover design study. Mol Autism (2014) 5(1):20. doi: 10.1186/2040-2392-5-20

429. Wu N, Li Z, Su Y. The association between oxytocin receptor gene polymorphism (OXTR) and trait empathy. J Affect Disord (2012) 138(3):46872. doi: 10.1016/j.jad.2012.01.009

430. Groen Y, Wijers AA, Tucha O, Althaus M. Are there sex differences in ERPs related to processing empathy-evoking pictures? Neuropsychologia (2013) 51(1):142-55. doi: 10.1016/j.neuropsychologia.2012.11.012

431. Cheng Y, Lee PL, Yang CY, Lin CP, Hung D, Decety J. Gender differences in the mu rhythm of the human mirror-neuron system. PLoS One (2008) 3(5):e2113. doi: 10.1371/journal.pone.0002113

432. Oliveira Silva P, Maia L, Coutinho J, Brandon F, Miguel Soares J, Sampaio A, Goncalves O. Empathy by default: Correlates in the brain at rest. Psicothma (2018) 30(1):97-103.

433. Parkinson C, Wheatley T. Relating anatomical and social connectivity: White matter microstructure predicts emotional empathy. Cereb Cortex (2014) 24(3):614-25. doi: 10.1093/cercor/bhs347

434. Kaplan JT, Iacoboni M. Getting a grip on other minds: mirror neurons, intention understanding, and cognitive empathy. Soc Neurosci (2006) 1(34):175-83. doi: 10.1080/17470910600985605

435. Haas BW, Anderson IW, Filkowski MM. Interpersonal reactivity and the attribution of emotional reactions. Emotion (2015) 15(3):390-8. doi: 10.1037/emo0000053

436. Dodell-Feder D, Tully LM, Lincoln SH, Hooker CI. The neural basis of theory of mind and its relationship to social functioning and social anhedonia in individuals with schizophrenia. Neuroimage Clin (2013) 4:154-63. doi: 10.1016/j.nicl.2013.11.006

437. Jabbi M, Swart M, Keysers C. Empathy for positive and negative emotions in the gustatory cortex. Neuroimage (2007) 34(4):1744-53. doi: 10.1016/j. neuroimage.2006.10.032

438. Diaconescu AO, Mathys C, Weber LA, Daunizeau J, Kasper L, Lomakina EI, et al. Inferring on the intentions of others by hierarchical Bayesian learning. PLoS Comput Biol (2014) 10(9):e1003810. doi: 10.1371/journal.pcbi.1003810

439. Sarlo M, Lotto L, Rumiati R, Palomba D. If it makes you feel bad, don’t do it! Egoistic rather than altruistic empathy modulates neural and behavioral responses in moral dilemmas. Physiol Behav (2014) 130:127-34. doi: 10.1016/j.physbeh.2014.04.002

440. Garaigordobil M. Cooperative conflict-solving during adolescence: relationships with cognitive-behavioural and predictor variables. Infancia y Aprendizaje (2012) 35(2):151-65. doi: 10.1174/021037012800217998

441. Aghvinian M, Sergi MJ. Social functioning impairments in schizotypy when social cognition and neurocognition are not impaired. Schizophr Res Cogn (2018) 14:7-13. doi: 10.1016/j.scog.2018.07.001

442. Singh S, Modi S, Goyal S, Kaur P, Singh N, Bhatia T, et al. Functional and structural abnormalities associated with empathy in patients with schizophrenia: an fMRI and VBM study. J Biosci (2015) 40(2):355-64. doi: 10.1007/s12038-015-9509-5

443. Michaels TM, Horan WP, Ginger EJ, Martinovich Z, Pinkham AE, Smith MJ. Cognitive empathy contributes to poor social functioning in schizophrenia: evidence from a new self-report measure of cognitive and affective empathy. Psychiatry Res (2014) 220(3):803-10. doi: 10.1016/j.psychres.2014.08.054

444. Fujino J, Takahashi H, Miyata J, Sugihara G, Kubota M, Sasamoto A, et al. Impaired empathic abilities and reduced white matter integrity in schizophrenia. Prog Neuropsychopharmacol Biol Psychiatry (2014) 48:11723. doi: 10.1016/j.pnpbp.2013.09.018 
445. Montag C, Heinz A, Kunz D, Gallinat J. Self-reported empathic abilities in schizophrenia. Schizophr Res (2007) 92(1-3):85-9. doi: 10.1016/j. schres.2007.01.024

446. McCormick LM, Brumm MC, Beadle JN, Paradiso S, Yamada T, Andreasen N. Mirror neuron function, psychosis, and empathy in schizophrenia. Psychiatry Res (2012) 201(3):233-9. doi: 10.1016/j. pscychresns.2012.01.004

447. Haker H, Rössler W. Empathy in schizophrenia: impaired resonance. Eur Arch Psychiatry Clin Neurosci (2009) 259(6):352-61. doi: 10.1007/ s00406-009-0007-3

448. Fujiwara H, Shimizu M, Hirao K, Miyata J, Namiki C, Sawamoto N, et al. Female specific anterior cingulate abnormality and its association with empathic disability in schizophrenia. Prog Neuropsychopharmacol Biol Psychiatry (2008) 32(7):1728-34. doi: 10.1016/j.pnpbp.2008.07.013

449. Gul A, Ahmad H. The relationship between dispositional empathy and prefrontal cortical functioning in patients with frontal lobe epilepsy. Pakistan J Med Sci (2017) 33(1):200-4.

450. Jiang Y, Hu Y, Wang Y, Zhou N, Zhu L, Wang K. Empathy and emotion recognition in patients with idiopathic generalized epilepsy. Epilepsy Behav (2014) 37:139-44. doi: 10.1016/j.yebeh.2014.06.005

451. Sturm VE, Yokoyama JS, Seeley WW, Kramer JH, Miller BL, Rankin KP. Heightened emotional contagion in mild cognitive impairment and Alzheimer's disease is associated with temporal lobe degeneration. Proc Natl Acad Sci U S A (2013) 110(24):9944-9. doi: 10.1073/pnas.1301119110

452. Oliver LD, Mitchell DG, Dziobek I, MacKinley J, Coleman K, Rankin KP, et al. Parsing cognitive and emotional empathy deficits for negative and positive stimuli in frontotemporal dementia. Neuropsychologia (2015) 67:14-26. doi: 10.1016/j.neuropsychologia.2014.11.022

453. Sollberger M, Rosen HJ, Shany-Ur T, Ullah J, Stanley CM, Laluz V, et al. Neural substrates of socioemotional self-awareness in neurodegenerative disease. Brain Behav (2014) 4(2):201-14. doi: 10.1002/brb3.211

454. Hsieh S, Irish M, Daveson N, Hodges JR, Piguet O. When one loses empathy: its effect on carers of patients with dementia. J Geriatr Psychiatry Neurol (2013) 26(3):174-84. doi: 10.1177/0891988713495448

455. Parlar M, Frewen P, Nazarov A, Oremus C, MacQueen G, Lanius R, et al. Alterations in empathic responding among women with posttraumatic stress disorder associated with childhood trauma. Brain Behav (2014) 4(3):381-9. doi: 10.1002/brb3.215

456. Nietlisbach G, Maercker A, Rössler W, Haker H. Are empathic abilities impaired in post-traumatic stress disorder? Psychol Rep (2010) 106(3):83244. doi: 10.2466/pr0.106.3.832-844

457. Beadle JN, Paradiso S, Salerno A, McCormick LM. Alexithymia, emotional empathy, and self-regulation in anorexia nervosa. Ann Clin Psychiatry (2013) 25(2):107-20.

458. Narme P, Mouras H, Roussel M, Duru C, Krystkowiak P, Godefroy O. Emotional and cognitive social processes are impaired in Parkinson's disease and are related to behavioral disorders. Neuropsychology (2013) 27(2):18292. doi: $10.1037 / \mathrm{a} 0031522$

459. Schmidt N, Paschen L, Deuschl G, Witt K. Reduced empathy scores in patients with Parkinson's disease: a non-motor symptom associated with advanced disease stages. J Parkinsons Dis (2017) 7(4):713-8. doi: 10.3233/ JPD-171083

460. Tousignant B, Jackson PL, Massicotte E, Beauchamp MH, Achim AM, VeraEstay E, et al. Impact of traumatic brain injury on social cognition in adolescents and contribution of other higher order cognitive functions. Neuropsychol Rehabil (2018) 28(3):429-47. doi: 10.1080/09602011.2016.1158114

461. Hazelton JL, Irish M, Hodges JR, Piguet O, Kumfor F. Cognitive and affective empathy disruption in non-fluent primary progressive aphasia syndromes. Brain Impairment (2017) 18(1):117-29. doi: 10.1017/BrImp.2016.21

462. Gleichgerrcht E, Tomashitis B, Sinay V. The relationship between alexithymia, empathy and moral judgment in patients with multiple sclerosis. Eur J Neurol (2015) 22(9):1295-303. doi: 10.1111/ene.12745

463. Mandel A, Helokunnas S, Pihko E, Hari R. Brain responds to another person's eye blinks in a natural setting-The more empathetic the viewer the stronger the responses. Eur J Neurosci (2015) 42(8):2508-14. doi: 10.1111/ ejn. 13011

464. Stange K, Krüger M, Janke E, Lichtinghagen R, Bleich S, Hillemacher T, et al. Positive association of personal distress with testosterone in opiate-addicted patients. J Addict Dis (2017) 36(3):167-74. doi: 10.1080/10550887.2017.1303980

465. Rupp CI, Derntl B, Osthaus F, Kemmler G, Fleischhacker WW. Impact of social cognition on alcohol dependence treatment outcome: poorer facial emotion recognition predicts relapse/dropout. Alcohol Clin Exp Res (2017) 41(12):2197-206. doi: 10.1111/acer.13522

466. Lam BY, Raine A, Lee TM. The relationship between neurocognition and symptomatology in people with schizophrenia: social cognition as the mediator. BMC Psychiatry (2014) 14:138. doi: 10.1186/1471-244X-14-138

467. Achim AM, Ouellet R, Roy MA, Jackson PL. Assessment of empathy in first-episode psychosis and meta-analytic comparison with previous studies in schizophrenia. Psychiatry Res (2011) 190(1):3-8. doi: 10.1016/j. psychres.2010.10.030

468. Montag C, Dziobek I, Richter IS, Neuhaus K, Lehmann A, Sylla R, et al. Different aspects of theory of mind in paranoid schizophrenia: evidence from a video-based assessment. Psychiatry Res (2011) 186(2-3):203-9. doi: 10.1016/j.psychres.2010.09.006

469. Lavoie MA, Plana I, Jackson PL, Godmaire-Duhaime F, Bédard Lacroix J, Achim AM. Performance in multiple domains of social cognition in parents of patients with schizophrenia. Psychiatry Res (2014) 220(1-2):118-24. doi: 10.1016/j.psychres.2014.07.055

470. Houston-Price C, Goddard K, Séclier C, Grant SC, Reid CJ, Boyden LE, et al. Tracking speakers' false beliefs: is theory of mind available earlier for word learning? Dev Sci (2011) 14(4):623-34. doi: 10.1111/j.1467-7687.2010. 01003.x

471. Hendriks AL, Barnes-Holmes Y, McEnteggart C, De Mey HRA, Witteman CLM, Janssen GTL, et al. The relationship between theory of mind and relational frame theory: convergence of perspective-taking measures. Clin Neuropsychiatry (2016) 13(1-2):17-23.

472. Brewer N, Young RL, Barnett E. Measuring theory of mind in adults with autism spectrum disorder. J Autism Dev Disord (2017) 47(7):1927-41. doi: 10.1007/s10803-017-3080-X

473. Stanford AD, Messinger J, Malaspina D, Corcoran CM. Theory of Mind in patients at clinical high risk for psychosis. Schizophr Res (2011) 131(1-3):117. doi: 10.1016/j.schres.2011.06.005

474. Zalla T, Korman J. Prior knowledge, episodic control and theory of mind in autism: toward an integrative account of social cognition. Front Psychol (2018) 9:752. doi: 10.3389/fpsyg.2018.00752

475. Bosco FM, Gabbatore I, Tirassa M, Testa S. Psychometric properties of the theory of mind assessment scale in a sample of adolescents and adults. Front Psychol (2016) 7:566. doi: 10.3389/fpsyg.2016.00566

476. Ventura J, Ered A, Gretchen-Doorly D, Subotnik KL, Horan WP, Hellemann GS, et al. Theory of mind in the early course of schizophrenia: stability, symptom and neurocognitive correlates, and relationship with functioning. Psychol Med (2015) 45(10):2031-43. doi: 10.1017/S0033291714003171

477. Brunet E, Sarfati Y, Hardy-Baylé MC, Decety J. A PET investigation of the attribution of intentions with a nonverbal task. Neuroimage (2000) 11(2):157-66. doi: 10.1006/nimg.1999.0525

478. Bazin N, Brunet-Gouet E, Bourdet C, Kayser N, Falissard B, Hardy-Baylé $\mathrm{MC}$, et al. Quantitative assessment of attribution of intentions to others in schizophrenia using an ecological video-based task: a comparison with manic and depressed patients. Psychiatry Res (2009) 167(1-2):28-35. doi: 10.1016/j.psychres.2007.12.010

479. Lawrence K, Campbell R, Skuse D. Age, gender, and puberty influence the development of facial emotion recognition. Front Psychol (2015) 6:761. doi: 10.3389/fpsyg.2015.00761

480. Dodich A, Cerami C, Canessa N, Crespi C, Marcone A, Arpone M, et al. Emotion recognition from facial expressions: a normative study of the Ekman 60-Faces Test in the Italian population. Neurol Sci (2014) 35(7):101521. doi: 10.1007/s10072-014-1631-x

481. Jarros RB, Salum GA, Belem da Silva CT, Toazza R, de Abreu Costa M, Fumagalli de Salles J, et al. Anxiety disorders in adolescence are associated with impaired facial expression recognition to negative valence. J Psychiatr Res (2012) 46(2):147-51. doi: 10.1016/j.jpsychires.2011.09.023

482. Habota T, McLennan SN, Cameron J, Ski CF, Thompson DR, Rendell PG. An investigation of emotion recognition and theory of mind in people with chronic heart failure. PLoS One (2015) 10(11):e0141607. doi: 10.1371/ journal.pone.0141607 
483. Lamberts KF, Fasotti L, Boelen DHE, Spikman JM. Self-awareness after brain injury: relation with emotion recognition and effects of treatment. Brain Impairment (2017) 18(1):130-7. doi: 10.1017/BrImp.2016.28

484. Larkin KT, Martin RR, McClain SE. Cynical hostility and the accuracy of decoding facial expressions of emotions. J Behav Med (2002) 25(3):285-92. doi: 10.1023/A:1015384812283

485. Heitz C, Noblet V, Phillipps C, Cretin B, Vogt N, Philippi N, et al. Cognitive and affective theory of mind in dementia with Lewy bodies and Alzheimer's disease. Alzheimers Res Ther (2016) 8(1):10. doi: 10.1186/s13195-016-0179-9

486. Dimitrovsky L, Spector H, Levy-Chiff R, Vakil E. Interpretation of facial expressions of affect in children with learning disabilities with verbal or nonverbal deficits. J Learning Disabilities (1998) 31(3):286-312.

487. Crawford HJ, Harrison DW, Kapelis L. Visual-field asymmetry in facial affect perception - moderating effects of hypnosis, hypnotic-susceptibility level, absorption, and sustained attentional abilities. Int J Neurosci (1995) 82(1-2):11-23.

488. Sutterby SR, Bedwell JS, Passler JS, Deptula AE, Mesa F. Social anxiety and social cognition: the influence of sex. Psychiatry Res (2012) 197(3):242-5. doi: 10.1016/j.psychres.2012.02.014

489. McDonald S, English T, Randall R, Longman T, Togher L, Tate RL. Assessing social cognition and pragmatic language in adolescents with traumatic brain injuries. J Int Neuropsychol Soc (2013b) 19(5):528-38. doi: 10.1017/ S1355617713000039

490. Grainger SA, Henry JD, Steinvik HR, Vanman EJ, Rendell PG, Labuschagne I. Intranasal oxytocin does not reduce age-related difficulties in social cognition. Horm Behav (2018) 99:25-34. doi: 10.1016/j.yhbeh.2018.01.009

491. Westerhof-Evers HJ, Visser-Keizer AC, McDonald S, Spikman JM. Performance of healthy subjects on an ecologically valid test for social cognition: the short, Dutch version of The Awareness of Social Inference Test (TASIT). J Clin Exp Neuropsychol (2014) 36(10):1031-41. doi: 10.1080/13803395.2014.966661

492. Burdon P, Dipper L, Cocks N. Exploration of older and younger British adults' performance on The Awareness of Social Inference Test (TASIT). Int J Lang Commun Disord (2016) 51:589-93. doi: 10.1111/1460-6984.12233

493. Phillips LH, Allen R, Bull A, Kliegal M, Channon S. Older adults have difficulty decoding sarcasm. Dev Psychol (2015) 51:1840-52. doi: 10.1037/ dev0000063

494. McDonald S, Fisher A, Togher L, Tate R, Rushby J, English T, et al. Adolescent performance on The Awareness of Social Inference Test: TASIT. Brain Impairment (2015) 16(1):3-18. doi: 10.1017/BrImp.2015.7

495. Lavrencic LM, Kurylowicz L, Valenzuela MJ, Churches OF, Keage HA. Social cognition is not associated with cognitive reserve in older adults. Neuropsychol Dev Cogn B Aging Neuropsychol Cogn (2016) 23(1):61-77. doi: 10.1080/13825585.2015.1048773

496. McDonald S, Honan C, Allen SK, El-Helou R, Kelly M, Kumfor F, et al. Normal adult and adolescent performance on TASIT-S, a short version of The Assessment of Social Inference Test. Clin Neuropsychol (2018b) 32(4):700-19. doi: 10.1080/13854046.2017.1400106

497. Hawco C, Kovacevic N, Malhotra AK, Buchanan RW, Viviano JD, Iacoboni $\mathrm{M}$, et al. Neural activity while imitating emotional faces is related to both lower and higher-level social cognitive performance. Sci Rep (2017) 7(1):1244. doi: 10.1038/s41598-017-01316-z

498. Duval J, Ensink K, Normandin L, Carla S, Fonagy P. Measuring reflective functioning in adolescents: relations to personality disorders and psychological difficulties. Adolesc Psychiatry (2018) 8(1):5-20. doi: 10.2174 /2210676608666180208161619

499. Lecce S, Ceccato I, Cavallini E. Investigating ToM in aging with the MASC: from accuracy to error type. Neuropsychol Dev Cogn B Aging Neuropsychol Cogn (2018) 1-17. doi: 10.1080/13825585.2018.1500996

500. Pinkham AE, Penn DL. Neurocognitive and social cognitive predictors of social skill in schizophrenia. Psychiatry Res (2006) 143:167-78.

501. Catalan A, Angosto V, Díaz A, Martínez N, Guede D, Pereda M, et al. The relationship between theory of mind deficits and neurocognition in first episode-psychosis. Psychiatry Res (2018) 268:361-7. doi: 10.1016/j. psychres.2018.06.066

502. Smeets T, Dziobek I, Wolf OT. Social cognition under stress: differential effects of stress-induced cortisol elevations in healthy young men and women. Horm Behav (2009) 55(4):507-13. doi: 10.1016/j.yhbeh.2009.01.011
503. McGlade N, Behan C, Hayden J, O’Donoghue T, Peel R, Haq F, et al. Mental state decoding $\mathrm{v}$. mental state reasoning as a mediator between cognitive and social function in psychosis. Br J Psychiatry (2008) 193(1):77-8. doi: 10.1192/bjp.bp.107.044198

504. Michelas A, Faget C, Portes C, Lienhart AS, Boyer L, Lançon C, et al. Do patients with schizophrenia use prosody to encode contrastive discourse status? Front Psychol (2014) 5:755. doi: 10.3389/fpsyg.2014.00755

505. Bahk YC, Jang SK, Lee JY, Choi KH. Korean facial emotion recognition tasks for schizophrenia research. Psychiatry Investig (2015) 12(2):235-41. doi: 10.4306/pi.2015.12.2.235

506. de Sousa P, Sellwood W, Eldridge A, Bentall RP. The role of social isolation and social cognition in thought disorder. Psychiatry Res (2018) 269:56-63. doi: 10.1016/j.psychres.2018.08.048

507. van der Gaag M, Schütz C, Ten Napel A, Landa Y, Delespaul P, Bak M, et al. Development of the Davos Assessment of Cognitive Biases Scale (DACOBS). Schizophr Res (2013) 144(1-3):63-71. doi: 10.1016/j.schres.2012.12.010

508. Gooding DC, Pflum MJ. Theory of mind and psychometric schizotypy. Psychiatry Res (2011) 188:217-23. doi: 10.1016/j.psychres.2011.04.029

509. Donohoe G, Duignan A, Hargreaves A, Morris DW, Rose E, Robertson D, et al. Social cognition in bipolar disorder versus schizophrenia: comparability in mental state decoding deficits. Bipolar Disord (2012) 14(7):743-8. doi: 10.1111/bdi.12011

510. Couture SM, Granholm EL, Fish SC. A path model investigation of neurocognition, theory of mind, social competence, negative symptoms and real-world functioning in schizophrenia. Schizophr Res (2011) 125(23):152-60. doi: 10.1016/j.schres.2010.09.020

511. Bora E, Vahip S, Gonul AS, Akdeniz F, Alkan M, Ogut M, et al. Evidence for theory of mind deficits in euthymic patients with bipolar disorder. Acta Psychiatr Scand (2005) 112(2):110-6. doi: 10.1111/j.1600-0447.2005.00570.x

512. Fernandez-Gonzalo S, Jodar M, Pousa E, Turon M, Garcia R, Rambla CH, et al. Selective effect of neurocognition on different theory of mind domains in first-episode psychosis. J Nerv Ment Dis (2014) 202(8):576-82. doi: 10.1097/NMD.0000000000000164

513. Woodward T, Mizrahi R, Menon M, Christensen B. Correspondences between theory of mind, jumping to conclusions, neuropsychological measures and the symptoms of schizophrenia. Psychiatry Res (2009) 179:119-23. doi: 10.1016/j.psychres.2008.10.018

514. Robertson DA, Hargreaves A, Kelleher EB, Morris D, Gill M, Corvin A, et al. Social dysfunction in schizophrenia: an investigation of the GAF scale's sensitivity to deficits in social cognition. Schizophr Res (2013) 146(1-3):3635. doi: 10.1016/j.schres.2013.01.016

515. Redondo I, Herrero-Fernández D. Validation of the Reading the Mind in the Eyes Test in a healthy Spanish sample and women with anorexia nervosa. Cogn Neuropsychiatry (2018) 23(4):201-17. doi: 10.1080/13546805.2018.1461618

516. Lawson R. I just love the attention: implicit preference for direct eye contact. Visual Cogn (2015) 23(4):450-88. doi: 10.1080/13506285.2015.1039101

517. Nazarov A, Frewen P, Parlar M, Oremus C, MacQueen G, McKinnon M, et al. Theory of mind performance in women with posttraumatic stress disorder related to childhood abuse. Acta Psychiatr Scand 2014 129(3):193-201. doi: 10.1111/acps. 12142

518. Pestana J, Menéres S, Gouveia MJ, Oliviera RF. Reading the Mind in the Eyes Test: uma versão portuguesa do teste para adultos. Análise Psicológica (2018) 36(3):369-81. doi: 10.14417/ap.1305

519. Brambilla M, Cotelli M, Manenti R, Dagani J, Sisti D, Rocchi M, et al. Oxytocin to modulate emotional processing in schizophrenia: a randomized, double-blind, cross-over clinical trial. Eur Neuropsychopharmacol (2016) 26(10):1619-28. doi: 10.1016/j.euroneuro.2016.08.001

520. MacKinnon AL, Carter CS, Feeley N, Gold I, Hayton B, Santhakumaran S, et al. Theory of mind as a link between oxytocin and maternal behavior. Psychoneuroendocrinology (2018) 92:87-94. doi: 10.1016/j. psyneuen.2018.03.018

521. Guastella AJ, Hermens DF, Van Zwieten A, Naismith SL, Lee RS, CacciottiSaija C, et al. Social cognitive performance as a marker of positive psychotic symptoms in young people seeking help for mental health problems. Schizophr Res (2013) 149(1-3):77-82. doi: 10.1016/j.schres.2013.06.006

522. Hallerback MU, Lugnegard T, Hjarthag F, Gillberg C. The Reading the Mind in the Eyes Test: test-retest reliability of a Swedish version. Cogn Neuropsychiatry (2009) 14:127-43. doi: 10.1080/13546800902901518 
523. Jankowiak-Siuda K, Baron-Cohen S, Bialaszek W, Dopierala A, Kozlowska A, Rymarczyk K. Psychometric evaluation of the 'Reading the Mind in the Eyes' test with samples of different ages from a polish population. Stud Psychol (Bratisl) (2016) 58(1):18-31. doi: 10.21909/sp.2016.01.704

524. Guariglia P, Piccardi L, Giaimo F, Alaimo S, Miccichè G, Antonucci G. The eyes test is influenced more by artistic inclination and less by sex. Front Hum Neurosci (2015) 9:292. doi: 10.3389/fnhum.2015.00292

525. Kirkland RA, Peterson E, Baker CA, Miller S, Pulos S. Metaanalysis reveals adult female superiority in "Reading the mind in the eyes test". N Am J Psychol (2013) 15:121-46.

526. Panero ME, Weisberg DS, Black J, Goldstein TR, Barnes JL, Brownell H, et al. Does reading a single passage of literary fiction really improve theory of mind? An attempt at replication. J Pers Soc Psychol (2016) 111(5):e46-54. doi: $10.1037 /$ pspa0000064

527. Nandrino JL, Gandolphe MC, Alexandre C, Kmiecik E, Yguel J, Urso L. Cognitive and affective theory of mind abilities in alcohol-dependent patients: the role of autobiographical memory. Drug Alcohol Depend (2014) 143:65-73. doi: 10.1016/j.drugalcdep.2014.07.010

528. Baker CA, Peterson E, Pulos S, Kirkland RA. Eyes and IQ: a meta-analysis of the relationship between intelligence and "Reading the Mind in the Eyes". Intelligence (2014) 44:78-92. doi: 10.1016/j.intell.2014.03.001

529. van Zwieten A, Meyer J, Hermens DF, Hickie IB, Hawes DJ, Glozier N, et al. Social cognition deficits and psychopathic traits in young people seeking mental health treatment. PLoS One (2013) 8(7):e67753. doi: 10.1371/journal. pone. 0067753

530. Del Valle Rubido M, McCracken JT, Hollander E, Shic F, Noeldeke J, Boak $\mathrm{L}$, et al. In search of biomarkers for autism spectrum disorder. Autism Res (2018) 11(11):1567-79. doi: 10.1002/aur.2026

531. Lombardo MV, Lai MC, Auyeung B, Holt RJ, Allison C, Smith P, et al. Unsupervised data-driven stratification of mentalizing heterogeneity in autism. Sci Rep (2016) 6:35333. doi: 10.1101/034454

532. Cochran DM, Sikoglu EM, Hodge SM, Edden RA, Foley A, Kennedy DN, et al. Relationship among glutamine, $\gamma$-aminobutyric acid, and social cognition in autism spectrum disorders. J Child Adolesc Psychopharmacol (2015) 25(4):314-22. doi: 10.1089/cap.2014.0112

533. Hamilton J, Radlak B, Morris PG, Phillips LH. Theory of mind and executive functioning following stroke. Arch Clin Neuropsychol (2017) 32(5):507-18. doi: 10.1093/arclin/acx035

534. Burke T, Pinto-Grau M, Lonergan K, Elamin M, Bede P, Costello E, et al. Measurement of social cognition in amyotrophic lateral sclerosis: a population based study. PLoS One (2016) 11(8):e0160850. doi: 10.1371/ journal.pone. 0160850

535. Nolte T, Bolling DZ, Hudac CM, Fonagy P, Mayes L, Pelphrey KA. Brain mechanisms underlying the impact of attachment-related stress on social cognition. Front Hum Neurosci (2013) 7:816. doi: 10.3389/fnhum.2013. 00816

536. Fernandes JM, Cajão R, Lopes R, Jerónimo R, Barahona-Corrêa JB. Social cognition in schizophrenia and autism spectrum disorders: a systematic review and meta-analysis of direct comparisons. Front Psychiatry (2018) 9:504. doi: 10.3389/fpsyt.2018.00504

537. Harkness K, Sabbagh M, Jacobson J, Chowdrey N, Chen T. Enhanced accuracy of mental state decoding in dysphoric college students. Cogn Emotion (2005) 19(7):999-1025. doi: 10.1080/02699930541000110

538. Kynast J, Schroeter ML. Sex, age, and emotional valence: revealing possible biases in the "Reading the Mind in the Eyes" task. Front Psychol (2018) 9:570. doi: 10.3389/fpsyg.2018.00570

539. Varas-Diaz G, Brunetti EP, Rivera-Lillo G, Maldonado PE. Patients with Chronic Spinal Cord Injury Exhibit Reduced Autonomic Modulation during an Emotion Recognition Task. Front Hum Neurosci (2017) 11:59. doi: 10.3389/fnhum.2017.00059

540. Meier SL, Charleston AJ, Tippett LJ. Cognitive and behavioural deficits associated with the orbitomedial prefrontal cortex in amyotrophic lateral sclerosis. Brain (2010) 133(11):3444-57. doi: 10.1093/brain/awq254

541. Muller F, Simion A, Reviriego E, Galera C, Mazaux JM, Barat M, et al. Exploring theory of mind after severe traumatic brain injury. Cortex (2010) 46(9):1088-99. doi: 10.1016/j.cortex.2009.08.014

542. de Achával D, Costanzo EY, Villarreal M, Jáuregui IO, Chiodi A, Castro MN, et al. Emotion processing and theory of mind in schizophrenia patients and their unaffected first-degree relatives. Neuropsychologia (2010) 48(5):120915. doi: 10.1016/j.neuropsychologia.2009.12.019

543. Geraci A, Surian L, Ferraro M, Cantagallo A. Theory of Mind in patients with ventromedial or dorsolateral prefrontal lesions following traumatic brain injury. Brain Inj (2010) 24(7-8):978-87. doi: 10.3109/02699052.2010.487477

544. Gregory C, Lough S, Stone V, Erzincioglu S, Martin L, Baron-Cohen S, et al. Theory of mind in patients with frontal variant frontotemporal dementia and Alzheimer's disease: theoretical and practical implications. Brain (2002) 125:752-64. doi: 10.1093/brain/awf079

545. Milders M, Fuchs S, Crawford JR. Neuropsychological impairments and changes in emotional and social behaviour following severe traumatic brain injury. J Clin Exp Neuropsychol (2003) 25(2):157-72. doi: 10.1076/jcen.25.2.157.13642

546. Ubukata S, Tanemura R, Yoshizumi M, Sugihara G, Murai T, Ueda K. Social cognition and its relationship to functional outcomes in patients with sustained acquired brain injury. Neuropsychiatr Dis Treat (2014) 10:2061-8. doi: 10.2147/NDT.S68156

547. Homer BD, Halkitis PN, Moeller RW, Solomon TM. Methamphetamine use and HIV in relation to social cognition. J Health Psychol (2013) 18(7):900-100. doi: 10.1177/1359105312457802

548. Giovagnoli AR, Franceschetti S, Reati F, Parente A, Maccagnano C, Villani F, et al. Theory of mind in frontal and temporal lobe epilepsy: cognitive and neural aspects. Epilepsia (2011) 52(11):1995-2002. doi: 10.1111/j.1528-1167.2011.03215.x

549. Cox SR, Bak TH, Allerhand M, Redmond P, Starr JM, Deary IJ, et al. Bilingualism, social cognition and executive functions: a tale of chickens and eggs. Neuropsychologia (2016) 91:299-306. doi: 10.1016/j. neuropsychologia.2016.08.029

550. Bottiroli S, Cavallini E, Ceccato I, Vecchi T, Lecce S. Theory of Mind in aging: comparing cognitive and affective components in the faux pas test. Arch Gerontol Geriatr (2016) 62:152-62. doi: 10.1016/j.archger.2015.09.009

551. Aboulafia-Brakha T, Christe B, Martory MD, Annoni JM. Theory of mind tasks and executive functions: a systematic review of group studies in neurology. J Neuropsychol (2011) 5(1):39-55. doi: 10.1348/174866410X533660

552. Savina I, Beninger RJ. Schizophrenic patients treated with clozapine or olanzapine perform better on theory of mind tasks than those treated with risperidone or typical antipsychotic medications. Schizophr Res (2007) 94(13):128-38. doi: 10.1016/j.schres.2007.04.010

553. Yarnold P, Bryant FB, Nightingale SD, Martin GJ. Assessing physician empathy using the interpersonal reactivity index: a measurement mode and cross-sectional analysis. Psychol Health Med (1996) 1:207-21. doi: $10.1080 / 13548509608400019$

554. Haker H, Schimansky J, Jann S, Rössler W. Self-reported empathic abilities in schizophrenia: a longitudinal perspective. Psychiatry Res (2012) 200(23):1028-31. doi: 10.1016/j.psychres.2012.04.004

555. Lehmann A, Bahçesular K, Brockmann EM, Biederbick SE, Dziobek I, Gallinat J, et al. Subjective experience of emotions and emotional empathy in paranoid schizophrenia. Psychiatry Res (2014) 220(3):825-33. doi: 10.1016/j. psychres.2014.09.009

556. Smith MJ, Horan WP, Karpouzian TM, Abram SV, Cobia DJ, Csernansky JG. Self-reported empathy deficits are uniquely associated with poor functioning in schizophrenia. Schizophr Res (2012) 137(1-3):196-202. doi: 10.1016/j. schres.2012.01.012

557. Cusi A, Macqueen GM, McKinnon MC. Altered self-report of empathic responding in patients with bipolar disorder. Psychiatry Res (2010) 178(2):354-8. doi: 10.1016/j.psychres.2009.07.009

558. Cliffordson C. Parents' judgments and students' self-judgments of empathy: the structure of empathy and agreement of judgments based on the interpersonal reactivity index (IRI). Eur J Psychol Assess (2001) 17:36-47. doi: $10.1027 / / 1015-5759.17 .1 .36$

559. Lee J, Zaki J, Harvey PO, Ochsner K, Green MF. Schizophrenia patients are impaired in empathic accuracy. Psychol Med (2011) 41(11):2297-304. doi: $10.1017 /$ S0033291711000614

560. Curwen T. The importance of offense characteristics, victimization history, hostility, and social desirability in assessing empathy of male adolescent sex offenders. Sex Abuse (2003) 15(4):347-64. doi: 10.1177/107906320301500410

561. Bonfils KA, Lysaker PH, Minor KS, Salyers MP. Empathy in schizophrenia: a meta-analysis of the Interpersonal Reactivity Index. Psychiatry Res (2017) 249:293-303. doi: 10.1016/j.psychres.2016.12.033 
562. Baron-Cohen S, Wheelwright S. The Empathy Quotient: an investigation of adults with Asperger syndrome or high functioning autism, and normal sex differences. J Autism Dev Disord (2004) 34(2):163-75. doi: 10.1023/B:J ADD.0000022607.19833.00

563. Mumper ML, Gerrig RJ. Leisure reading and social cognition: a metaanalysis. Psychol Aesthet Creat Arts (2017) 11(1):109-20. doi: 10.1037/aca00 00089

564. Chrysikou EG, Thompson WJ. Assessing cognitive and affective empathy through the interpersonal reactivity index: an argument against a two-factor model. Assessment (2016) 23(6):769-77.

565. Meert G, Wang J, Samson D. Efficient belief tracking in adults: the role of task instruction, low-level associative processes and dispositional social functioning. Cognition (2017) 168:91-8. doi: 10.1016/j.cognition.2017.06.012

566. Melchers M, Montag C, Markett S, Reuter M. Assessment of empathy via self-report and behavioural paradigms: data on convergent and discriminant validity. Cogn Neuropsychiatry (2015) 20(2):157-71. doi: 10.1080/13546805. 2014.991781

567. Ru W, Fang P, Wang B, Yang X, Zhu X, Xue M, et al. The impacts of Val158Met in Catechol-O-methyltransferase (COMT) gene on moral permissibility and empathic concern. Personal Individ Differ (2017) 106:52-6. doi: 10.1016/j. paid.2016.10.041

568. Sohn HS, Lee DH, Lee KJ, Noh EC, Choi SH, Jang JH, et al. Impaired empathic abilities among patients with complex regional pain syndrome (type I). Psychiatry Investig (2016) 13(1):34-42. doi: 10.4306/pi.2016.13.1.34

569. Zupan B, Neumann D, Babbage D, Willer B. Sex-based differences in affective and cognitive empathy following severe traumatic brain injury. Neuropsychology (2018) 32(5):554-63. doi: 10.1037/neu0000462
570. Chen YC, Chen CC, Decety J, Cheng Y. Aging is associated with changes in the neural circuits underlying empathy. Neurobiol Aging (2014) 35(4):82736. doi: 10.1016/j.neurobiolaging.2013.10.080

571. Fonagy P, Bateman AW. Adversity, attachment, and mentalizing. Compr Psychiatry (2016) 64:59-66. doi: 10.1016/j.comppsych.2015.11.006

572. Midgley N, Vrouva I eds. Minding the child: Mentalization-based interventions with children, young people and their families. New York, US: Routledge/ Taylor \& Francis Group (2012). doi: 10.4324/9780203123003

573. Eddy CM, Hansen PC. Predictors of performance on the Reading the Mind in the Eyes Test. Submitted for publication.

574. Eddy CM, Beck SR, Mitchell IJ, Praamstra P, Pall HS. Theory of mind deficits in Parkinson's disease: a product of executive dysfunction? Neuropsychology (2013) 27(1):37-47. doi: 10.1037/a0031302

575. Samson D, Apperly IA, Kathirgamanathan U, Humphreys GW. Seeing it my way: a case of a selective deficit in inhibiting self-perspective. Brain (2005) 128(5):1102-11.

Conflict of Interest Statement: The author declares that the research was conducted in the absence of any commercial or financial relationships that could be construed as a potential conflict of interest.

Copyright (c) 2019 Eddy. This is an open-access article distributed under the terms of the Creative Commons Attribution License (CC BY). The use, distribution or reproduction in other forums is permitted, provided the original author $(s)$ and the copyright owner(s) are credited and that the original publication in this journal is cited, in accordance with accepted academic practice. No use, distribution or reproduction is permitted which does not comply with these terms. 